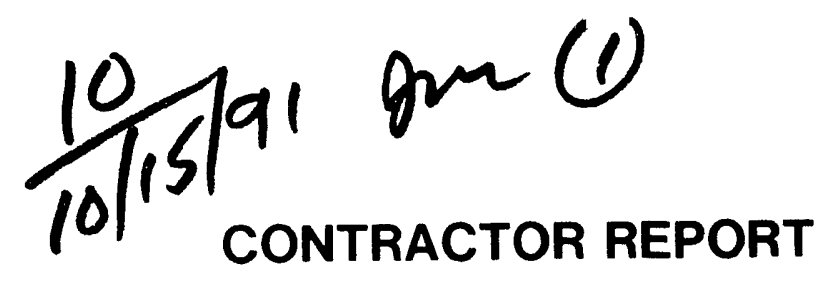

SAND9 $1-7007$

Unlimited Release

UC -237

\title{
Design of the Support Structure, Drive Pedestal, and Controls for a Solar Concentrator
}

Vernon R. Goldberg John L. Ford

Arnold E. Anderson

WG Associates

6607 Stonebrook Circle

Dallas, TX 75240

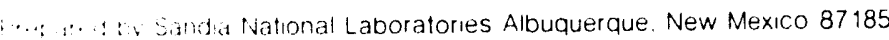

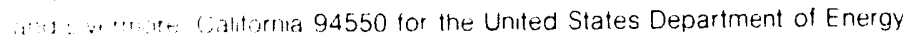
a. 1 . AC04.76DPn0789

Printed August 1991 
Issued by Sandia National Laboratories, operated for the United States Department of Energy by Sandia Corporation.

NOTICE: This report was prepared as an account of work sponsored by an agency of the United States Government. Neither the United States Government nor any agency thereof, nor any of their employees, nor any of their contractors, subcontractors, or their employees, makes any warranty, express or implied, or assumes any legal liability or responsibility for the accuracy, completeness, or usefulness of any information, apparatus, product, or process disclosed, or represents that its use would not infringe privately owmed rights. Reference herein to any specific commercial product, process, or service by trade name, trademark, manufacturer, or otherwise, does not necessarily constitute or imply its endorsement, recommendation, or favoring by the United States Government, any agency thereof or any of their contractors or subcontractors. The views and opinions expressed herein do not necessarily state or reflect those of the United States Government, any agency thereof or any of their contractors.

Printed in the United States of America. This report has been reproduced directly from the best available copy.

Available to DOF and DOE contractors from

Office of Scientific and Technical Information

PO Bux 62

Oak Ridge, TN $378: 31$

Prices available from (615) 576-8401. FTS 626-8401

Available to the public from

National Technical Information Service

US Department of Commerce

5285 Port Royal Rd

Springfield, VA 22161

N'TIS price codes

Printed copy: A06

Microfiche copy: A01 
SAND91-7007

Unlimited Release

Printed August 1991

DESIGN OF THE SUPPORT STRUCTURE, DRIVE PEDESTAL AND

CONTROLS FOR A SOLAR CONCENTRATOR

Vernon R. Goldberg

John L. Ford

Arnold E. Anders on

WG Associates

Dallas, Texas

Sandia Contract 42-9815

\begin{abstract}
The glass/metal McDonnell-Douglas dish is the state-of-the-art of parabolic dish concentrators. Because of the perceived high production cost of this concentrator, the Department of Energy's Solar Thermal Program is developing stretched-membrane technology for large ( $75 \mathrm{kWt}$ ) solar concentrators for integration with receivers and engines in $25 \mathrm{kWe}$ dish-stirling systems. The objective of this development effort is to reduce the cost of the concentrator while maintaining the high levels of performance characteristic of glass/ metal dishes. Under contract to Sandia National Laboratories, Science Applications International Corporation, Solar Kinetics Inc. and WG Associates are developing a faceted stretched-membrane dish concentrator based on successful stretched-membrane heliostat technology. This design will result in a low-risk, near-term concentrator for dish-stirling systems.
\end{abstract}

WG Associates has designed the support structure, drives and tracking controls for this dish. The structure is configured to support 12 stretched-membrane, 3.5-meter diameter facets in a shaped dish configuration. The dish design is sized to power a dishstirling system capable of producing $25 \mathrm{~kW}$ (electric).

In the design of the structure, trade-off studies were conducted to determine the "best" facet arrangement, dish contour, disn focal length, tracking control and walk-off protection. As part of the design, in-depth analyses were performed to evaluate pointing accuracy, compliance with AISC steel design codes, and the economics of fabrication and installation. Detailed fabrication and installation drawings were produced, and initial production cost estimates for the dish were developed. These issues, and the final dish design, are presented in this report. 
. . 
CONTENTS

Page

ABSTRAC'

ii 1

TABLE OF CONTENTS

v

LIST OF FIGURES

vi1

LIST OF TABLES

v111

INTRODUCTION

1.1

1.1 .1

1.1 .2

1.1 .3

1.1 .4

1.2

1.3

Summary of Dish Design Requirements.

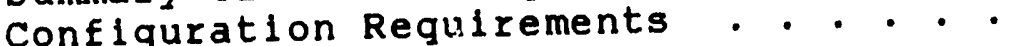

Environmental Requirements . . . . . .

Performance Requirements . . . . . . . 3

Miscellaneous. . . . . . . . . . . .

project Results . . . . . . . . . . .

Report organization... . . . . . . 4

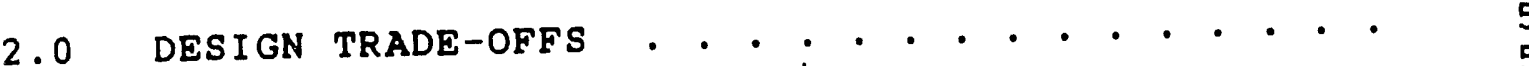

Facet Arrangement . . . . . . . .

2.2 Parabolic vs. Spherlcal Facet 8

Support contour .......... 13

2.3 Focal Length ontion . . . . . . . . . 18

2.4 Windmill Option protection...... 20

2.5 Solar Walk 23

2.6 Tracking Error Considerations... $\cdot{ }^{*} \cdot{ }^{\circ} \quad 24$

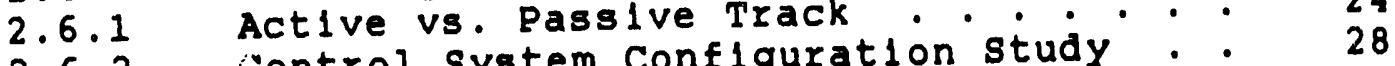

2.6.2 Control system Configurations . . . . 28

2.6.2.1 Collector Drive Considerations $\cdot \cdot \cdot \cdot \cdot$

2.6.2.2 Collector Position Sensor .... 31

2.6.3 Control system selection summary . . $\quad 34$

3.0 STRUCTURE DESIGN • . . . . .

Facet support structure (FSS) $\cdot \cdot \cdot \cdot \cdot$

Splne Truss.............. . 39

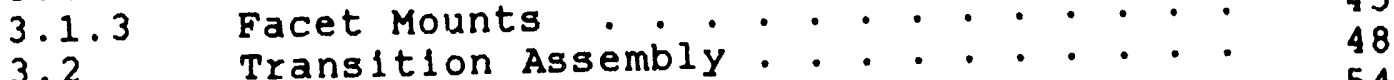

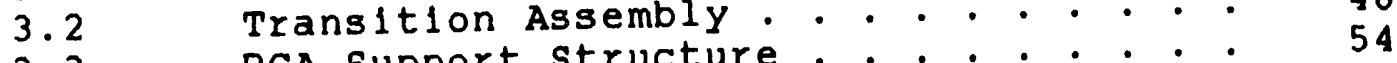

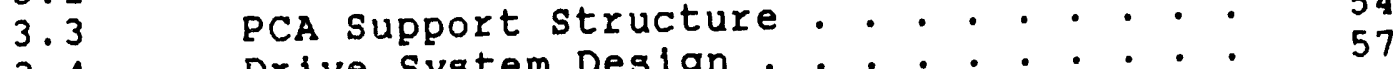

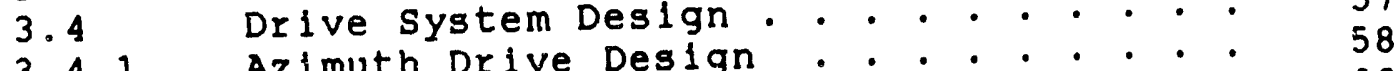

3.4.1 Azlmuth Drive Dlevation Drive Design . . . . . . . . 63 
Page

3.5 Pedestal . . . . . 65

3.6 Structural Analysis......... . 67

3.6 Discussion . . . . . . . . . . 68

3.6.2 Summary................ . .074

3.7 Weight summary . . . . . . . . . 78

4.0 TRACKING CONTROL SYSTEM DESIGN • . . . . . . . . 81

4.1 System Design . . . . . . . 81

Systral Computer 83

Front End Processor (FEP)....... . 84

4.4 Motor Controllers.......... . 85

4.5 Axis Encoders... . . . . . . . . . . 85

5.0 COLLECTOR SYSTEM POINTING ERROR BUDGET . . . . . . 87

6.0 COLLECTOR PRODUCTION AND INSTALLATION COST . . . 89

7.0 SUMMARY . . . . . . . . . . . . . . 97

7.1 Trade-off studies.... . . . . . 97

7.1 Facet Arrangement . . . . . . . . . 97

7.1.2 Parabolic vs. Spherical Facet 97

7.1 .3 Focal Length . . . . . . . . . . 98

7.1 .4 Windmill Option . . . . . . . . . . . . 98

7.1 .5 Solar Walk-off Protection . . . . . . . 98

7.1.6 Tracking Error Considerations . . . . . 99

7.2 Structure Design . $\cdot \cdot \cdot \cdot \cdot \cdot \cdot \cdot \cdot \cdot \cdot r 9$

7.3 Tracking Control system . $\cdot \cdot \cdot \cdot \cdot \cdot \cdot \cdot 100$

7.4 Tracking Error Budget... . . . . . . 101

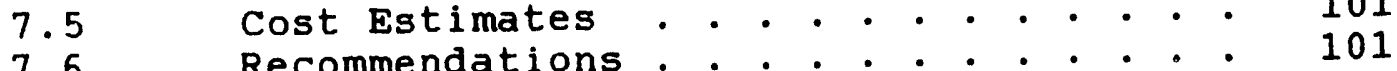

7.6 Recommendations . . . . . . . . . . . . . . 101

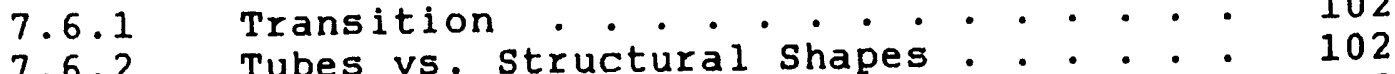

7.6.2 Tubes vs. Structural Shapes. $\cdot \cdot \cdot \cdot \cdot \cdot 102$

7.6 .3 Pedestal $\dot{7 .} \cdot \cdot \cdot \cdot \cdot \cdot \cdot \cdot \cdot \cdot \cdot \cdot \cdot \cdot \cdot \cdot 103$

7.6.4 Elevation Drive . . . . . . . . . . . . . . 101

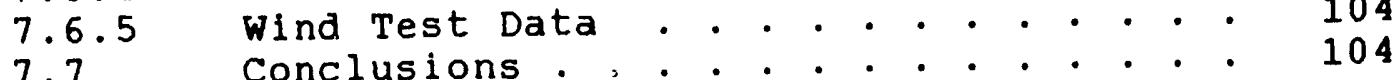

8.0 GLOSSARY . . . . . . . . . . . . . . 107

9.0 BIBLIOGRAPHY . . . . . . . . . . . . . . . 109 
LIST OF FIGURES

Page

$1.0-1$

Faceted Stretched-Membrane Dish Concentrator. . 2

$2 \cdot 1-1$

$2.2-1$

$2.2-2$

$2.2-3$

$2 \cdot 2-4$

$2 \cdot 3-1$

$2 \cdot 3-2$

$2 \cdot 3-3$

$2 \cdot 3-4$

Alternate Facet Arrangement . . . . . . . . . 6

Facets on a Spherical Contour . . . . . . . . 9

Facets on a Parabolic Contour . . . . . . . . . 10

Facet Focal Lengths on Parabolic Contours. . . 11

Contour Comparison, $F=29.9 \mathrm{ft}$. . . . . . . . 12

System Weight us. Focal Length . . . . . . . . 15

Balance Point vs. Focal Length . . . . . . . 16

Drive Inertia vs. Focal Length . . . . . . . . 17

$2 \cdot 5-1$ Required Drive Inertial spring Rate vs.

Focal Length . . . . . . . . . . . . . . . 17

$3.0-1$

Articulated PCA Support structure . . . . . . . 22

$3.0-2$

Faceted Stretched-Membrane Dish Concentrator. . 36

$3.1-1$

$3.1-2$

$3.1-3$

$3.1-4$

$3 \cdot 2-1$

$3 \cdot 2-2$

$3 \cdot 3-1$

$3.3-2$

$3.4-1$

$3.4-2$

$3.4-3$

$3 \cdot 5-1$

$3.6-1$

$3.6-2$

2TOP Collector Configuration . . . . . . . 37

Facet support structure . . . . . . . . . . . 40

Vertical Truss . . . . . . . . . . . . . . . . 42

Secondary Truss . . . . . . . . . . . . . . . . 44

Facet Mounts . . . . . . . . . . . . . . 47

Transition Assembly. . . . . . . . . . . . . 51

Transition Assembly Installation . . . . . . . 53

PCA Support Structure . . . . . . . . . . . . 55

PCA Root structure . . . . . . . . . . . 56

Elevation Torque Load w/31.25 MPH Wind. . . . 59

Azimuth Torque Load, $31.25 \mathrm{MPH}$ Wind... . . . 59

Azimuth Drive. . . . . . . . . . . . . . . . 60

Pedestal ... . . . . . . . . . . . 66

Gravity vector . . . . . . . . . . . . . 69

Elevation Torque Load, $50 \mathrm{MPH}$ Wind . . . . . 70

$3.6-3$

$3.6-4$

$3 \cdot 6-5$

$3 \cdot 6-6$

Azimuth Torque Load, $50 \mathrm{MPH}$ Wind . . . . . . 71

Pedestal and Drive Elevation Wind Deflection . 72

Pedestal and Drive Azimuth Wind Deflection . . 73

$3 \cdot 6-7$

Pedestal and Drive Elevation Dead

Weight Deflection . . . . . . . . . . . . . . 73

$4.1-1$

PCA Support Dead Weight Deflection . . . . .

74

Tracking Control System Block Diagram . . . . . 82 
Page

2.2-I Final Facet Vertex Locations . . . . . . . . 14

2.6-I Pointing Error W/Linear Drive and . . . . . 26

2.6-II Pointing Error W/Linear Drive and . . 27

2.6-II Pointing Error $\dot{W} /$ "Bang-Bang" and Resolvers. . 29

2.6-IV Pointing Error $W /$ "Soft Bang-Bang" and . . . 32

2.6-V Pointing Error W/Mot.: Revolution Counters . - 33

3.1-I Mounting Bolt Centers . . . . . . . . . . . 49

3.1-I Facet Cledrances . . . . . . . . . . . . 50

3.4-I Winsmith Azimuth Drive Characteristics . . . 61

3.6-I Worst Case Dead Weight Deflection ... 75

3.6-II Dead Weight Deflection, $4 \dot{5}$ deg. Alignment . . 76

3.6-III $20 \mathrm{MPH}$ Wind Deflection.......... . . . 77

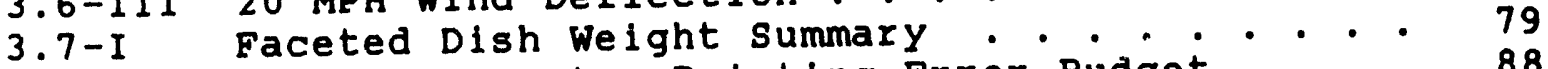

5.0-I Collector System Pointing Error Budget . • • 88

6.0-I Collector production cost summary . . . . . . 89

6.0-II Annual Production Quantity - 50 collectors . . 93

6.0-II Annual production Quantity - 100 Collectors • 94

6.0-IV Annual Production Quantity - 1000 Collectors . 95

$6.0-\mathrm{V}$ specialty Items . . . . . . . . . . . . . . 96 


\subsection{INTRODUCTION}

This report documents the trade-off studies, analysis, and design of the support structure, drive pedestal, and control system for a faceted, stretched-membrane solar concentrator. The configuration is similar to a conventional point focus system with a 10-to-11 meter diameter parabolic reflector except that the continuous parabolic reflector is replaced with 12 facets. The 12 facets are stretched membranes with an active surface diameter of 3.5 meters each. When attached to the structure, the facets can be aimed so that 12 sun images are at the same focal point. The dish is designed to provide about $75 \mathrm{kWt}$ of thermal power to a receiver-stirling enginegenerator located at the focal point of the dish. The electrical output of the dish-stirling system is about $25 \mathrm{kWe}$. The faceted dish-stirling system is illustrated by the artist concept shown in Figure 1.0-1.

This report covers the design of the prototype support structure and drive pedestal illustrated in the figure, and the system to control collector pointing.

The project objectives included designing a prototype concentrator that would meet all of the reguirements of the statement of work (sow) while reducing fabrication and installation costs below those of the glass-metal dish. Where cholces were made between added cost to insure performance and economy with the potential of compromising performance, priority was placed on meeting performance objectives without "gold plating" the design. Thus, the design objectives have been approached conservatively. If the prototype proves to have performance in excess of the requirements, economies readily can be achieved for future models. Similarly, with large-volume production, design adjustments, and production tooling, changes can be made to yield significant per unit cost savings. This report includes production cost estimates based on the current conservative prototype design. 


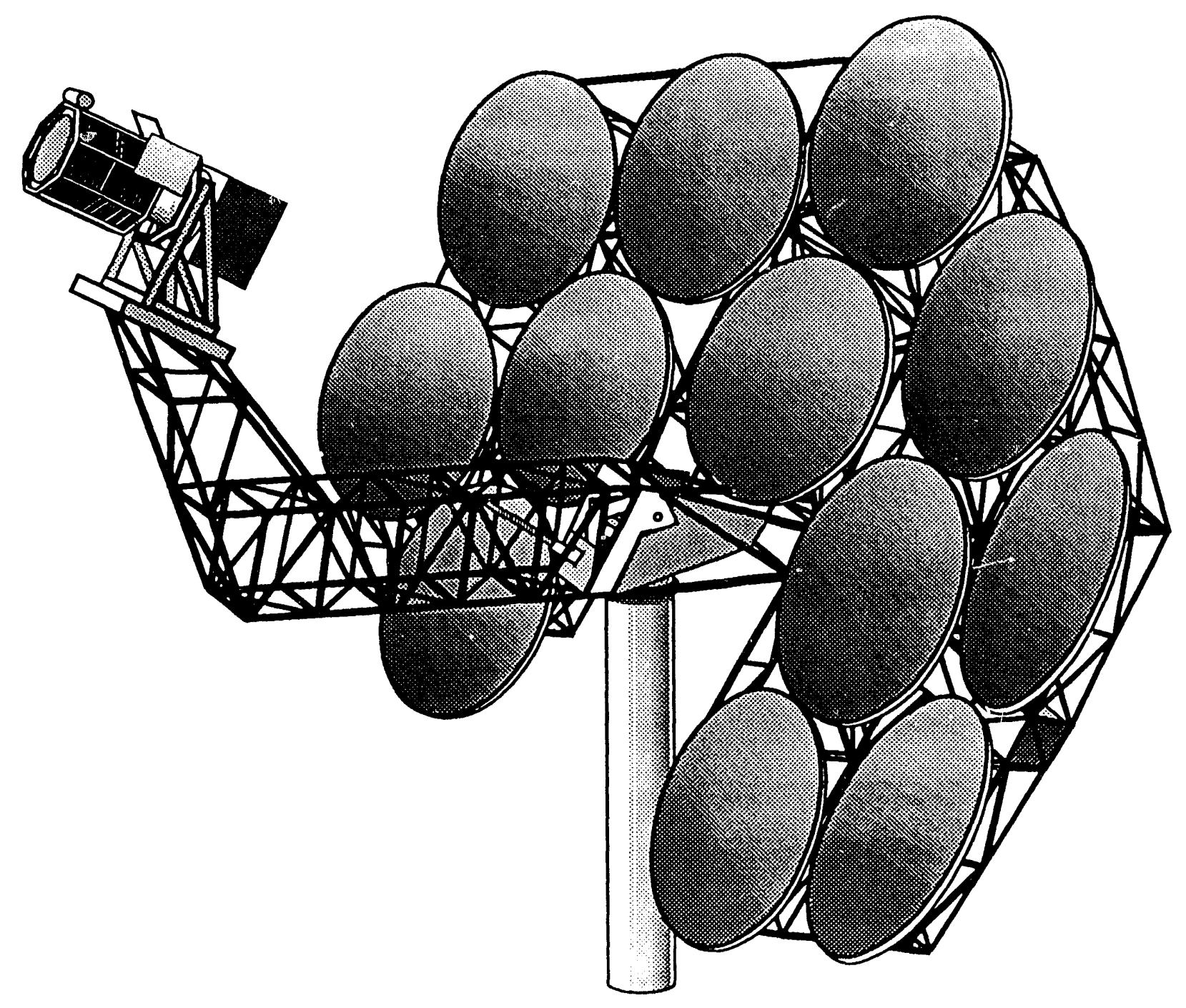

Figure 1.0-1 Faceted Stretched-Membrane Dish Concentrator 


\subsection{Summary of Dish Design Requirements}

The requirements that the facet support structure (FSS) and drive pedestal must meet are defined in the sow for Contract No. 42-9815 and subsequently modified by program management directive. They are categorized for ease of reference and summarized below.

\subsubsection{Configuration Requirements}

- Axis Configuration - Elevation over azimuth

- Number of Facets - 12

- Diameter of Facets - $3.5 \mathrm{~m}$ (11.5 ft.)

- Facet Mounting - 3 points, approximately equally spaced

- Receiver/Engine/Generator Weight - $1500 \mathrm{lb}$.

- Dish $\mathrm{E} / \mathrm{D}$, nominal - 0.6

- Control system - 2-axis ephemeris tracker using off-the-shelf components

\subsubsection{Environmental Requirements}

\section{Operating}

- Temperature: -30 deg. to +50 deg.C $(-22$ deg. to +122 deg.F $)$

- Humidity: 0 to $100 \%$ RH

- Wind: $27 \mathrm{mph}$ (including gusts) - full performance 35 mph (including gusts) - degraded performance

\section{Survival}

- Temperature: -30 deg. to +50 deg.C ( -22 deg. to +122 deg.F)

- Humidity: 0 to $100 \%$ RH

- Wind: $50 \mathrm{mph}$ (including gusts) - dish at any attitude $90 \mathrm{mph}$ (including gusts) - dish at stow position

- Seismic: Per Unified Building Code, Zone " $Z$ "

- Snow and Ice: 10 psf on upward-facing surfaces, stow position (not concurrent with $90 \mathrm{mph}$ wind)

\subsubsection{Performance Requirements}

- Structural Deflection: $1.0 \mathrm{mr}$, one sigma, relative to receiver

- Tracking system Error: $0.6 \mathrm{mr}$, one sigma

- Sky Coverage: Zenith to both horizons anywhere in Continental U.s. and Hawaii 


\subsubsection{Miscellaneous}

The design must provide for:

- ground-level access to receiver/engine, and

- protection of structure from beam walk-off due to loss of power.

\subsection{Project Results}

The result of this project is a complete set of fabrication and assembly drawings for the faceted dish, including pedestal, drives, Fss, controls, etc. These drawings have been reviewed by potential vendors; prototype pricing has been developed and is included in this report. The faceted collector support structure and pointing controls built to these drawings will meet or exceed the requirements stated in section 1.1 without significant risk and without excessive cost. There is a high probability that further economies can be achieved through design modifications after the prototype has been fabricated and fully evaluated.

\subsection{Report Organization}

Trade-off studies conducted early in the program and their results are described in section 2 of this report. The design of the Fss, the azimuth and elevation drives, and the pedestal are described in section 3. Also in section 3 the structural analysis is discussed, and its results are summarized. Section 4 contains the control system description. In section 5 the pointing error budget for the dish is re-leveloped. In section 6 production cost methodology is presented, and costs are developed for several levels of production effort. A summary of the profect is contained in section 7 . Section 8 is a glossary of terms used in this report. Finally, Appendix A contains the details of the structural analysis. 


\subsection{DESIGN TRADE-OFFS}

Before design of the faceted dish could start, it was necessary to resolve a number of open issues. These issues were related to the integration of the facets and the configuration of the FSS. Tasks were assigned by project management to evaluate various concepts of facet arrangement, support structure contour and collector focal length. Other study tasks involved collector operational considerations such as windmilling and solar walk-off protection. In each of these studies the impacts of various design options on system performance, design risk and cost were evaluated.

Descriptions of these trade-off studies and the results are presented in this section.

\subsection{Facet Arrangement}

Several geometric arrangements of the 12 stretched-membrane facets were considered in developing an efflcient FSS design. All arrangements had similar performance levels; the two most viable options were selected for evaluation based on apparent simplicity and practicality of fabrication. These two candidate configurations, designated 4INLINE and 2TOP respectively, are shown in Figure 2.1-1. Both arrangements were analyzed and compared for structural weight, wind load effects on a drive system, facet interface requirements, lower conversion assembly (PCA) support structure interface, and ezse of fabrication.

A !raphic design was made of each of the conflgurations using comparable outine geometry and nominal assembly focal lengths. The structural elements - vertical trusses, horizontal trusses, diagonal beams, etc. - were defined and positioned to provide appropriate mounting facilities and load paths for the facet mounting. The welghts and center of gravity (CG) of all of the elements were determined, and a composite support structure CG was calculated. This data was the basis for comparison of the two arrangements. 


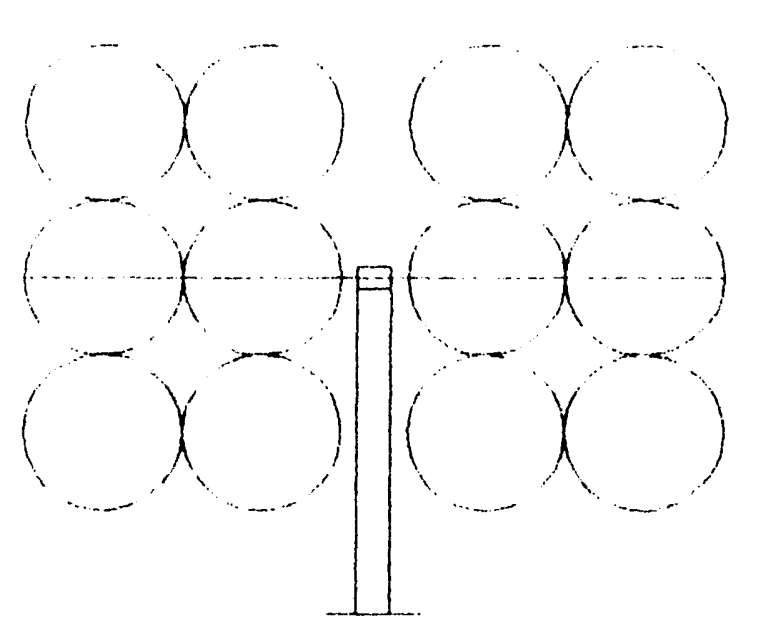

4INL. INE CONF IGIIRATION

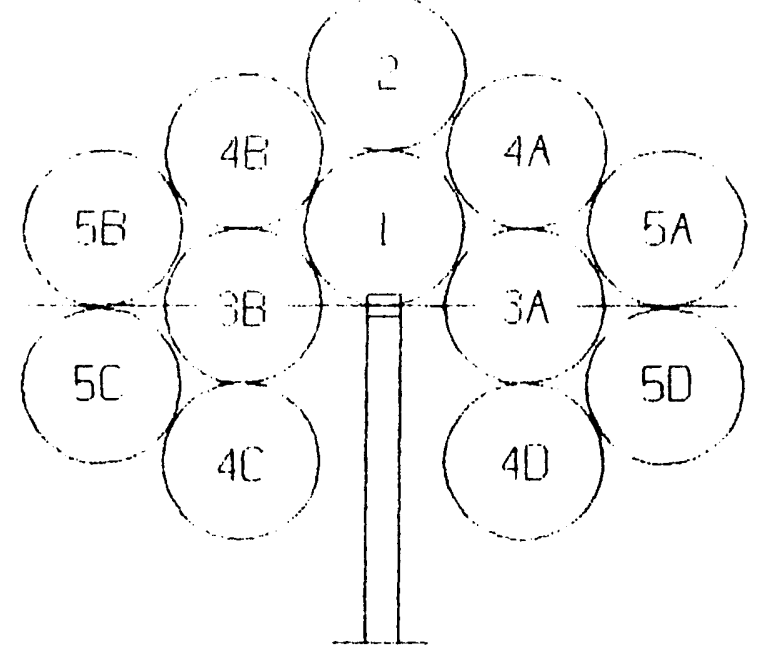

PTOF CONF IGURATION

Figure 2.1-1 Alternate Facet Arrangement

The 2TOP configuration was found to be lighter than the 4INLINE, primarily because it has a shorter total length of all trusses. The difference, however, is so slight that this effect alone is considered of no consequence to the design.

Geometry considerations disclose wind load and inertia differences. The horizontal chord length of the 2 TOP is about 58 greater than that of the 4INLINE, due primarily to the larger "gap" at the drive interface. On the other hand, the 4INLINE arrrangement, with 3 facets at the extreme radius versus 2 for the 2 TOP, has a greater area and weight concentration at the maximum moment arm. The chord length and area distribution differences tend to cancel each other relative to wind-caused yaw effects. But the attendant weight concentration at the extremities of the 4INLINE result in it having a somewhat higher mass moment of inertia. Therefore, the 4INLINE requires sightly more azimuth drive power. 
The vertical height of the 2 TOP is about $14 \%$ greater than the 4INLINE. But again, the area distribution tends to reduce the difference between the two designs. Nevertheless, the 2TOP windInduced overturning moments are somewhat greater than the 4INLINE. Therefore, the 2TOP requires slightly greater azimuth bearing capacity and elevation drive power than the 4INLINE conflguration.

To evaluate the interface of the PCA support structure, including the transition, it was assumed that the horizontal chord of the 4INLINE would be held to a minimum to reduce wind and inertia effects. Since, in this arrangement, no facets are on the vertical centerline, the gap, or clearance, about the drive and pedestal is limited only by the diameters of those elements and/or the width of the transition. In the 2TOP arrangement the gap is dictated by the mounting provisions for the centerline facets. The relatively large, unused lateral space in the gap area of the 2TOP allows abundant room for diagonal bracing of the transition structure. This space does not exist on the 4INLINE. Therefore, the 2TOP arrangement results in a significantly stiffer assembly,

With regard to economy of fabrication, the 4INLINE structure is symmetrical about both the $X$ and $Y$ axes. The 2 TOP is symmetric only about the $Y$ axis. Thus, it is reasonable to conclude that the 4INLINE, with fewer different, parts, has a potential cost advantage.

Other less important factors were considered such as shear loads, axial loads, facet mounting facilities, factory/field assembly, and alignment. But in each of these, the differences between the two configurations were too slight to have impact.

In consideration of the above, the 2 TOP arrangement was selected for the faceted dish design because its interface assembly is stiffer. As a result, the 2 TOP configuration has a higher system resonant frequency, better tracking accuracy and, ultimately, better system performance than the 4INLINE configuration. 


\subsection{Earabolle vs. Spherlcal Facet support contour}

Optical studies conducted by sandia showed that the contour of a facet array support structure has little impact on concentrator optical/thermal performance. However, at the outset of this contract, it had not been fully determined that readily adjustable stretched membrane facets were practlcal with focal length to diameter $(f / D)$ ratios in the range of 2.2 to 3.0. It was not clear that elastically-formed membranes could be made at all in this range. On the other hand, plastically-formed membranes, which can be made in this $f / D$ range, may not be readily adjustable. since facets of both forming methods were being considered for the dish, it was desirable to devise a single structural contour with an $f / D$ that could accommodate both facet designs.

Three basic structural conflgurations were considered initially: flat, spherical and parabollc. It was immediately obvious that a flat structure would require facets with a larger $f / D$ range than elther the parabolic or spherical contour structure. since there was no significant optical, structural or economic advantage to a flat structure, it was eliminated from further consideration.

A comparison was made between a spherically-contoured structure and one that is parabolically contoured. Two dish focal lengths were investigated for each contour. For the first, the focal length of the outermost facet was set to $25 \mathrm{ft}$.; and, for the second, the length was set to $34.5 \mathrm{ft}$. Only a single facet diameter of $11.5 \mathrm{ft}$. was considered.

Both contours were shown to have problems. In the spherical arrangement, the vertex of each facet is on a spherical surface; and all facets have the same focal length. However, as lllustrated by Figure 2.2-1, the difference between adjacent facet edges in the line-of-sight ( $\mathrm{z}$ axis) direction ("Z offset") is about 29 in. for a facet No. 5 focal length of $34.5 \mathrm{ft}$. The $z$ offset for a No. 5 focal length of $25 \mathrm{ft} .1 \mathrm{~s}$ about $3.5 \mathrm{ft}$. An offset this large increases the complexity of the facet mounting pads and could compromise the integrity of the 
structure design. The excessive length of the "standoffs" add weight and cost to the design, and can also contribute significantly to the overall structural deflection error.

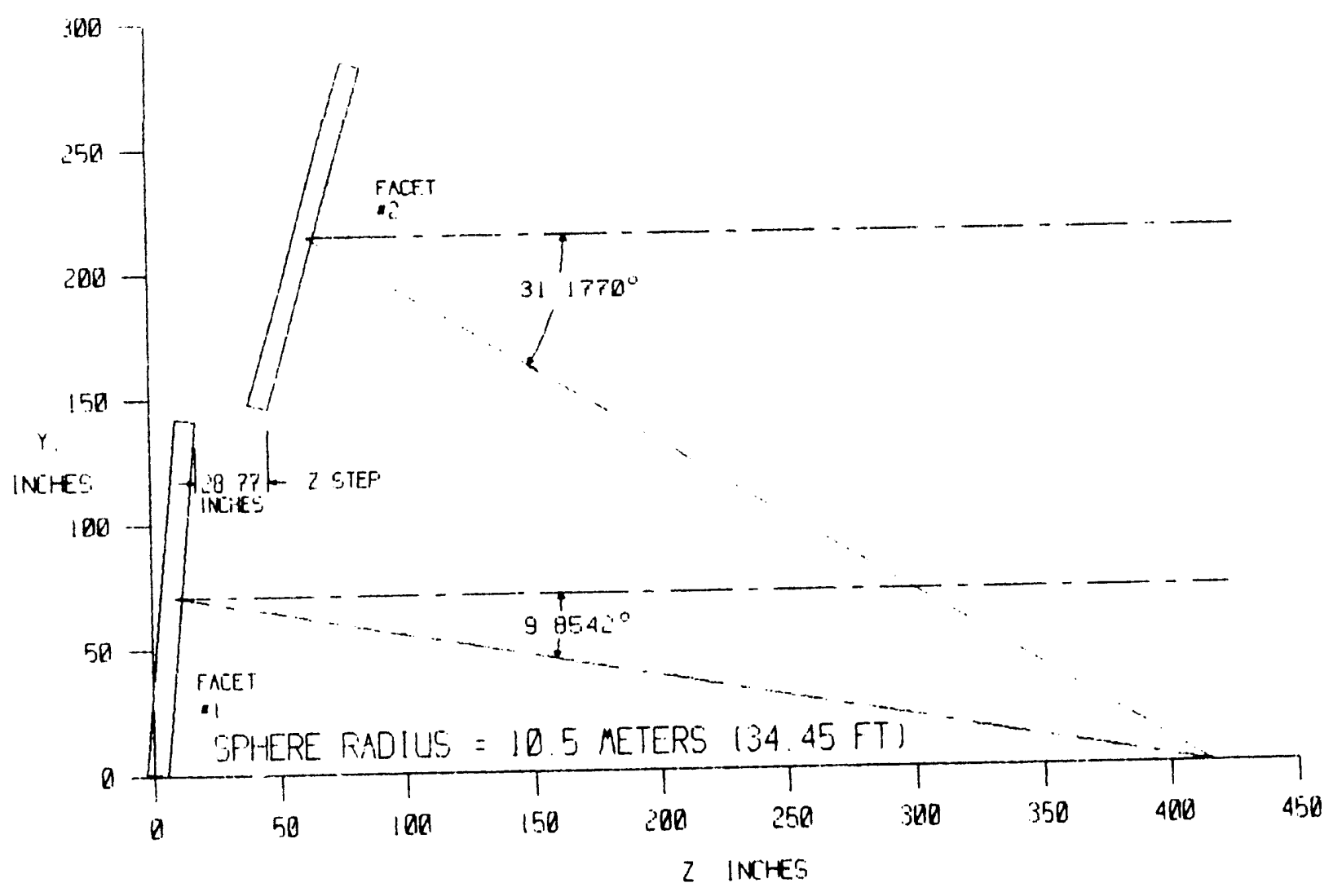

Figure 2.2-1 Facets on a Spherical Contour

With a parabolic contour, the facet $z$ offsets are considerably reduced for the case where the No. 5 focal length is $34.4 \mathrm{ft}$.; 1.e., they are essentlally planar as shown in Figure 2.2-2. Thus they require iittle or no intermedlate structure for attachment to the backup structure. However, the focal lengths of the facets around a system centerline of symmetry vary significantly. 


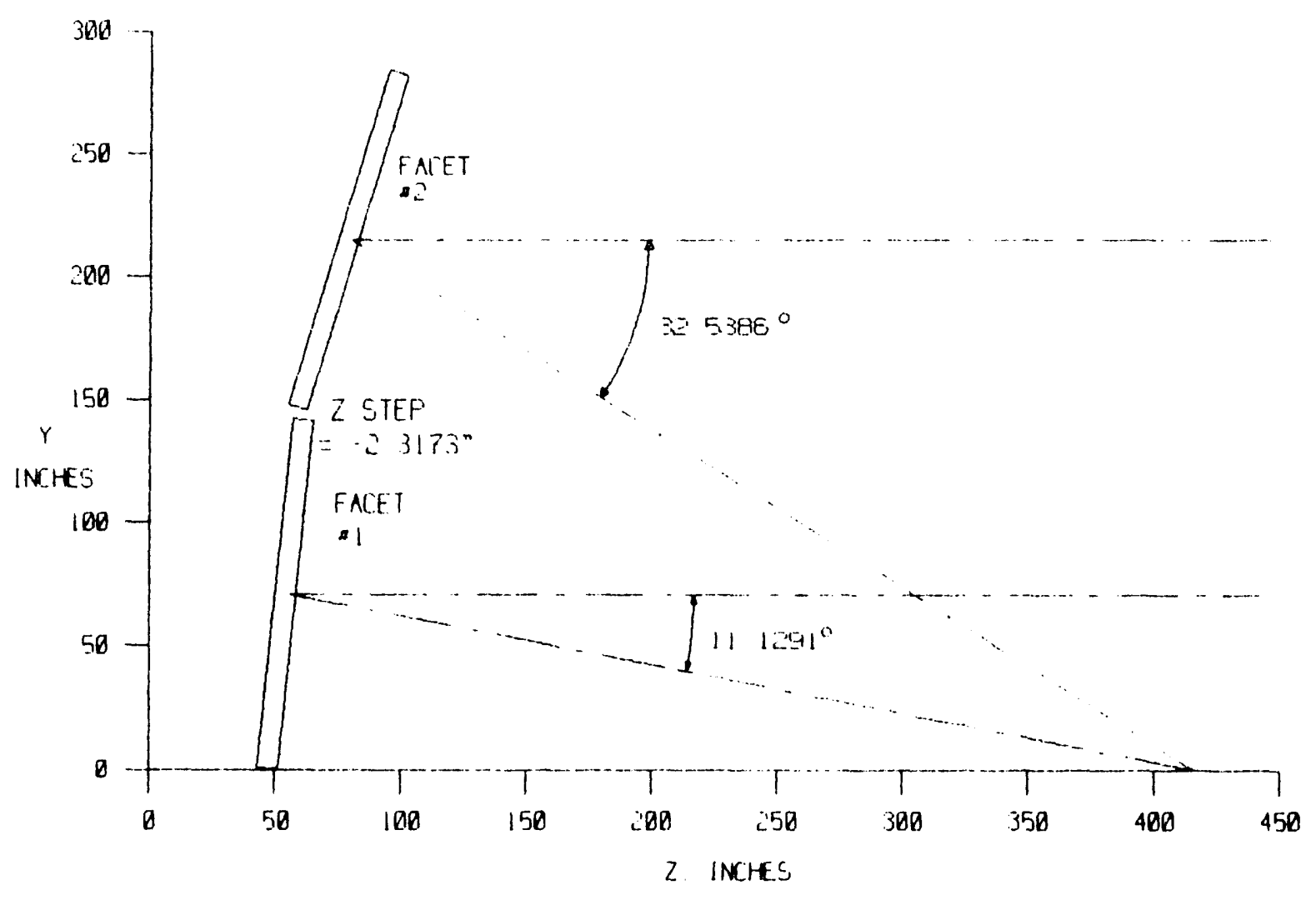

Figure 2.2-2 Facets on a Parabolic Contour

In Flgure 2.2-3, the varlation of facet focal lengths is shown for two parabolic contour focal lengths of $30.7 \mathrm{ft}$ and $25 \mathrm{ft}$. In the first case, the focal length of facet No. 5 is $34.5 \mathrm{ft}$., and the difference in focal length between facet Nos. 1 and 5 is 41.1 in. In the second case, the focal length of facet No. 5 is $29.6 \mathrm{ft}$. , and the focal length difference between facet Nos. 1 and 5 is 51.5 in. Therefore, unless the facets have a large range of focal length adjustment, it probably will be necessary to manufacture facets with different focal lengths. The attendant cost increases in the fabrication of facets with different focal lengths is not insignificant.

Both the spherical and the parabolic dish contours offer optimum optical performance characteristics, but neither is a good choice for different reasons. It was concluded that a compromise configuration with greater overall cost effectiveness was needed. The new configuration would be an uncomplicated structure that would minimize the facet focal length variations. 


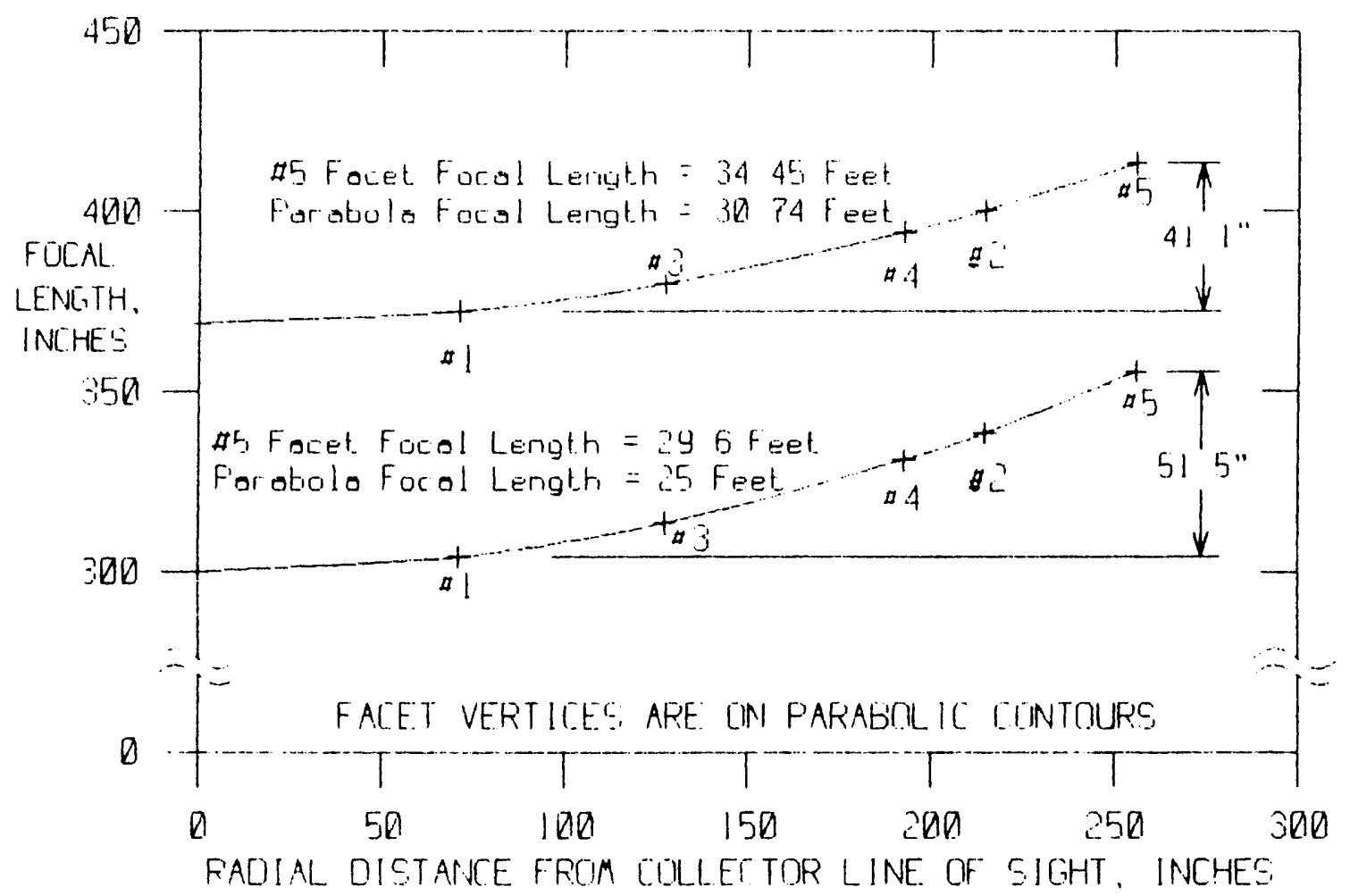

Figure 2.2-3 Facet Focal Lengths on Parabollc Contours

To this end, two structure contours, falling between the spherical and parabolic, were considered. As shown in Figure 2.2-4, contour No. 1 maintains the outermost facets, No's. 5A, 5B, 5C, and 5D (see Figure 2.1-1 above), on a spherical radius. The remaining facets are moved off the spherical radius closer to the focal point. In contour No. 2, the inner facets are moved toward the focal point as in contour No. 1 . However, the outer facets are also moved off the spherical radius but away from the focal point. since the outer facets, with their large off-axis aberrations, strongly influence the size of the image, 1t became Immediately apparent that the defocussing of outer facets in contour No. 2 would serve to increase the size of the receiver with an attendant loss of efficlency. Therefore, contour No. 2 was dropped from further consideration, and contour No. 1 was selected as the starting compromise contour for the Fss. 


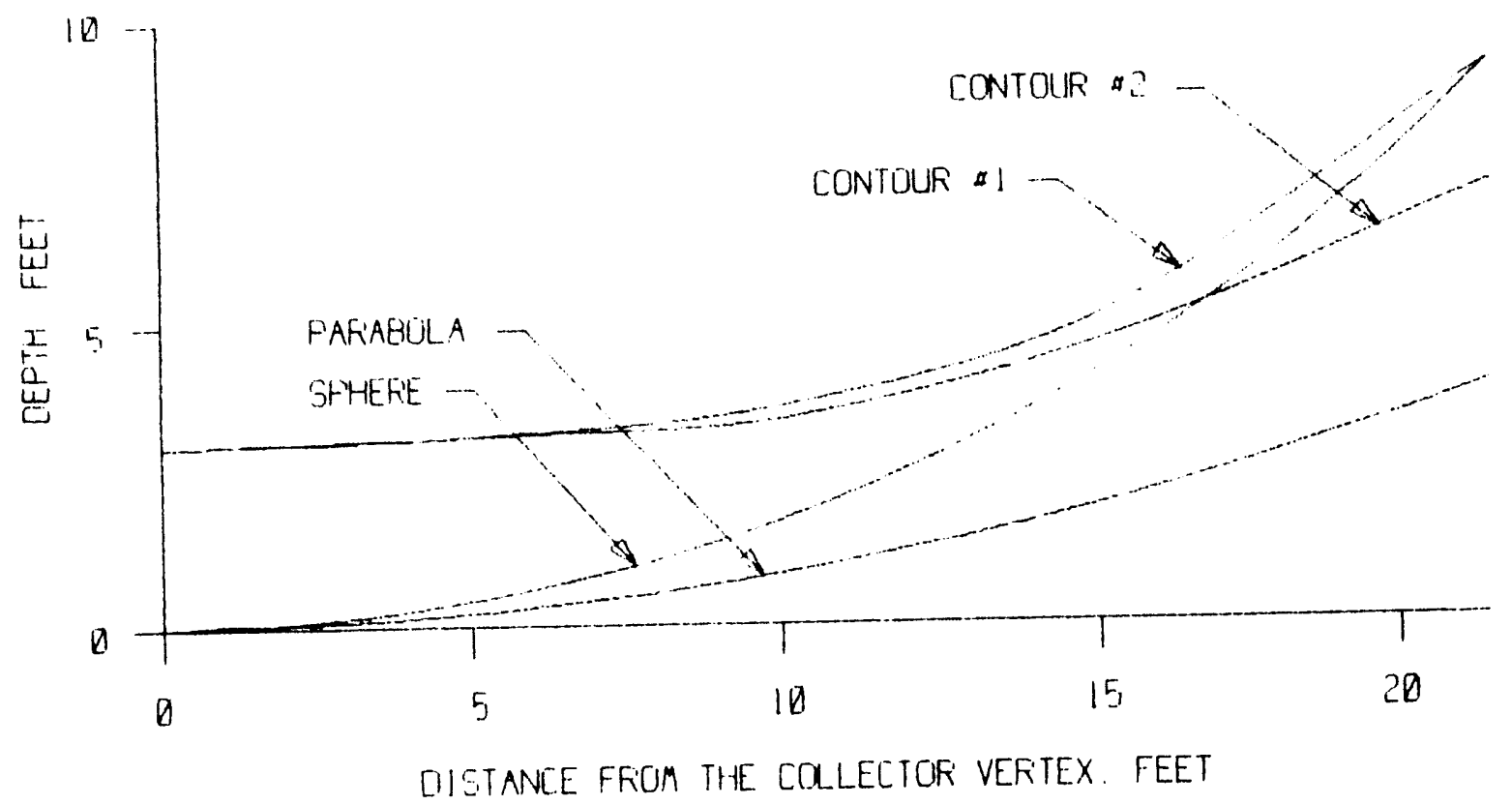

Figure 2.2-4 Contour Comparison, $F=29.9 \mathrm{ft}$.

A computer routine was developed to define the geometry of the facet locations relative to the vertex of the $\operatorname{dish}(X=0, Y=0, Z=2.8$ in.) of a spherical contour of $f=34.5 \mathrm{ft}$. The routine calculates the $z$ offsets, facet interference points, and the facet bolt clrcle geometry.

If the facet focal length and the radial distance of the facets from the dish vertex are varied, the facets can be positioned to achleve a reasonable compromise between the $z$ offsets and the $f / D$ varlations while providing approprlate rim-to-rim clearances. Analysis of sequential runs with selected input parameters enabled optimization of the facet locations.

Table 2.2-I shows the facet focal lengths for the selected dish contour. It also shows the position of the facet vertices, the radial distance in the $X Y$ plane of the vertices from the $X=0, Y=0$ point (DistFrmXY), the angle in the $X Y$ plane of the facet vertices from the $X$ axis, the tilt of the facet relative to the $X Y$ plane (RotateAng), and 
the minor axis of the projection of the facet into the XY plane (Radius InXY).

As shown in Table $2.2-I$, the maximum facet $f / D$ varlation is approximately 0.3 (from 2.7967 to 3.0911). This is equivalent to a facet focal length variation of $39.4 \mathrm{in}$.

The resultant compromise contour is within the adjustment range of both the plastically-formed and the elastically-formed facets while having little or no effect on the thermal/optical performance of the dish. The $z$ offsets are minimized so that the facet mounting pads are in close proximity to the backup structure and, thus, make negligible contribution to deflection errors. Both of these factors represent significant cost savings by limiting fabrication to only a single facet configuration and by reducing the amount and complexity of structure, respectively.

\subsection{Focal Length}

Prior studies [Ref. 1] indicate that, at a dish $f / D$ of about 0.6 , the optical efficiency is almost independent of support structure contour. In this case, structural considerations, such as simplicity of design, commonality of parts, system inertia, etc., are more significant. The drive system is of particular interest since it is sensitive to load changes, and such sensitivity could impact the cost of the dish. Therefore, a study was initlated to determine how changes in the dish focal length, within a limited range, impact the drive system. In this study, certain parameters were held fixed while others were varied. The effect of any given parameter was then plotted to establish trends and to ascertain lts effect on design.

Both spherical and parabolic support structure configurations were examined. Fixed parameters, established by directive, included a collector focal-length range from $25 \mathrm{ft}$. to $34.5 \mathrm{ft}$. and a dish populated with twelve facets, each of 11.5-ft. diameter. The 2TOP conflguration defined the dish size of about $47 \mathrm{ft}$. $x 40 \mathrm{ft}$. 
Table 2.2-I

FINAL FACET VERTEX LOCATIONS

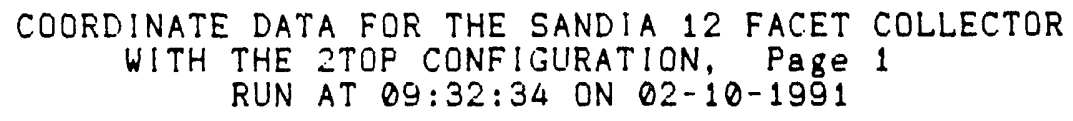

DEFAULT FILE: ADJMOUNT.DFT, ENTITLED: FINAL DESIGN

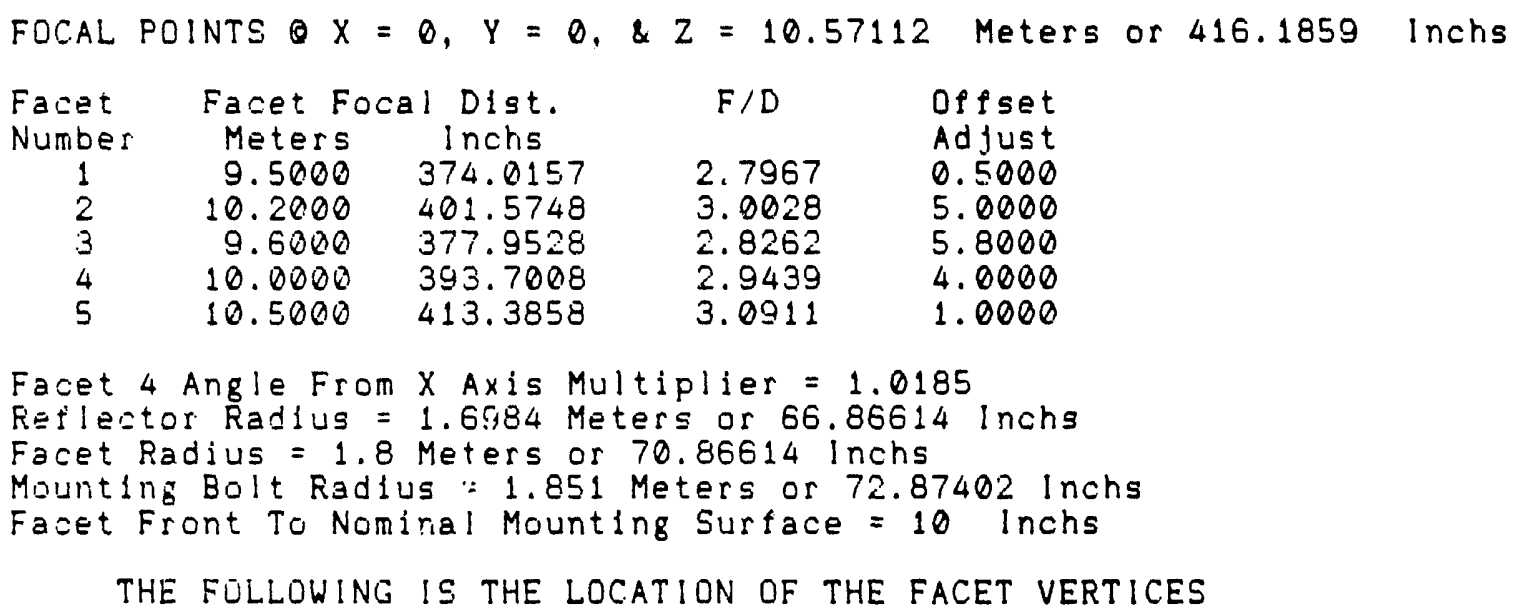

The units are inchs and degrees.

Number $X$. Inchs $Y$. Inchs $Z$, Inchs Vertex Depth

$\begin{array}{lr}1 & 0.0000 \\ 2 & 0.0000 \\ 3 \mathrm{~A} & 127.6805 \\ 4 \mathrm{~A} & 126.5884 \\ 5 \mathrm{~A} & 246.1739 \\ 3 \mathrm{~B} & -127.6605 \\ 4 \mathrm{E} & -126.5834 \\ 5 \mathrm{~B} & -246.1739 \\ 4 \mathrm{C} & -126.5884 \\ 5 \mathrm{C} & -246.1739 \\ 4 \mathrm{D} & 126.5884 \\ 5 \mathrm{D} & 246.1739\end{array}$

Number [is tFrmXY

$\begin{array}{lr}1 & 71.0429 \\ 2 & 214.6533 \\ 3 \mathrm{~A} & 127.6805 \\ 4 \mathrm{~A} & 192.4641 \\ 5 \mathrm{~A} & 256.1710\end{array}$
71.0429

214.6533

0.0000

144.9751

70.8661

0.0000

144.9751

70.8661

$-144.9751$

$-70.8651$

$-144.9751$

$-70.8661$

Ang leFrmX

90.0000

90.0000

0.0000

48.8734

16.0595
48.9786

76.7937

60.4522

72.7342

91.7391

60.4522

72.7342

91.7391

72.7342

91.7391

72.7342

91.7391

RotateAng

5.4746

16. 1558

9.8720

14.6325

19.1465
$-2.9886$

$-2.7835$

$-2.9574$

$-2.8391$

$-2.7039$

$-2.9574$

$-2.8391$

$-2.7039$

$-2.8391$

$-2.7039$

$-2.8391$

$-2.7039$

Radius InXY

66.5611

64.2255

65.8761

64.6974

63.1673 
With reference to Figure 2.3-1, the welght of the structure was found to remain virtually unchanged as the dish focal length changes from $25 \mathrm{ft}$. to $34.5 \mathrm{ft}$. As the focal length increases, however, the CG of the dish assembly moves toward the focal point (see Figure 2.3-2), moving the "balance" point, or elevation axis, of the assembly in the same direction. This causes the center of pressure of the reflector to move relatively further from the elevation axis, increasing the wind torque loading on the azimuth drive. At the same time, the mass moment of inertia of the assembly (the drive inertia) increases slightly, as shown in Figure 2.3-3, causing an increase in inertial (acceleration) loading of the drive.

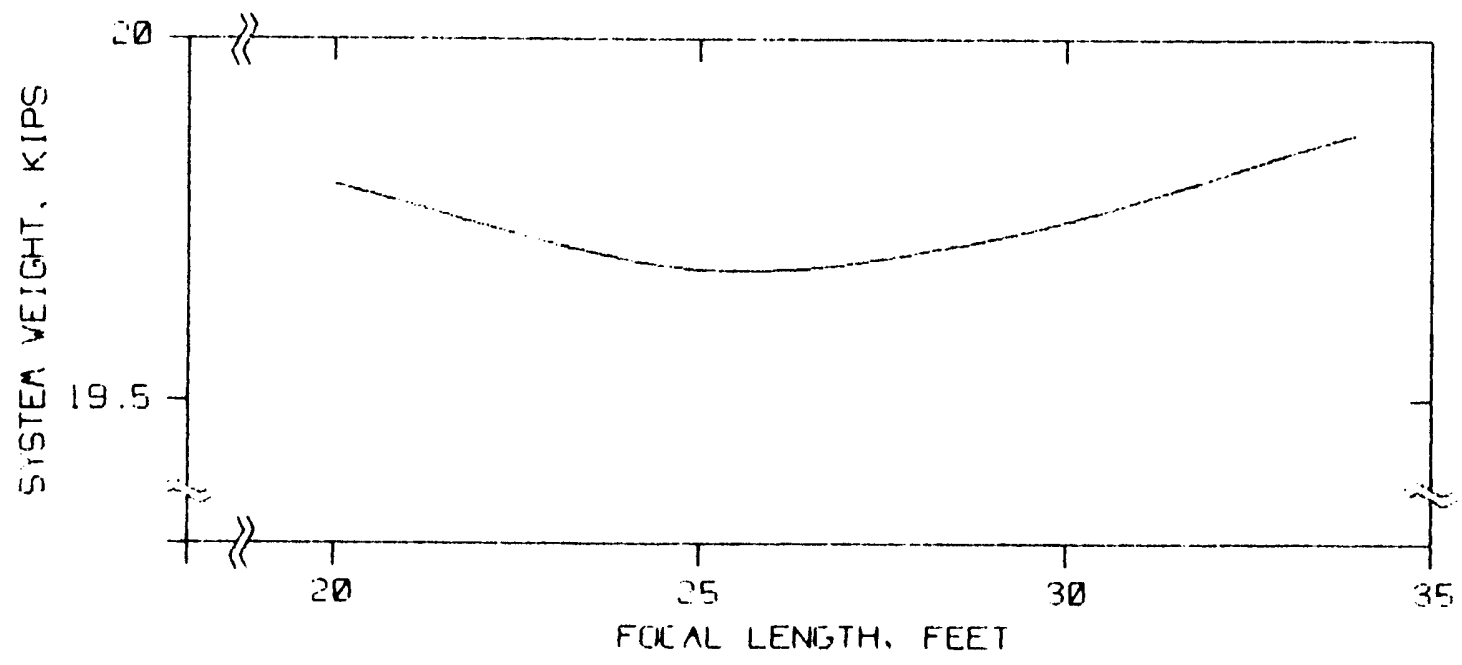

Figure 2.3-1 system Weight vs. Focal Length

The increased system inertia tends to reduce the natural resonance, or control frequency, of the system. The natural resonance is a function of the stiffness of the drive, which in turn 19 defined as the spring rate. Two load conditions must be considered when determining spring rate requirements - Inertial loads and wind loads. Each of these is represented by a different spring rate. In the case of inertial loads, the resonant frequency of the system is a function of the drive spring rate. For wind loads, the angular deflection, or 
rotation, of the drive is a function of drive spring rate. Since the two spring rates are derlved from unrelated load factors, the largest, or most dominant, spring rate drives the design.

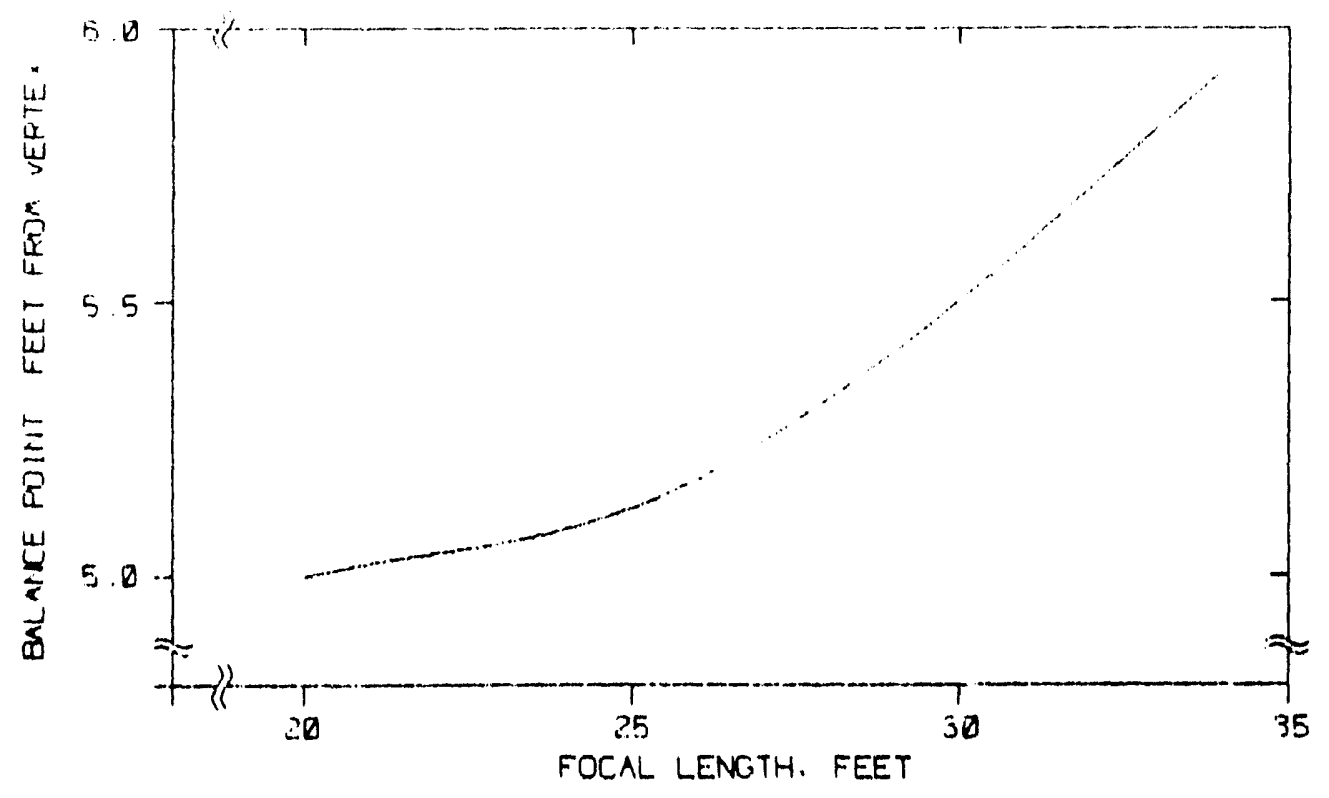

Figure 2.3-2 Balance Point vs. Focal Length

In the faceted dish, the resonant frequency can be as little as $1 \mathrm{hz}$ and still be fully compatible with control system capabilities. The Inertial spring rate required to maintain a $1 \mathrm{~Hz}$ resonance is shown in Figure 2.3-4 as a function of dish focal length. It shows that, for a fixed resonance, the required spring rate must increase by about 508 when the focal length increases from $25 \mathrm{ft}$. to $34.5 \mathrm{ft}$.

To hold structural deflections at operating wind conditions within specifled limits, a spring rate $2-1 / 2$ times the inertial spring rate is required. Preliminary calculations indicate that the deflection spring rate should be on the order of $1.75 \times 10 \mathrm{E} 08 \mathrm{in}-1 \mathrm{~b} /$ radian. Thus, the wind loads, requiring the largest spring rate of the two, define the minimum stiffness of the drive. 


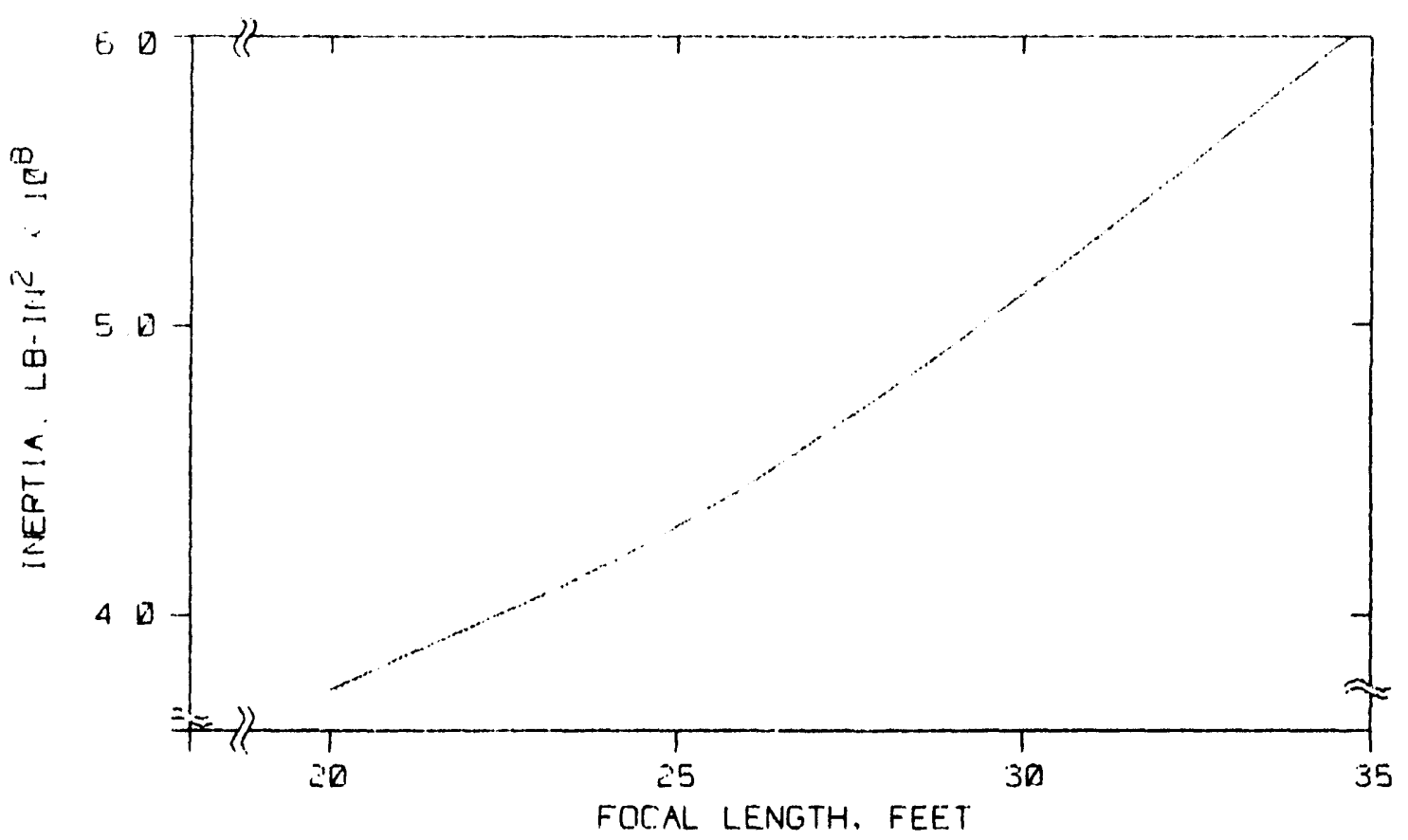

Figure 2.3-3 Drive Inertia vs. Focal Length

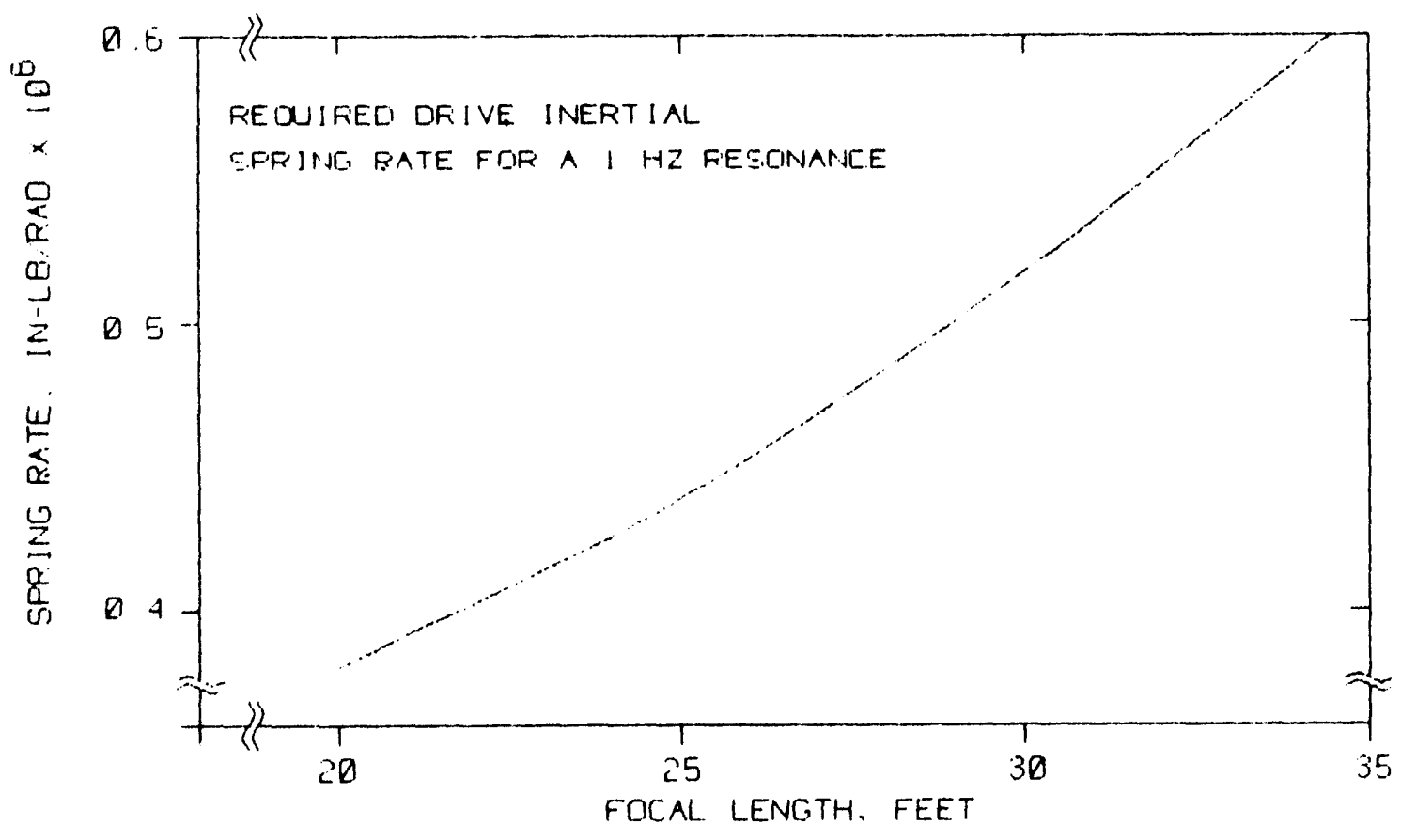

Flgure 2.3-4 Regulred Drive Inertial Spring Rate vs. Focal Length 
The inertia and wind loading tend to increase as the dish focal length increases in the range from 25 to $34.5 \mathrm{ft}$. In turn, these cause increases in drive loading and stiffness requirements as the focal length increases. However, the magnitude of these increases is slight.

In summary, although drive loads are greater at a focal length of 34.5 ft. than at a focal length of $24 \mathrm{ft}$., the difference is slight and has little impact on drive system design. Since the longer focal length favors facet manufacturing, and since it causes no significant drive disadvantage, it was decided that the dish focal length would be designed to accommodate a maximum facet focal length of 34.5 feet.

\subsection{Windmill Option}

Wind loads on full-motion concentrating dishes can be reduced by allowing the dish the freedom to seek the position of least resistance when ac stow. The availability of this option, called "windmilling", was examined for applicability to the faceted dish.

Windmilling serves to minimize the projected area of the faceted dish at stow relative to the wind. Since the total wind force is proportional to the projected area, both unbalanced azimuth torque and overturning moment are positively affected.

The windmilling option is available only when the dish is in a "power off" mode. This condition exists

1. when the dish is at 0 deg. elevation (Mode 1) awaiting morning start-up or evering go-to-stow signals, or

2. When the dish is at 90 deg. elevation in stow mode (Mode 2), or

3. when a power failure occurs (Mode 3), which can happen at any look angle.

Moreover, windmilling can only be available about the azimuth axis since the elevation drive must always be in a locked position when the power is off. Therefore, it can be reasonably concluded that the 
prine beneflciary of windmilling is azimuth torque and gear tooth loading.

Examination of each of the three power-off modes disclosed the following:

- Mode 1 - 0 deg. elevation

The dish is in this position only if wind conditions are favorable for start-up, i.e., under $35 \mathrm{mph}$. If, after reaching this position, the wind exceeds $35 \mathrm{mph}$, then a go-to-stow signal is transmitted to the drives and the dish immediately proceeds under power to the zenith position. Thus, the dish never sees winds above $35 \mathrm{mph}$ in this mode. Since the driving design loads occur at wind velocities of $50 \mathrm{mph}$ at any dish attitude, the loads at $35 \mathrm{mph}$ are not critical and windmilling offers no advantage.

- Mode 2 - 90 deg. elevation

At this position, the dish presents minimum profected arsa at all azimuth angles. Therefore, the windmilling option is a non1ssue.

- Mode 3 - Power Fallure

since power fallure can occur at any dish orientation, the dish could experience survival-level wind loads well in excess of the design criteria. In this mode the capability of windmilling allows the dish to feather, thus presenting a minimum area to the wind and reducing wind loading.

The windmiling option was examined for compatibility with the two candidate drive systems - the winsmith azimuth drive and a conventional spur-gear/pin: n-type drive. This option, however, is available only on a drive ticain that can freewheel in both clockwise and counter-clockwise directions. The winsmith drive is non-backdriving, and thus it is incapable of windmilling by virtue of a 460:1 primary stage gear reducer. (For a differential planetary reducer, ratios greater than 400:1 are consldered to be self-locking.) The conventional drive train is capable of windmilling only if it has no directly coupled worm gear or equally inefficient stage. However, to achieve 
the overall reduction desired in the azimuth drive of about $30,000: 1$, a gear train without one or more worm gear stages would be too massive and costly for use on the faceted concentrator. It is concelvable that the last stage of this type drive could be clutchcoupled so that, in a power-off condition, the clutch would release and allow the dish to windmill. But the added complexity and cost of such an approach would not be fustifled by the advantages of windmilling.

In summary, the following conclusions and recommendations were reached:

1. Only in case of power fallure does the windmilling option have a significant advantage.

2. Nelther of the two candidate drive systems, in consideration of practicalities, can windmill.

3. Since the windmilling option is not avallable, three alternatives have been considered.

- An emergency power source will be provided to drive the dish to stow in case of power fallure.

- The probabillty of power fallure occurring at a worst case attitude of the dish is assumed to be too low for consideration.

- The design criterla must be changed to include the power fallure mode.

The approach taken in the parabollc dish concentrator development task was to provide an uninterruptable power source. This approach will also be used in the faceted dish.

\section{5 solar Walk-off Protection}

The sow for the Faceted Dish project requires that the structure be provided with walk-off protection, or a "safe" path, when the concentrated solar beam is acquiring the sun, when it is leaving the recelver, or when beam walk-off results froil loss of power. A safe path can be provided by passlve means such as placing insulation on 
the structural elements over which the concentrated beam would pass. This appears to be the most practical solution to a loss-ofpower situation. However, at the outset of the design it was believed that, under operational conditions, quick engagement or disengagement by a relatively high-speed drive was a more positive solution.

The critical operational condition occurs when emergency defocussing is required. Assuming a 16-in. diameter concentrated beam image at the recelver, and a recelver structure diameter of $36 \mathrm{in.}$, the beam must be moved $26 \mathrm{in}$. to be totally clear of the recelver structure. with a $34.5 \mathrm{ft}$. (414 in.) nominal dish focal length this represents an angular change of $3.6 \mathrm{deg}$.

The on-sun, off-sun capability at high elevation angles reguires use of the elevation plane of motion since, t high elevation angles, azimuth motion is ineffective at moving the concentrator image. Two methods for achleving the requisite elevation motion were investigated. One method entalled articulating the PCA support structure. The other approach was to design the elevation drive so that it has adequately high output speed to move the Image off of the recelver.

An articulated PCA support structure had the potentlal advantage of accommodating both emergency defocussing and recelver/engine maintenance. By plvoting the truss at or near the "elbow", one could lower the outboard section to near ground level, as shown in Figure 2.5-1, using a linear actuator screw Jack as the driving element. The same drive could also be used to move the recelver/engine out of the concentrated focal point image. However, it was found that these two functions were very different.

For emergency defocus, the recelver must be moved out of the concentrated solar image quickly. In the malntenance mode, it can be lowered at a very slow rate. Therefore, the size and cost of the motor required for adequate defocussing is signiflcantly greater than is required for the maintenance function. 


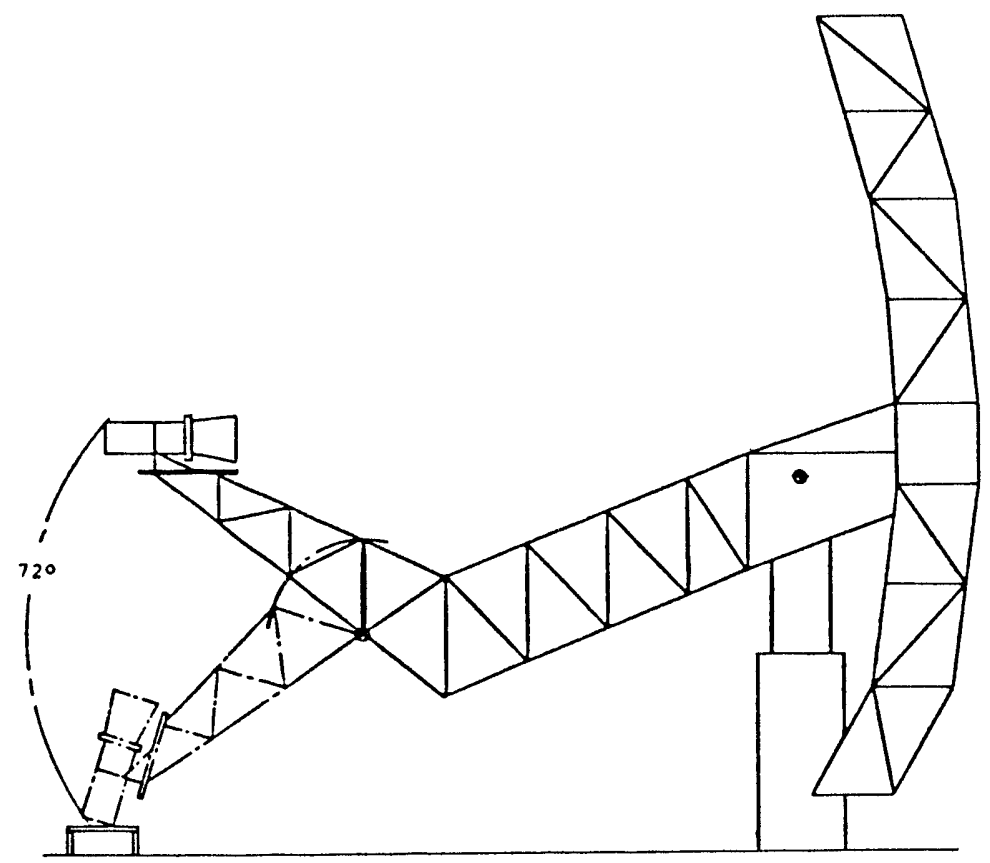

Figure 2.5-1 Articulated PCA support structure

It was determined that the planned elevation drive could provide sufficlently rapid movement for tracking the image off of the recelver without a significant cost penalty. Further, a relatively inexpensive cable winch could be used to meet the maintenance requirement of lowering the receiver/engine assembly. Therefore, the use of the articulation for the walk-off requirement was not employed in this design.

The elevation drive design moves the dish at an average rate of 9 deg./min. with the drive motor operating at its rated speed of 1140 RPM. Thus, the elevation drive alone will move the concentrated beam off the structure in about 24 seconds. The control system has the capability of driving the motor at twice its rated speed for a limited period of time. A speed of 2300 RPM is required for 12 seconds for the image to be clear of the structure. This is within the capability of the motor and the motor controller. The control system will use this high-speed mode to acquire and move off the sun, for example, in an emergency or upon recelving an appropriate signal from the fault alarm on the receiver/stirling engine. 
other factors can help reduce the time required to move the image off the structure. The 36 -in. diameter receiver/engine mount is an estimate based on the preliminary design of the heat-pipe recelver and the stirling engine. If the stirling engine package designated for the faceted collector is foot mounted, as opposed to radially mounted, the 36-in. dimension could be reduced. Further, as the dish drives off target, the images from the facets start to separate; and the heat energy is less concentrated as a function of the off-track angle. Finally, the above discussion is based on a high dish elevation angle. At lower elevation angles, simultaneous azimuth motion is avallable to further reduce the time required to move the concentrated image.

In summary, the designed elevation drive can operate for a limited perlod of time at twice rated speed. This capability facilitates moving the receiver/stirling engine and its support structure off sun in about 12 seconds. Thus, in worst-case conditions of high elevation pointing angles, the elevation drive accommodates the sow requirements for walk-off protection.

\subsection{Tracking Error Considerations}

The project sow defines the required pointing error for the concentrator in terms of the contribution of three sources. First, the allowable facet slope error is less than $2.5 \mathrm{mr}, 1$ standard deviation. second, the support structure shall have a maximum error no greater than $1.0 \mathrm{mr}$. Third, the control system shall have a standard deviation error of no greater than $0.6 \mathrm{mr}$.

The portion of the project covered by this report includes design of the control system and the support structure up to the facet mounting interface. Facet design is treated in reports by SAIC [Ref. 2] and SKI [Ref. 3]. As a result, this report neglects any error in the lineof-sight of the facets relative to the facet mountings on the support structure. Deflections of the support structure that cause movement of the facet mounts are included. 
The proper allocation of the support system individual error sources to elther the structure or control system depends on the system configuration. As a result, it was decided to combine the structure and control system erroxs into an overall error. This overall error (excluding facet errors) is referred to below as the collector system error.

If the maximum structural error is taken to be equivalent to a three sigma error, the sow requirement for the one sigma collector system pointing error is $0.69 \mathrm{mr}(.039$ deg.).

While this accuracy is within reach with proper implementation, it appeared that it might be more demanding than could be justifled. Consequently, a trade-off study of several alternate control system designs was undertaken.

\subsubsection{Active versus Passive Track}

The sow required that the system would "... have a closed-loop, aperture feedback control ...". This is referred to below as "active track". The specifled accuracy could be achleved with relative ease using active tracking. In this case, the term "active track" is taken to mean that the collector position control loop would be closed through a sun-direction sensor. The sun sensor would be mounted on the collector structure. The sensor error output would be used to drive the collector so that the sensor would be on the line-of-sight to the sun.

To test this, an estimated error budget was developed. In this budget, each of the error source values is an ESTIMATED peak value for the conditions stated, except for the effect of the backup structure and PCA dead weight deflections. The exror of the line-of-sight of the sun sensor relative to the line-of-sight of the collector caused by these two sources is used at 208 of their estimated peak value. It was estimated that these error sources would be corrected to within 20 of thelr actual value by causing the program to insert blas in the error output of the sensor. The wind-induced deflections 
of the backup structure, the engine, and the control system are not similarly reduced since they cannot be predicted easily. It should be noted that these estimates were made before the structure was designed or analyzed and, therefore, the values used here are not the same as the final values for the structure reported in section 5.0.

In order to evaluate the configuration promising the most accuracy, linear drives were used, e.g., silicon-controlled rectifier motor controllers driving DC servo motors inside torque and velocity loops. such drives have small errors under the conditions expected here.

The resulting error budget is shown in Table 2.6-I. The errors, as shown in the table, include the composite deflections of the structure and, therefore, the facet mounts, due to gravity and wind relative to the sun position sensor. They do not include deflections of the facet mountings relative to each other.

The pointing error for this case is well within the one sigma error specification of $0.69 \mathrm{mr}$. However, due to the problems that had been experlenced with previous sun sensors, the project manager made the decision to use passive tracking in lieu of active tracking even though the errors would be larger.

In this case, passive tracking is taken to mean that the position loops would be closed using the error between the calculated sun position and the collector position as reported by position sensors coupled directly to the collector axes.

With passive tracking, the errors caused by backup structure deflection, pedestal deflections, and collector axis misalignments are greater than for active tracking since the errors of concern are the deflections relative to the earth-based coordinate system used to calculate the position of the sun. Some of these errors can be partially corrected, but the residial errors will still appear. In the active case, only deflections of the collector relative to the sun sensor mounting are of primary concern. 
Table 2.6-I Pointing Error W/Linear Drive and Sun Tracker

COLLECTOR SYSTEM POINTING ERROR ESTIMATES

USING A CONTROL SYSTEM WITH LINEAR DRIVE AND A SUN TRACKER

\begin{tabular}{|c|c|c|c|c|}
\hline \multirow{3}{*}{$\begin{array}{c}\text { ERROR SOURCE } \\
3 \text { SIGMA OR PEAK VALUES }\end{array}$} & \multirow{2}{*}{\multicolumn{2}{|c|}{$\begin{array}{cc}16.8 & \text { MPH WIND } \\
\text { AZIMUTH } & \text { ELEVATION }\end{array}$}} & \multicolumn{2}{|c|}{27 MPH WIND } \\
\hline & & & AZIMUTH & ELEVATION \\
\hline & Millirad & Millirad & Millirad & Millirad \\
\hline Backup struct Gravity X.2 & .00 & .15 & .00 & .15 \\
\hline Engine Dead Welght $\times .2$ & .00 & .08 & .00 & .08 \\
\hline Backup structure wind Def. & .25 & .25 & .65 & .65 \\
\hline Englne Wind Deflection & .01 & .01 & .01 & .01 \\
\hline Linear Servo Wind Error & .01 & .01 & .01 & .01 \\
\hline Linear Servo LImit Cycle & .02 & .02 & .03 & .03 \\
\hline Sun Sensor Error & .10 & .10 & .10 & .10 \\
\hline & $--\cdots-$ & ----- & $-\cdots-$ & ---- \\
\hline RSS AXIS RESULT & .27 & .32 & .66 & .68 \\
\hline RSS TOTAL & & .42 & & .95 \\
\hline $\begin{array}{l}\text { NoTES: The Indlvidual err } \\
\text { marked } x .2 \text { whlch a } \\
\text { The errors in each } \\
\text { each axls. The va } \\
\text { an Rss calculation } \\
\text { Thus, it can be ex } \\
27 \text { mph, the result } \\
\text { estimate of the pr } \\
27 \text { mph case repres } \\
\text { error for the } 16 .\end{array}$ & $\begin{array}{l}\text { ors are es } \\
\text { ire } 208 \text { of } \\
\text { axis are } \\
\text { lues for } \\
\text { ivected the } \\
\text { spef the } 1 \\
\text { obable er } \\
\text { onts a re }\end{array}$ & $\begin{array}{l}\text { stimated ped } \\
\text { estimated } \\
\text { combined by } \\
\text { the axis tot } \\
\text { at, for a } 1 \\
6.8 \text { mph case } \\
\text { or lone s1 } \\
\text { asonable es } \\
\text { gusting to }\end{array}$ & $\begin{array}{l}\text { errors exce } \\
\text { k errors. } \\
\text { n RSS calct } \\
\text { are also } \\
\text { mph wind } \\
\text { epresents } \\
\text { l. The re } \\
\text { ate of the } \\
\text { mph cond }\end{array}$ & $\begin{array}{l}\text { pt those } \\
\text { dlation for } \\
\text { che result of } \\
\text { gusting to } \\
\text { reasonable } \\
\text { 3ult of the } \\
\text { three slgma } \\
\text { tion. }\end{array}$ \\
\hline
\end{tabular}

The sun position calculation will have some small error due to incomplete algorithm implementation, calculation errors, incorrect time, etc. The error due to a time error can affect either or both axes depending on the sun position. In this analysis, all the estimated time error was arbltrarlly taken to be in the azimuth budget.

Finally, the axis position sensors have errors that must be included. At the time, the avallabllity of reasonable cost encoders with 
sufficient accuracy was not known, so it was assumed that two-speed resolvers would be used to close the control loops.

An error budget for this case is shown in Table 2.6-II.

Table 2.6-II Pointing Error W/LInear Drive and Resolvers

COLLECTOR SYSTEM POINTING ERROR ESTIMATES

USING A PASSIVE CONTROL SYSTEM W/LINEAR DRIVE AND RESOLVERS

\begin{tabular}{|c|c|c|c|c|}
\hline $\begin{array}{c}\text { ERROR SOURCE } \\
3 \text { SIGMA OR PEAK VALUES }\end{array}$ & $\begin{array}{r}16.8 \\
\text { AZIMUTH }\end{array}$ & $\begin{array}{l}\text { MPH WIND } \\
\text { ELEVATION }\end{array}$ & $\begin{array}{l}27 \mathrm{MPH} \\
\text { AZIMUTH }\end{array}$ & $\begin{array}{l}\text { WIND } \\
\text { ELEVATION }\end{array}$ \\
\hline & Mllllrad & Millirad & Mlllirad & Mill1rad \\
\hline Backup struct Gravity X.2 & .00 & .30 & .00 & .30 \\
\hline Engine Dead Welght $\times .2$ & .00 & .08 & .00 & .08 \\
\hline Backup structure wind Def. & .50 & .50 & 1.30 & 1.30 \\
\hline Englne Wind Deflection & .01 & .01 & .01 & .01 \\
\hline Pedestal Wind Deflection & .14 & .14 & .36 & .37 \\
\hline Ped \& El AxIs Allgn $X .2$ & .20 & .20 & .20 & .20 \\
\hline Linear Servo Wind Error & .01 & .01 & .01 & .01 \\
\hline Linear Servo LImlt Cycle & .02 & .02 & .03 & .03 \\
\hline Prediction Error w/o time & .20 & .20 & .20 & .20 \\
\hline TIme Error ( 5 seconds) & .40 & .00 & .40 & .00 \\
\hline Resolver Error & .30 & .30 & .30 & .30 \\
\hline & $-\cdots$ & $-\cdots-$ & $-\cdots-$ & $-\cdots$ \\
\hline RSS AXIS RESULT & .77 & .73 & 1.47 & 1.45 \\
\hline RSS TOTAL & & 1.07 & & 2.06 \\
\hline
\end{tabular}

NOTES: The notes for Table 2.6-I also apply to this table.

The resultant estimated system error of $1.07 \mathrm{mr}$ is in excess of the specified allowable error, but as a result of a study [Ref. 4], the error requirements were re-evaluated. It was decided that the error requirement would be relaxed and that passive tracking would be used for the faceted dish. 


\subsubsection{Control system Configuration study}

Table 2.6-II is not supported by existing solar control systems, and it is relatively expensive because of the linear drives and the resolver position sensors. Accordingly, a cost and performance trade-off study was performed with regard to these two components.

\subsubsection{Collector Drive Considerations}

The linear drives used for the estimates in Tables 2.6-I and 2.6-II would be relatively expensive regardless of the type of linear drive used. The three drive configurations examined included only fourquadrant controllers that would provide good performance under gusting wind loads. One type used sllicon-controlled rectifiers to drive DC servo motors. Another type used pulse-width modulation to drive DC servo motors. Both of these would be operated inside torque and velocity loops. The third type considered utillzed fourquadrant, flux-vector controllers with a full set of features driving standard 3-phase AC induction motors.

All three of these configurations would provide error performance near to that shown in Tables 2.6-I and 2.6-II. Any of these configurations would, however, cost more than two thousand dollars per axis for the two-Hp systems thought to be needed at the time the estimate was made.

A more economical drive method uses a "bang-bang" approach where drives with appropriate gear ratios and motor size for the drive-tostow situation are pulsed to produce tracking motion. This is done elther with multiple short pulses or with pulse-width modulation. The pulsing is done in a manner that attempts to move the collector axis the correct amount to ellminate the detected error. The pulses normally have an amplitude equal to the full voltage rating of the motor. If the motor is an AC motor, the applled frequency normally is the line frequency. This yields positioning with considerably greater error than is achieved with a linear drive. The additional error arises from the controller dead band, varying friction, backlash, etc. If the 
resultant error and intermittent application of power is acceptable, the method ylelds an effective, relatively low cost drive.

An error budget for this case is shown in Table 2.6-III.

Table 2.6-III Pointing Exror W/"Bang-Bang" and Resolvers

COLLECTOR SYSTEM POINTING ERROR ESTIMATES USING A PASSIVE CONTROL SYSTEM W/BANG-BANG DRIVE

$$
\text { POSITION FEEDBACK - RESOLVERS }
$$

ERROR SOURCE

3 SIGMA OR PEAK VALUES

Backup struct Gravity X.2

Englne Dead Welght $X .2$

Backup structure wind Def.

Engine wind Deflection

Pedestal Wind Deflection

Ped \& El Axis Align $X .2$

Bang-Bang Dead Band \& OS

Prediction Error w/o Time

Time Error (5 Seconds)

Resolver Error

RSS AXIS RESULT

\subsection{MPH WIND AZ IMUTH \\ Millirad \\ ELEVATION \\ M1111rad}

.00

.00

.50

.01

.14

.20

1.00

.20

.40

.30

1.26
.30

.08

.50

.01

.14

.20

1.00

.20

.00

.30

1.24
$27 \mathrm{MPH}$ WIND AZIMUTH ELEVATION

Mlllirad Millirad .00 .30 .00 .08

1.30

1.30

.01 .01

.36 .37

.20 .20

1.00

1.00

.20 .20

.40 .00

.30 .30

RSS TOTAL

NOTES: The notes for Table 2.6-I also apply to this table.

The only difference between the error sources in Table 2.6-III and Table 2.6-II is that the errors aue to the "bang-bang" full power method have replaced the errors due to the linear drive. The drive errors are labeled "bang-bang" dead band \& os (Over shoot). A "bangbang" drive must be pulsed for a perlod long enough to develop enough torque to overcome both maximum friction losses and the maximum load 
that can oppose the desired motion; if the pulse duration is not enough, no motion of the load will occur. Then, when less loss and/or load is present, the motion that results is usually larger than desired. This happens because the excess velocity achieved by the long pulse must be absorbed by a smaller load that may actually be in the direction of the motion. The result is that the system will substantially overshoot the zero error point when the drive is lightly loaded. If the overshoot triggers a reverse correction, back-andforth motion about zero error (hunting) can result. To prevent hunting, an error threshold must be used to prevent drive operation when the detected error is less than the threshold. This results in a dead band error equal to twice the value of tire threshold. The value of one $\mathrm{mr}$ error used for each axis is somewhere between realistic and quite optimistic. This value is probably very optimistic for the elevation axis where the gravity load is high at both low and high elevation angles but with a reversal ac about 35 deg. elevation.

The resultant RMS error of about $1.8 \mathrm{mr}$ was higher than desıred. This was felt to be particularly true with the possibility that this value might be optimistic for practical drives. This result led to a decision to use drives other than full power, rated frequency, "bangbang" drives even though they may be useful in the future. The controllers ultimately chosen are such that they can be set to simulate the full-power pulsing so that this method can be tested when the system is operated.

One requirement of the sow was that the control system design be based on existing and proven designs. However, none of the existing and proven solar collector controllers could control linear drives. As a result, it was decided to use motor controllers that will allow use of a "soft bang-bang" system. The controllers would be flux vector controllers but without the complexity and cost of those used with a fully linear control system.

The controllers selected are two-quadrant inverters from Polyspede Electronics Corporation; Dallas, Texas. This inverter generates 
synthesized, 3-phase, AC power at any of four preselected frequencies between 0.5 and $132 \mathrm{~Hz}$. Nearly full torque can be developed for any frequency. This means that the tracking command frequency can be set at $1 \mathrm{~Hz}$ and nearly full torque developed, but the motor velocity will not exceed $1 / 60$ th of rated speed. The consequence of using a two-quadrant inverter is that when the command to drive is removed, the controller does not aid in the deceleration of the motor. Under light load conditions, the coast-down travel is less than with a full power "bang-bang" system since the speed is less. The result is that. the overshoot in light load conditions is considerably less than if the normal $60 \mathrm{~Hz}$ is applied and the motor allowed to accelerate for the total pulse duration and then coast down from the higher speed.

The error budget shown in Table 2.6-IV applles for this case. Everything is the same except for the amount allocated to the "bang-bang" errors. This factor was reduced from $1.0 \mathrm{mr}$ to $0.5 \mathrm{mr}$. While this is not a large reduction, there is considerably more confidence that this value is achievable with the flux vector controller.

\subsubsection{Collector Position Sensor Considerations}

In all the above error budgets, a resolver with a total one sigma error of $0.3 \mathrm{mr}$ was assumed. This requires a two-speed resolver since a single-speed resolver and a resolver-to-digital converter together have errors greater than $0.3 \mathrm{mr}$ peak. Even though incremental encoders with sufficient accuracy and lower cost than a twospeed resolver were later found, the use of motor revolution counters was considered for position sensing since they are still less expensive.

Table 2.6-IV, modified by eliminating the resolver error and adjusting the other errors to account for using motor counters, resulted in Table 2.6-V, which shows the effect of using motor counters. The direct errors in the motor counters themselves are neglected.

The two new error sources are drive backlash and the drive deflections due to wind loads. The two new error sources must be included 
since they affect the relation between the position of the motors and the collector axes. Compensation for these changes cannot be made by biasing the control system.

Table 2.6-IV Pointing Error W/"Soft Bang-Bang" \& Resolvers

COLLECTOR SYSTEM POINTING ERROR ESTIMATES

USING A PASSIVE CONTROL SYSTEM W/SOFT BANG-BANG DRIVE

$$
\text { POSITION FEEDBACK - RESOLVERS }
$$

\begin{tabular}{|c|c|c|c|c|}
\hline ERROR SOURCE & \multicolumn{2}{|c|}{$16.8 \mathrm{MPH}$ WIND } & \multicolumn{2}{|c|}{$27 \mathrm{MPH}$ WIND } \\
\hline 3 SIGMA OR PEAK VALUES & AZIMUTH & ELEVATION & AZIMUTH & ELEVATION \\
\hline & Millirad & M1llirad & Mlllirad & Mlllirad \\
\hline Backup struct Gravity X.2 & .00 & .30 & .00 & .30 \\
\hline Engine Dead Weight $x .2$ & .00 & .08 & .00 & .08 \\
\hline Backup structure wind Def. & .50 & .50 & 1.30 & 1.30 \\
\hline Engine Wind Deflection & .01 & .01 & .01 & .01 \\
\hline Pedestal wind Deflection & .14 & .14 & .36 & .37 \\
\hline Ped \& El Axis Align X .2 & .20 & .20 & .20 & .20 \\
\hline Bang-Bang Dead Band oS & .50 & .50 & .50 & .50 \\
\hline Prediction Error w/o Time & .20 & .20 & .20 & .20 \\
\hline Time Error ( 5 Seconds) & .40 & .00 & .40 &, 00 \\
\hline Resolver Frior & .30 & .30 & .30 & .30 \\
\hline & $\cdots \cdots$ & $\ldots \ldots$ & $\cdots \cdots$ & 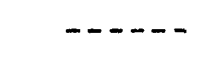 \\
\hline RSS AXIS RESULT & 0.92 & 0.89 & 1.55 & 1.53 \\
\hline RSS TOTAL & & 1.28 & & 2.18 \\
\hline
\end{tabular}

NOTES: The notes for Table 2.6-I also apply to this table.

As can be seen in Table $2.6-\mathrm{V}$, the use of motor counters in place of resolvers results in significantly larger errors. The size of the errors led to a decision to use the resolvers (later replaced by encoders). 
Table 2.6-V Pointing Error W/Motor Revolution Counters

COLLECTOR SYSTEM POINTING ERROR ESTIMATES

USING A PASSIVE CONTROL SYSTEM W/SOFT BANG-BANG DRIVE

$$
\text { POSITION FEEDBACK - MOTOR COUNTERS }
$$

\begin{tabular}{|c|c|c|c|c|}
\hline ERROR SOURCE & \multicolumn{2}{|c|}{$16.8 \mathrm{MPH}$ WIND } & \multicolumn{2}{|c|}{$27 \mathrm{MPH}$ WIND } \\
\hline 3 SIGMA OR PEAK VALUES & AZIMUTH & ELEVATION & AZIMUTH & ELEVATION \\
\hline & Millirad & Millirad & Millirad & Millirad \\
\hline Backup stinit Gravlty $x .2$ & .00 & .30 & .00 & .30 \\
\hline Engine Dead Weight $x .2$ & .00 & .08 & .00 & .08 \\
\hline Backup structure wind Def. & .50 & .50 & 1.30 & 1.30 \\
\hline Engine wind Deflection & .01 & .01 & .01 & .01 \\
\hline Pedestal Wind Detlection & .14 & .14 & .36 & .37 \\
\hline Drive Wind Deflection & .44 & .50 & 1.16 & 1.29 \\
\hline & $-\cdots$ & $-\cdots$ & --- & $-\cdots-$ \\
\hline Drlve \& Ped. Wind Total & .58 & .64 & 1.52 & 1.66 \\
\hline Drlve Backlash & 1.38 & 1.00 & 1.38 & 1.00 \\
\hline Ped \& El Axis Allgn $X .2$ & .20 & .20 & .20 & .20 \\
\hline Bang-Bang Dead Band \& OS & .50 & .50 & .50 & $.5 r$ \\
\hline Prediction Error w/o Time & .20 & .20 & .20 & .20 \\
\hline Time Error (5 seconds) & .40 & .00 & .40 & .00 \\
\hline & $\cdots-\cdots$ & $-\cdots-1$ & $\ldots-$ & $-\ldots$ \\
\hline RSS AXIS RESULT & 1.72 & 1.45 & 2.53 & 2.42 \\
\hline RSS TOTAL & & 2.25 & & 3.50 \\
\hline
\end{tabular}

NOTES: The notes for Table 2.6-I also apply to this table. Also: The Pedestal wind Deflection and the Drive Wind Defiection are directly added sirce they are always in the same direction.

The use of motor counters to replace the encoders may eventually prove to be acceptable if the actual errors are less than the requirement that exists at the time. The electronics as designed will be capable of utilizing motor counter pulses without hardware, firmware, or aftware modification. Also, the motors selected have rear 
ware, or software modification. Also, the motors selected have rear shaft extensions so that motor counters can easily be installed for test.

\subsubsection{Control system Selection S'dmmary}

In summary, the trade-off studies resulted in selecting a control system with the following characterestics for the faceted dish:

1. Passive tracking utilizing a modified solar collect or controller.

2. "Soft bang-bang" motor controller operation utllizing flux vector controllers.

3. Position feedback fron the collector axes utilizing incremental encoders.

4. Static structure errors compensated by the control system. 


\subsection{STRUCTURE DESIGN}

The design of the faceted, stretched membrane dish concentrator builds on the successful stretched membrane heliostat program. It integrates a reflective surface consisting of 12 stretched-membrane facets with a full-motion tracking structure capable of providing full hemisphere coverage. The tracking structure is a kingpost type in which the FSS and the power conversion assembly are balanced about the elevation axis.

The decisions impacting the structure, reached as a result of the studies described in section 2.0, are incorporated in the design, as listed below.

- The facets are arranged in the 2TOP configuration.

- The facet vertices are on a compromise contour, between parabolic and spherical.

- The nominal focal length is $34.5 \mathrm{ft}$.

- The elevation drive provides adequate walk-off protection.

The concentrator structure, as shown in Figures $1.0-1$ and $3.0-1$, consists of a FSS, a power conversion assembly (PCA), a transition assembly, a pedestal, and a drive system. The facets, each nominally $11.5 \mathrm{ft}$. in diameter, are positioned on the FSS in the 2TOP arrangement, as shown in Figure 3.0-2. The facet numbers and the coordinate axes used in the design, and referenced in subsequent paragraphs, are shown in Figure 3.0-2.

The FSS is a structural space frame with the primary function of providing the facets with a mounting base sufficiently stiff to maintain facet alignment within specified limits. The PCA support structure is a cantilevered space-frame beam that supports the PCA (receiver, engine and generator) at the focal point of the dish with minimum deflections. The transition assembly interfaces the FSS and the PCA support structure with the elevation axis and the azimuth drive. All moving structure loads are transmitted through the 


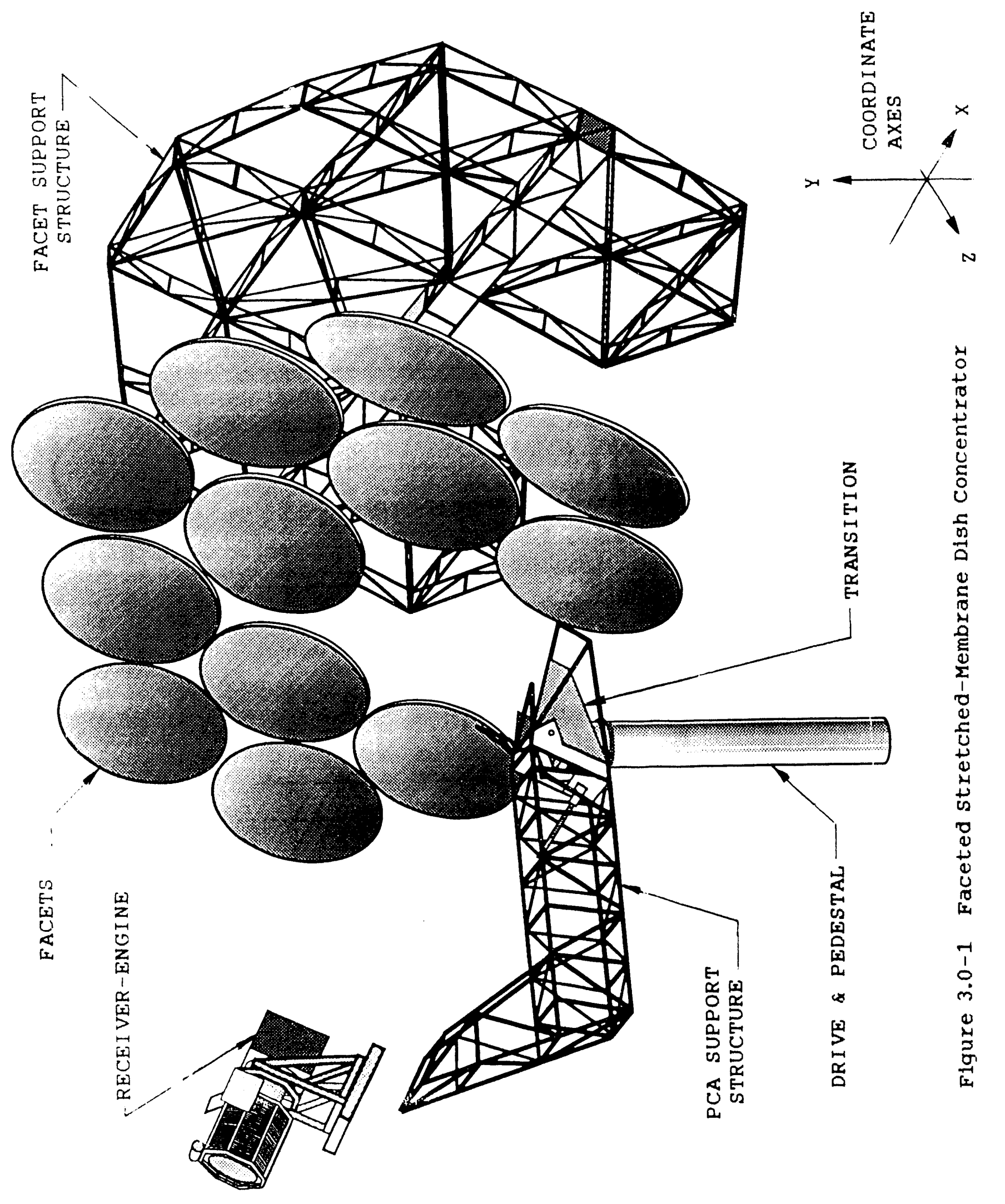


transition, into the drive assembly and thence to the pedestal and foundation.

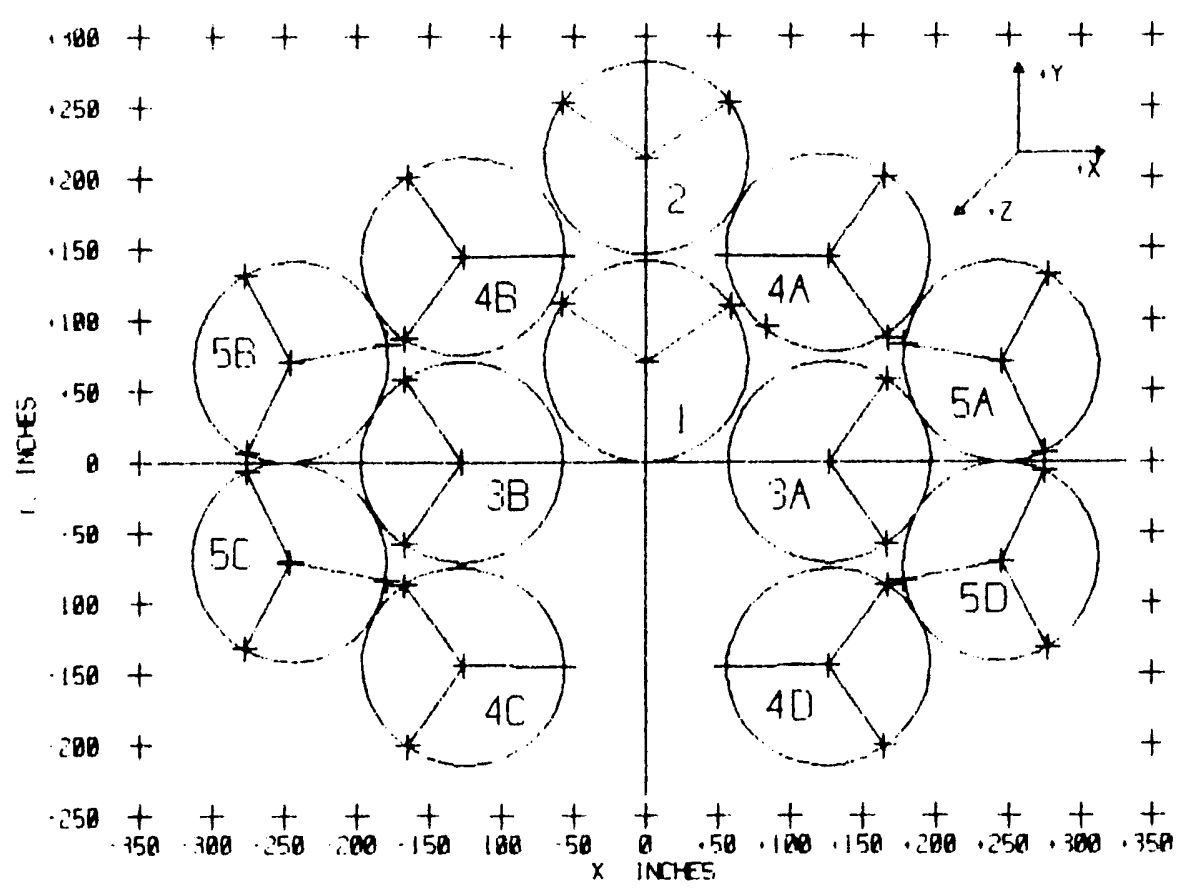

Figure 3.0-2 2TOP collector Configuration

The drive assembly consists of elevation and azimuth drives. The elevation axis is mounted at the top of the azimuth drive so that all loads from the moving structure are reacted by the azimuth drive. The elevation drive rotates with the azimuth drive but is independently controlled. The drive assembly bolts to the collector pedestal interfacing the moving structure with the foundation. The pedestal is a large-diameter structural steel tube designed for minimum deflection under normal dish operating conditions.

The prototype design meets the requirements delineated in section 1.1. The support structure is designed for low risk and near termavailability. The structure is designed for ease of fabrication using conventional shop equipment and tooling and for quick field assembly and installation. Facet adjustments are readily accessed, and the PCA maintenance can be performed at ground level. The prototype 
design employs standard structural steel shapes and fasteners, as well as off-the-shelf components such as drives, bearings, and motors.

The design was driven by four key considerations:

1. The geometry of the Fss was determined by two critical factors, the location of the elevation axis and the positioning of the vertical trusses. The elevation axis is between the facets and the focal point, relatively close to the boresight axis ( $\mathrm{z}$ axis) of the dish. When the structure rotates up in elevation, the lower half of the Fss straddles the pedestal. Thus, it was necessary to build a gap in the lower half of the FSS to clear the pedestal. It was also necessary to position the vertical trusses so that the facets, each with 3 mounting points, would interface with mounting facilities at hard points on the trusses.

2. Static and dynamic imbalance about the elevation axis could not be eliminated because of the lack of symmetry about the $x$ (horizontal) axis; it could only be minimized. This caused the overturning moment to be greater than originally calculated, and impacted the design of the drives and the pedestal.

3. The relatively high loads experienced by the drives, the expressed requirement for a low-risk configuration, and cost factors led to the selection of the proven winsmith azimuth drive. This had significant impact on the design of the transition assembly.

4. The requirement for ground-level access for maintenance of the PCA led to the decision to articulate the PCA support structure. This favorably impacted the elevation drive design by eliminating the need to rotate the concentrator assembly below 0 des. elevation.

A number of other factors contributed to design decisions but, for the most part, their impact on the structure was localized and had lesser effect on the overall design.

The structure was deslgned to meet the required deflection criteria and then analyzed for stress compliance with the AISC codes. Assem- 
blies and Individual elements such as plates, angles, tee's, etc., were selected to insure operational stiffness. After meeting the deflection criteria, the individual structural elements were checked for conformance under worst-case conditions with AISC codes for buckling and stress limits. As a result of the deflection design and this process, stresses throughout the structure are low.

\subsection{Facet support structure (FSS)}

The FSS, as shown in Figure $3.1-1$, is a rectangular grid, triangulated space frame configured symmetrically about the $x$ axis. The structure is designed to meet deflection requirements and to be low weight. It comprises a horizontal box section spine truss; segmented vertical flat trusses attached perpendicularly to the spine; and flat horizontal, diagonal and ring trisses to support and stabilize the vertical beams. Facet mounting pads are welded to the primary beams. The trusses are fully welded assemblles and are made exclusively from standard structural steel shapes. For ease of fabrication, assembly and economy of manufacture, they are of constant depth.

\subsection{1 spine Truss}

The spine truss is the main load-bearing member in the Fss. It is a 48-in.-square space-frame beam designed for torsional and bending stiffness. It reacts all wind and gravity loads transmitted by the vertical trusses and is the primary load path from the facets to the elevation axis. The spine truss is made in three sections, a center section and two mirror-image outer sections. The three sections bolt together at installation.

Analysis indicated that, to meet deflection requirements, the center section of the spine truss must be stiffer in torsion than the two outer sections. It also indicated that excessive point loads were likely at the corners of the center section frame. To solve both problems the center section is fully covered with a sheet metal web. With the web the center section becomes an effective torque box. The web also serves to distribute the loads uniformly into the transition assembly shear plates, thereby eliminating the point loading and 


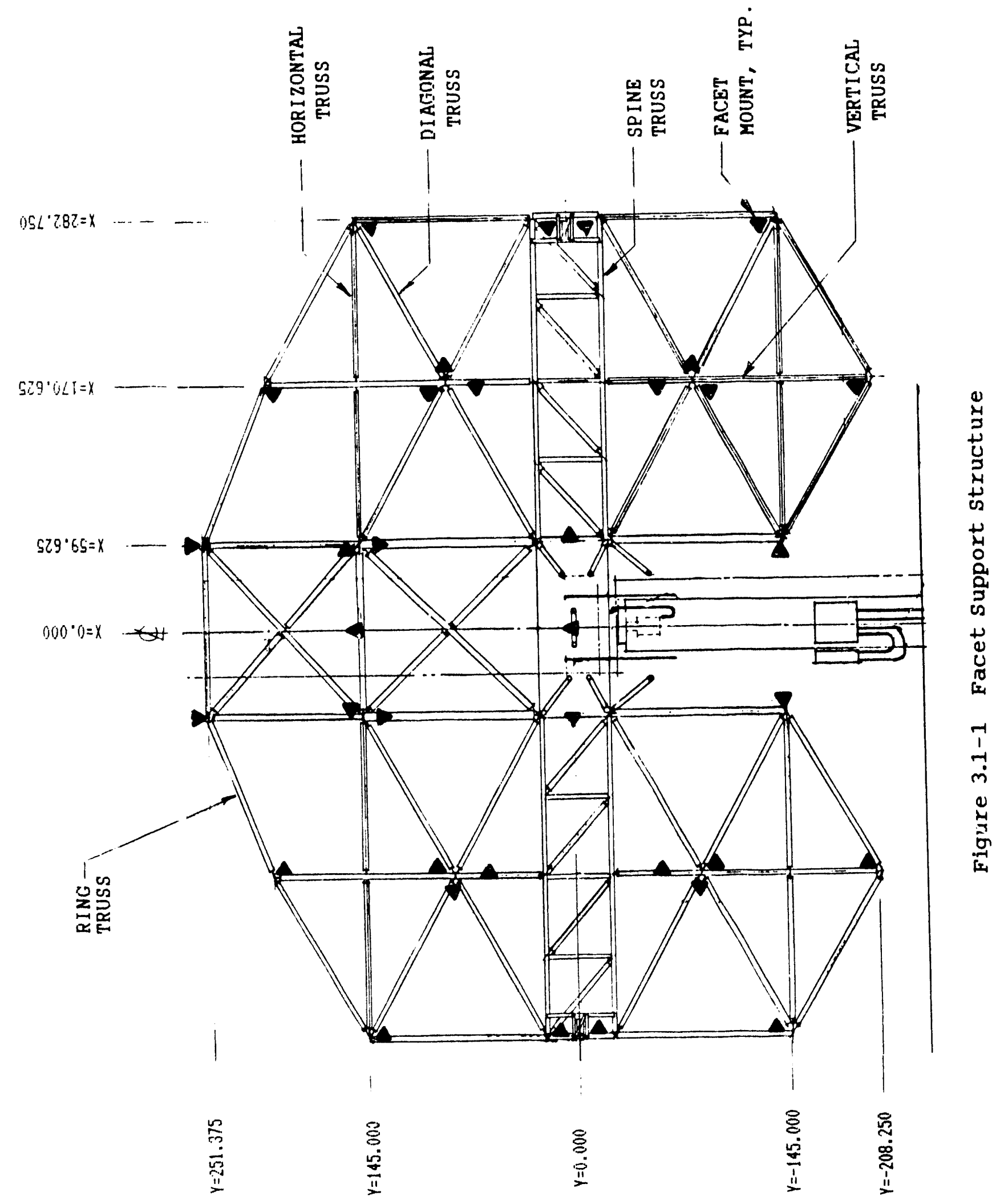


potentlal local buckling. The center section is notched on the bottom surface to allow the tracking structure to nest with the pedestal at high elevation angles.

The outer sections of the spine truss are open space frames. Analysis showed that these sections need not be true torque tubes for the structure to meet the specified deflection criteria. Although the outer two sections would be stiffer if webbed, the reduction in deflection does not justify the increased weight and cost.

\subsubsection{Trusses}

Vertical trusses are bolted orthogonally to the spine truss, symmetrical about the $x$ axis, as shown in Figure 3.1-1. Horizontal and diagonal trusses in each bay stabilize the vertical beams. Peripheral beams form a clrcumferential, or ring, beam integrating the truss structure to react torsional loads. All of the trusses experience load reversals with changes in dish elevation angle and with changes in the wind direction. Therefore, all members are designed to sustain maximum compression loads without buckling.

The vertical trusses are the major load-bearing trusses in the Fss. Most of the facet mounts are located on vertical trusses, as shown in Figure 3.1-1. (Seven mounts are on the spine truss, and one is on a secondary beam.) These facet loads are dumped directly into the vertical trusses. To minimize local deflections at the facet mounts, the mounts are positioned at or near "hard" points. A "hard" point is a location on the truss that has three-dimensional support. The vertical trusses are split into upper and lower sections that are attached to the spine truss at assembly. They are welded, flat trusses, as shown in Flgure 3.1-2, designed for simplicity of fabrication fixturing. The trusses are $48 \mathrm{in}$. deep, as determined by deflection analysis. The chord members, or caps, are sized for compatiblilty with deflection requirements and with the AISC code for buckling constant $(\mathrm{L} / \mathrm{r})$ limits. The two inner vertical trusses at $\mathrm{X}=$ $\pm 59.625 \mathrm{in}$. are more highly loaded than the other vertical trusses; thus, thelr cap sections are heavy-duty structural tee's. The 


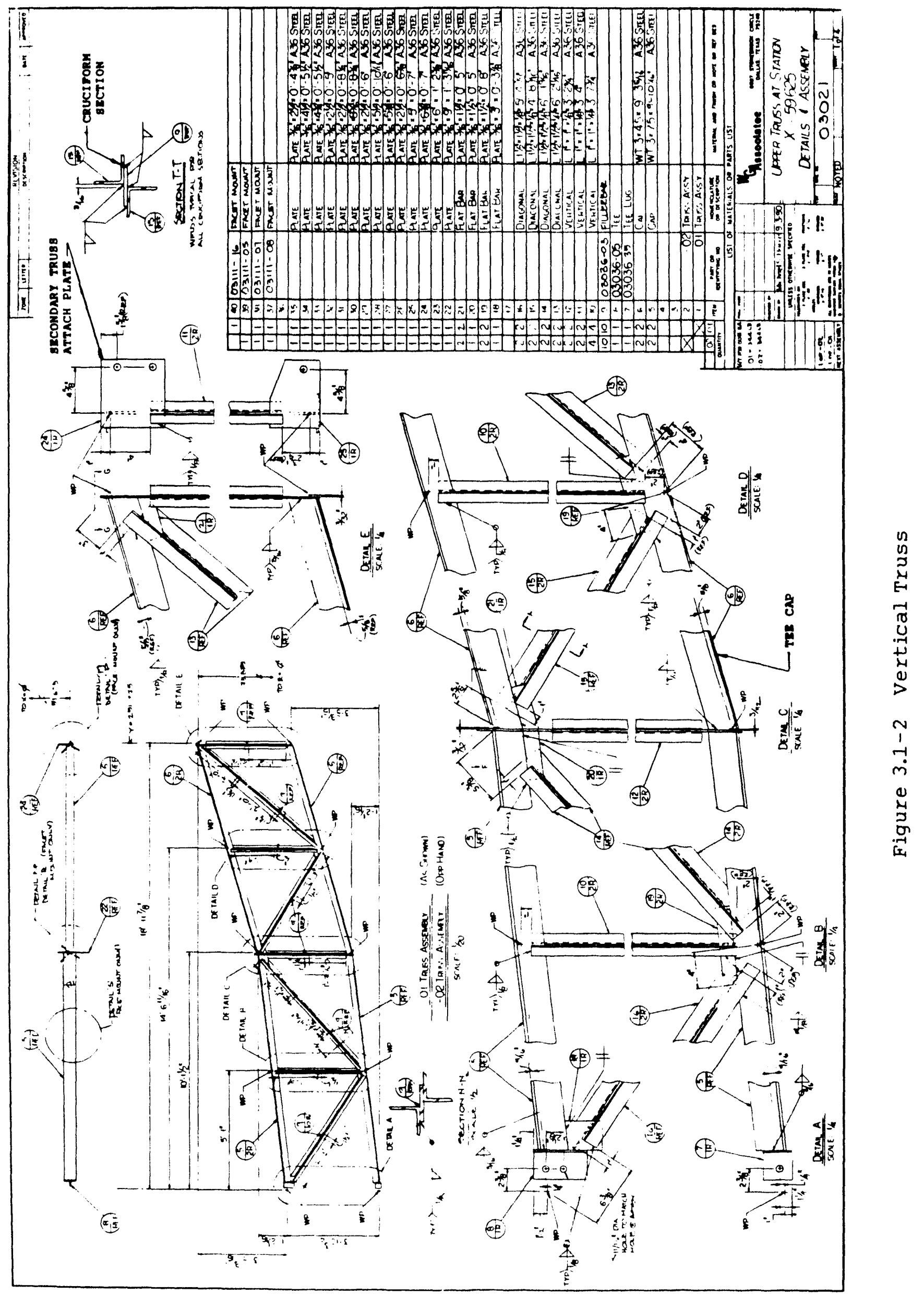


intermediate vertical trusses at $x= \pm 170.625$ in. are made with a comparably sized tee that has a smaller section modulus. The outer vertical trusses at $x= \pm 282.75$ in. are capped with an inverted structural angle. The material weight saved by "stepping" the vertical trusses in this manner and the lower drive inertial loading, Justifies the slightly higher cost of fabrication associated with these members.

The secondary members of the vertical tr sses are small structural angles arranged as shown in Figure 3.1-2, section $T-T$. The "cruciform" cross-section is similar in section modulus to the more conventionally used back-to-back angle section. The cruciform has the singular advantage of affording complete accessibiliy for postfabrication painting, whereas the back-to-back angles invariably are difficult to finish and corrosion-proof.

The horizontal, diagonal and ring beams are, like the vertical trusses, 48-in., constant-depth, welded, flat trusses. Their function is to stabilize the vertical trusses. Therefore, they are relatively lightly loaded in both tension and compression. Common materials are used for the cap members, vertical and diagonal members, and the end fittings of these trusses, with cost advantages accruing from quantity purchase. Only the arrangement of the members is varied to accommodate length and slope angle differences. Thus, economical tabletop fixtures, with pre-set clip locations for the various sized trusses, can be used for fabrication.

A typical secondary truss is shown in figure 3.1-3. These trusses efficiently meet stiffness requirements due to the use of inverted structural angles for cap members. The angle is weakest about its diagonal centroidal, or $\mathrm{z}$, axis. In this truss design, the cap angle is rotated so that its $\mathrm{Z}$ axis is perpendicular to the plane of the truss. Thus, the vertical center support shortens the effective length of the cap so that its $L / x$ meets the AISC code. The $L / x$ ratio in the unsupported plane is fully compatible with AISC code. The stiffness 


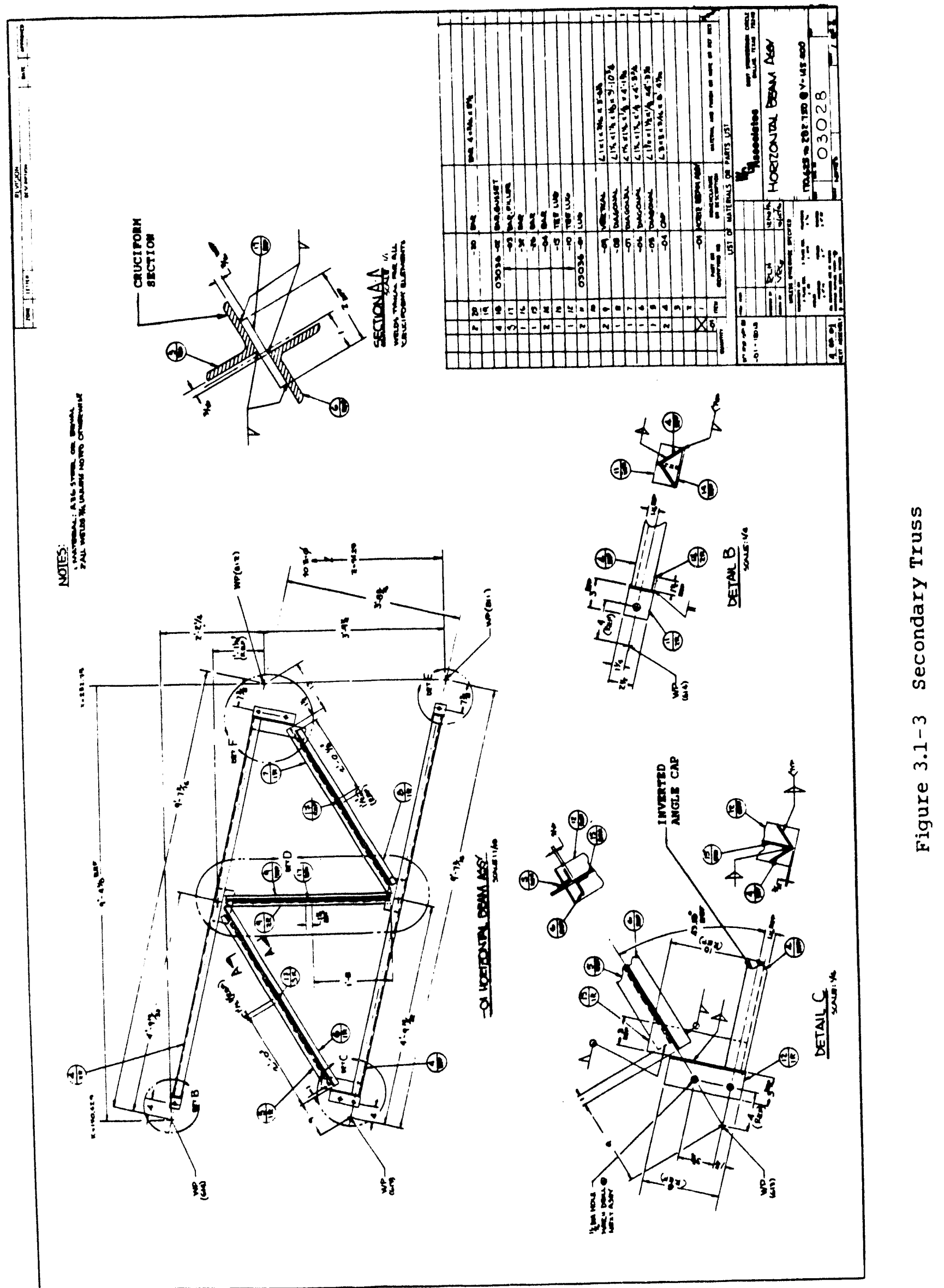


requirements could be met more easlly using standard structural tee caps, but only with a significant, weight penalty.

The cost effectiveness of using tubular. secondary members in the trusses was compared against the cost of structural shapes with equivalent section properties. Tubular members are more efficient, i.e., their stiffness-to-weight ratio is higher than structural shapes. However, tubing materlal costs are much higher and, even though the actual materlal welght of shapes is greater, the cost is less. Moreover, tube members require more fabrication processing for attachment than structural shapes, which also increases the cost of piece parts. Finishing of tubular members also has cost impact since the tube ends must be capped or the parts must be dipgalvanized to prevent corrosion. As a result, the decision was made to employ structural shapes throughout the Fss.

The FSS is designed to accommodate the pedestal clearance gap in the lower half. The ring beams integrate the two halves of the Fss into a single rigld structure. They also help minimize the in-plane torsional deflections. The vertical truss matrix and the spine are designed so that no $z$ deflections can be attributed to the gap.

\subsubsection{Facet Mounts}

The 12 facets are mounted in the 2 TOP arrangement on the support structure. Each facet has 3 mounting studs nominally equally spaced on a 72.87-1n. radius about the center of the 70.87-1n. radius facet ring. The studs are double-nutted to facilitate axial adjustment. A mounting pad for each stud is permanently installed on the structure at the nominal centerline of the facet stud.

The spacing of the studs is based on a best-flt analysis for attaching the mounting pads to structure. Ideally, for deflection considerations, each of the pads would be installed directly over the intersection of a vertical truss and a hwizontal or diagonal truss. However, this is impractical because the nesting of facets in the 2 TOP arrangement would require a spacing of as little as 60 deg. 
between mounting points, creating an unccable condition. From a manufacturing perspective, it would be economical if the facet mounts were equally spaced at 120 deg., since symmetry is desirable. This is also impractical because it would require some of the pads to be so far offset from the hard points that supplemental structure would be required to prevent excessive deflections. Therefore, various combinations of facet mount spacing and location relative to hard points were evaluated, to find a compromise solution for all of the facet mounting points.

The analysis resulted in angular spacing of the studs around the facet at 0 deg., 125 deg. and 250 deg. on each facet. The orientation of the facet mounts is shown in Figure 3.1-2. To accommodate this solution, some of the facet mounts are offset a relatively short distance from the hard points in the $X$ and $Y$ directions. Also, the height, or $\mathrm{z}$ dimension, of the facet mounts varies with location on the structure. In summary, to realize maximum economy, the relatively costly facets are identical while the less costly facet mount configurations vary with location on the structure.

The mounting pads are designed to provide maximum latitude for facet adjustment without adding significantly to their deflection error. They are configured to allow full accessibllity to the adjustment nuts using standard tools. The pads are designed for compatibllity with two installed conditions. In one, the pad is directly on a truss cap member. In the other, the pad is offset from the cap.

Figure 3.1-4 shows typlcal facet mounts. In Detall s, the facet mount is directly over the truss cap member. The pad is made from a 4-in.square tube, cut and installed so that the mounting surface is perpendicular to the facet line-of-sight. A 1.25-in. diameter hole in the mounting surface provides for radial adjustment of the $0.75-\mathrm{in}$. diameter mounting stud. At the centerline of the hole, the mounting surface $1 \mathrm{~s}$ typically $3.50 \mathrm{ln}$. above the cap member. This provides for $\pm .75 \mathrm{1n}$. axlal adjustment of the stud for allqnment. The mounting hole 


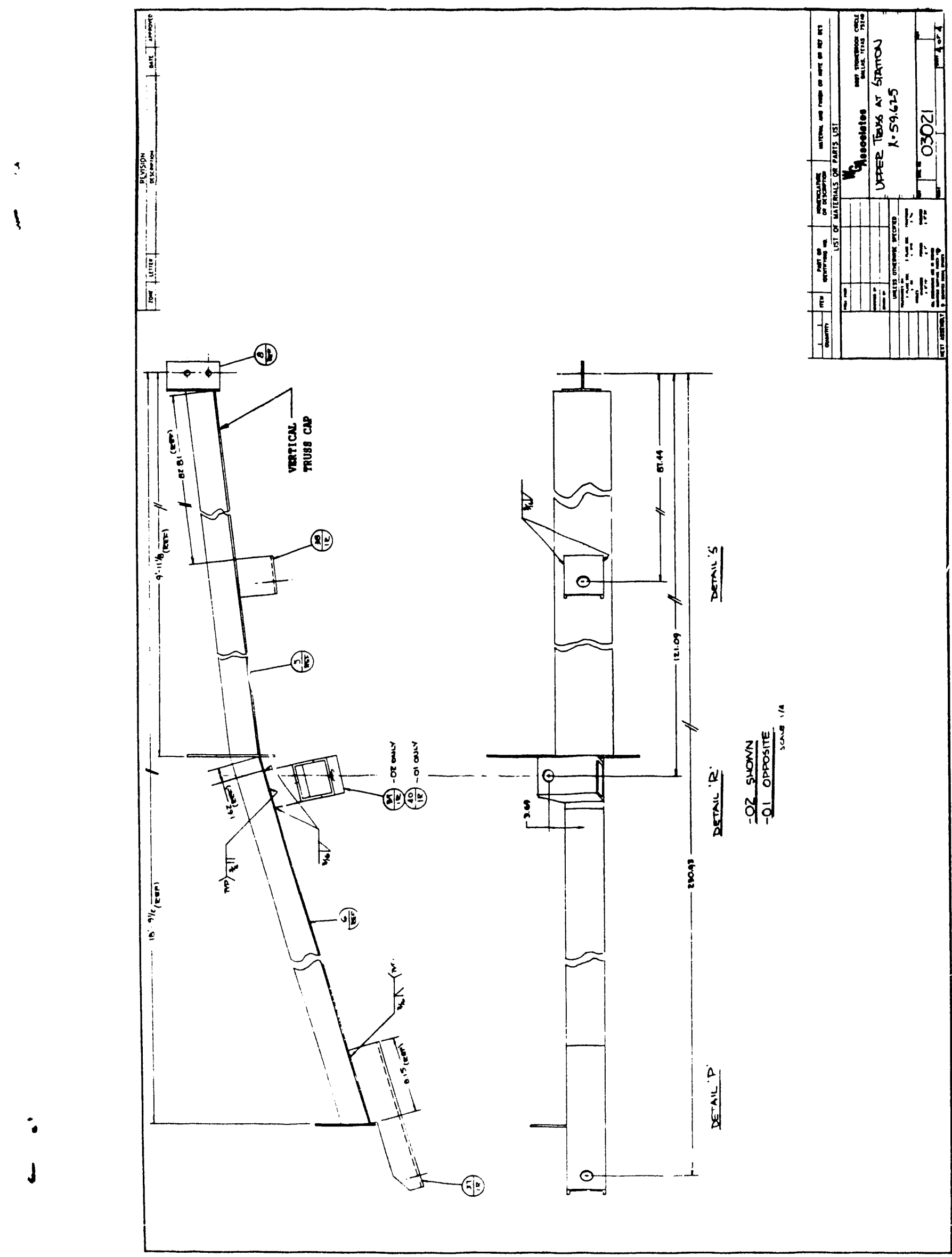

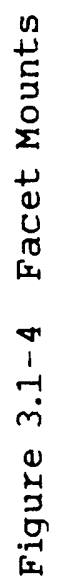


is positioned on the pad so that the adjustment nut on the underside can be accessed easily with a standard open-end wrench.

Two typical offset pads are shown in Detalls $P$ and $R$. These pads are also made from 4-in.-square tube. However, they require some minor supplemental structure for proper positioning of the mounting pad and for load path development. These pads allow access to the adjustment nuts with a socket wrench because there is no interfering structure on the underside.

The coordinates of the mounting pad centerlines correspond to the mounting boit centers shown in Table 3.1-1. With the facets installed on these centers, the clearances between facets at their closest proximity, or interference points, are shown in Table 3.1-II.

\subsection{Transition Assembly}

The transition assembly has two primary functions. First, it sirur:turally foins the FSS and the PCA support structure, integrating them into a single rigid body called the tracking structure. second, it interfaces the tracking structure with the elevation axis which is integral with the drive assembly. Thus, all gravity and wind loads acting on the moving structure are transmitted by the transition assembly to the drive assembly.

The transition assembly is shown in Flgure 3.2-1. It consists of the center section of the spine truss, two shear plates installed perpendicular to the spine, an elevation axis beam on each shear plate, the PCA support mount, and appropriate support trusses. The spine center section, as discussed earlier, is fully webbed over a structural frame for torsional rigidity. It is notched on the bottom so that it nests with the pedestal at high elevation angles. The shear plates are factory-welded to the frame of the center spine truss on the sides of the notch. The PCA structure mount is a factory-welded frame that bolts to the outer ends of the shear plates. Each of the elevation axis beams consists of two structural "hat" sections bolted together with the shear plate sandwiched between them to form 
Table 3.1-I Mounting Bolt Centers

COORDINATE DATA FOR THE SANDIA 12 FACET COLLECTOR

WITH THE 2TOP CONFIGIJRATION, PagE 4

RUN AT $09: 34: 12$ UN $02-10-1991$

[IEFAULT FILE: ADJMOUNT.DFT, ENTITLED: FINAL DESIGN

FOCAL POINTS $Q X=0, Y=0, \& Z=10.57112$ Meters or 416.1859 Inchs

$\begin{array}{ccccc}\text { Facet } & \text { Facet Focal Dist. } & \text { F/D } & \text { Offset } \\ \text { Number } & \text { Meters } & \text { Inchs } & & \text { Adjust } \\ 1 & 9.5000 & 374.0157 & 2.7967 & 0.5000 \\ 2 & 10.2000 & 401.5748 & 3.0028 & 5.0000 \\ 3 & 9.6000 & 377.9528 & 2.8262 & 5.8000 \\ 4 & 10.0000 & 393.7008 & 2.9439 & 4.0000 \\ 5 & 10.5000 & 413.3858 & 3.0911 & 1.0000\end{array}$

Facet 4 Angle From X Axis Multiplier $=1.0185$

Fetlector Radius $=1.6984$ Meters or 66.86614 lnchs

Facet Radius $=1.8$ Meters or 70.86614 lnchs

Muunting Eolt Radius $=1.851$ Meters or 72.87402 Inchs

Facet Front To Nominal Mounting Surface $=10$ Inchs

FOLLOWING IS FOR THE MOUNTING BOLT CENTER

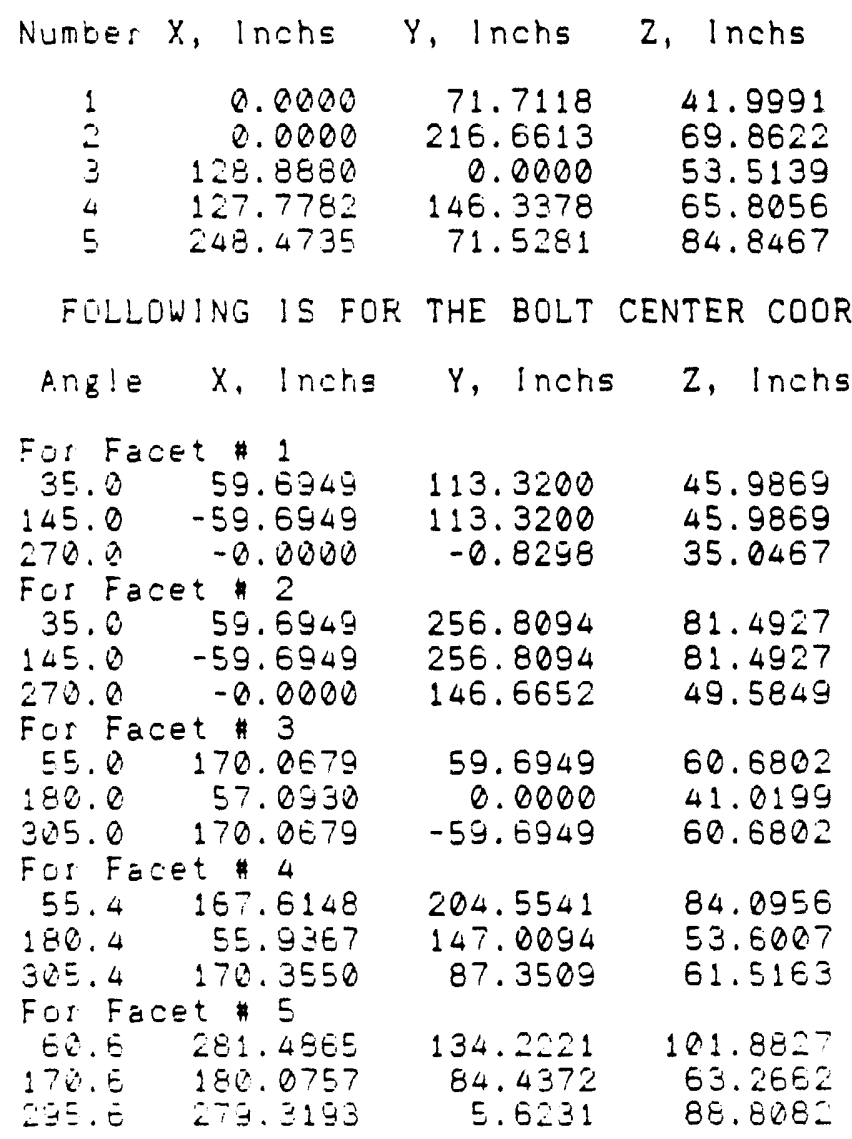




\section{COORLINATE DATA FOR THE SANDIA 12 FACET COLLECTOR \\ WITH THE ZTOP CONFIGURATION, Page 3 \\ RUN AT $09: 32: 39$ ON 02-10-1991}

DEFAIJLT FILE: ADJMOUNT.DFT, ENTITLED: FINAL DESIGN

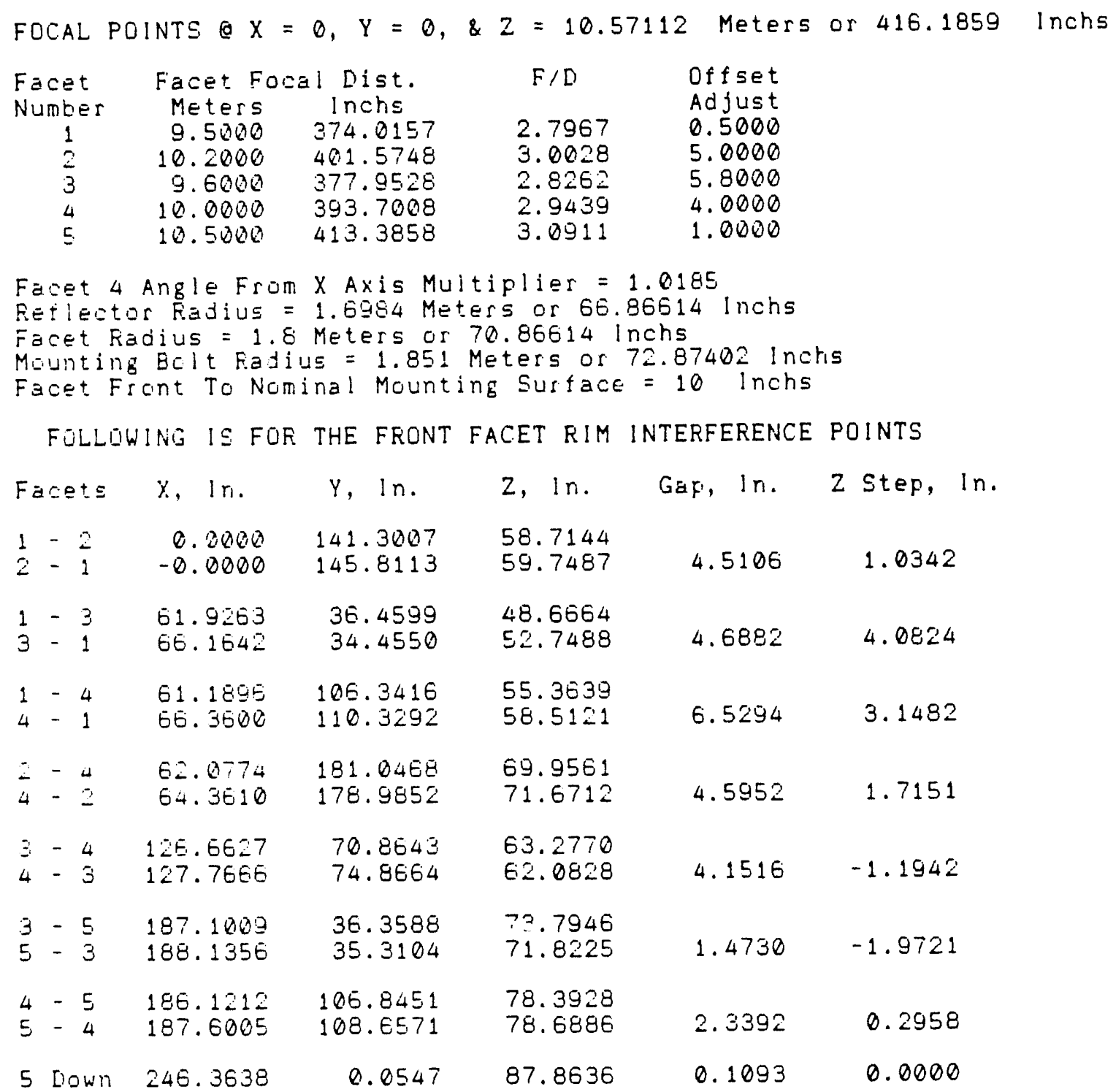




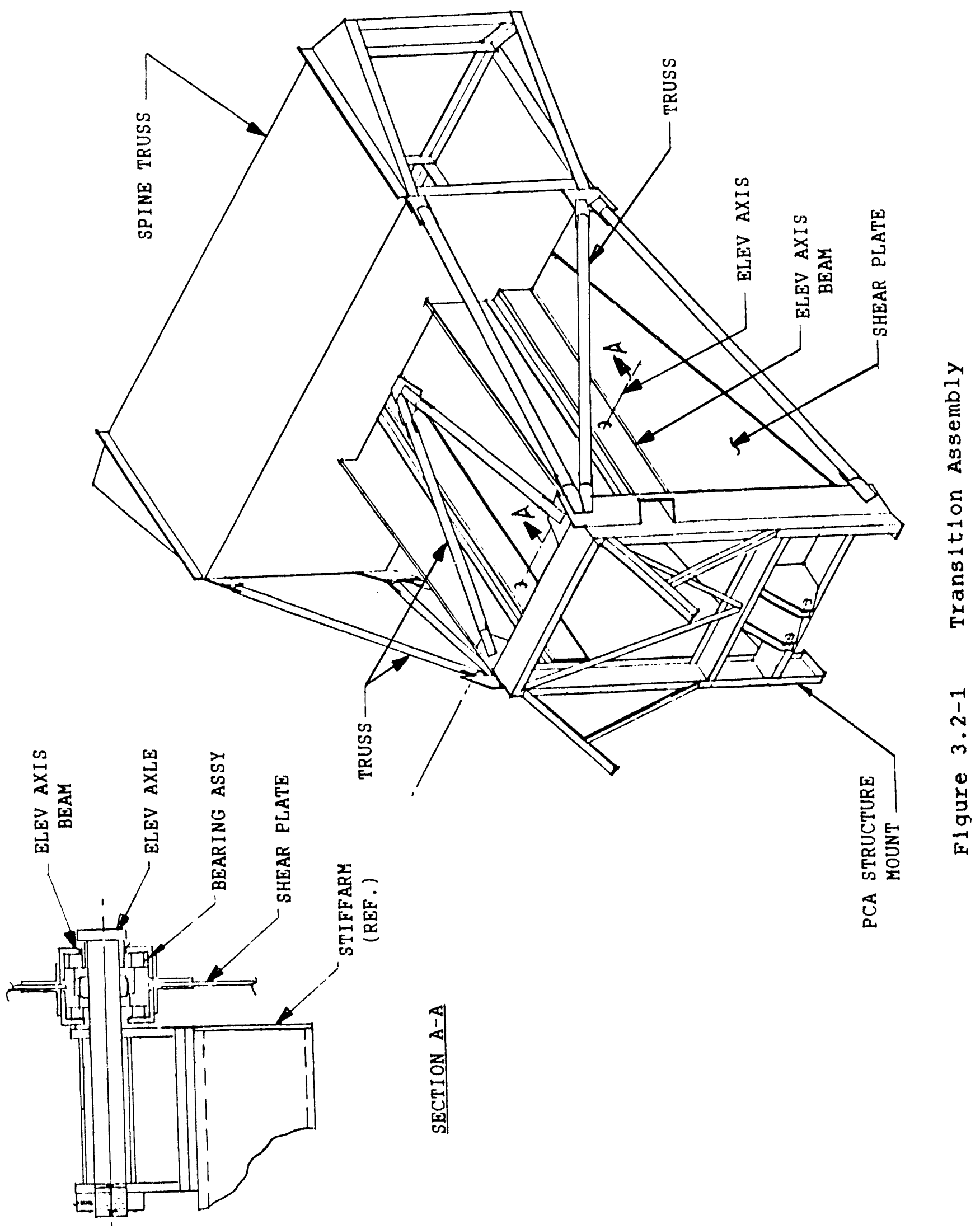


a high-strength box beam, as shown in section A-A of Figure 3.2-1. The elevation bearing is installed in the box beam, as shown in section A-A. Tubular trusses between the PCA structure mount and the spine center section stabilize the assembly in torsion and lateral bending.

The dominant loads in the transition assembly are due to dead-weight shear, with wind loads contributing to the total. The most effective method of transferring shear loads is with a plate. With the unitized configuration of the spine center section and the shear plates, the shear loads in the center section are uniformly distributed into the shear plates. Simllarly, the PCA support structure introduces additional shear loads into the opposite end of the plates. The shear plates react all of these in-plane loads. The shear plates are capped and beaded to minimize potentlal local buckling.

High load concentrations exist at the interface of the transition assembly with the elevation bearings and axle. The box beams dis-tribute these loads so that local stresses in the shear plates are reduced to allowable levels. The box beams also react side or outof-plane loads caused by off-axis winds.

The elevation axis 18 located near the top of the transition assembly which straddles the pedestal, as shown in Figure 3.2-2. To accommodate 90 deg. elevation movement of the tracking structure, the bottom of the transition assembly is open; 1.e., it is free of any structure that could interfere with the pedestal within the confines of the tracking arc. To develop torsional stability around the open section, trusses are installed on either side and in the top plane of the assembly. As shown in Flgure 3.2-1, the trusses triangulate the PCA structure mount, the shear plates and the spine center section to re-establish the load path normally existing in a closed section. Thus, the trusses are the primary load path for out-of-plane loads and help provide the torsional rigidity necessary to meet deflection requirements of the structure. 


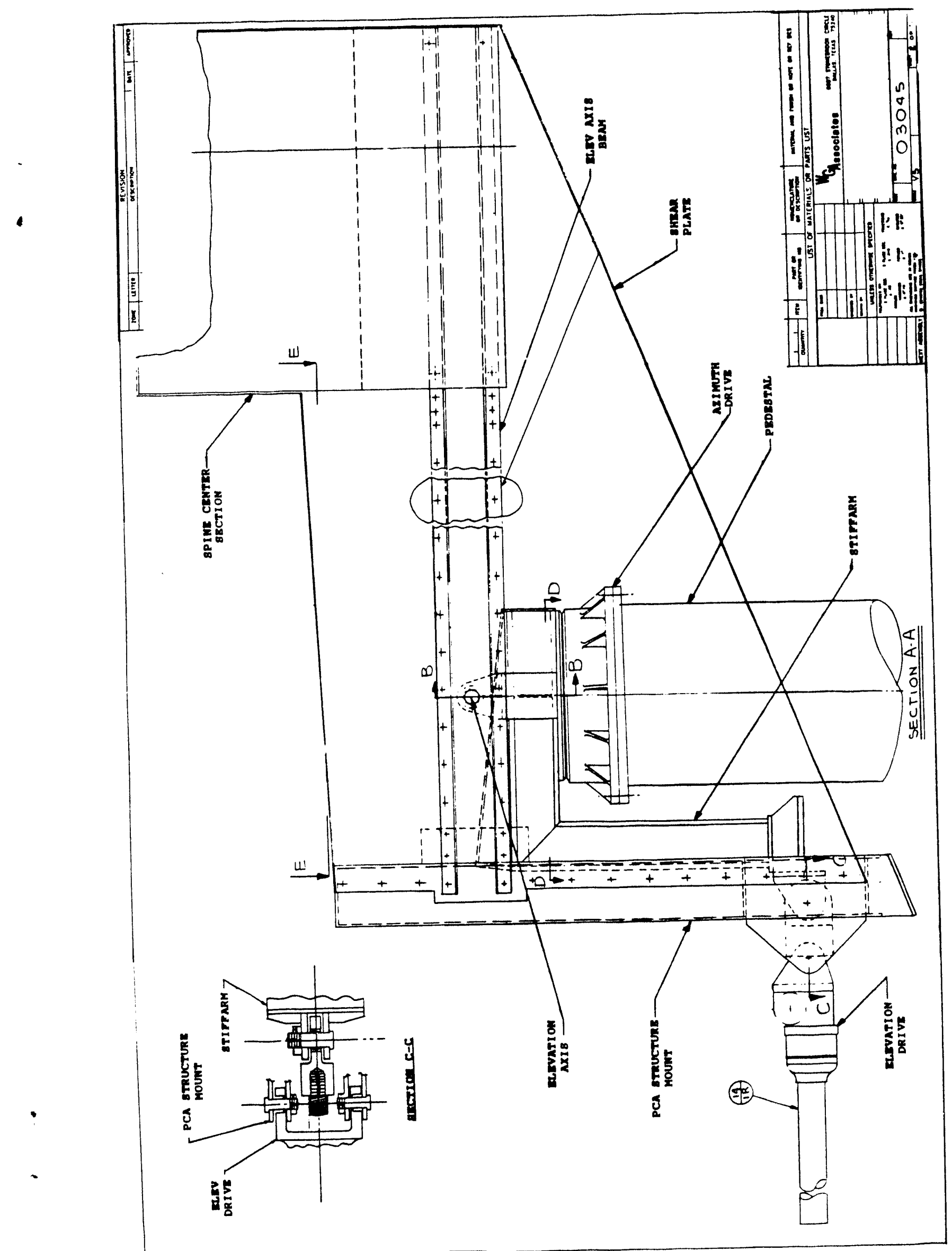

D 


\subsection{PCA support structure}

The PCA support structure is designed to maintain the position of the power conversion assembly relative to the facets. It is a fully triangulated, rectangular section, space frame beam, cantilever mounted to the transition assembly. As in the FSS, the PCA support structure is a deflection-driven design and, therefore, exhibits relatively low stress ratios.

The PCA support structure is shown in Figure 3.3-1. It is discontinuous, or "elbowed", so that it does not block any of the solar energy reflected from the facets. The beam is made in two sections. The inner, or root, section shown in Figure 3.3-2 contains the elbow and is of constant cross-section up to the elbow. From the elbow to the PCA mount, the structure, including the outboard section, is tapered to minimize material weight and reduce moment loading about the elevation axis. Both sections are constant width, factory-welded structures made of standard structural angle chord members and braces. Fabrication costs are minimized by the use of common parts.

The two sections are articulated at the first bay outboard of the elbow to allow lowering of the PCA to ground level for maintenance. They are hinged at the bottom with close tolerance, extra heavy-duty commercial hinges. The truss is bolted at the top to develop full structural integrity for normal operations. A machine screw linear actuator is used to lower the outboard section to the ground for engine and/or recelver maintenance. The screw fack is mounted on a pivoting trunnion outboard of the top plane of the root section. The screw Jack end is pinned to a clevis on top of the outboard section. Drive power is supplied by a $1 / 2$ HP electric drill motor with a 450 RPM output velocity. An interlock switch at the articulated joint prevents operation of the dish azimuth and elevation drive motors when the truss is in the maintenance mode. The switch is mounted at the top face of the root structure and is protected from accidental actuation. It is operated by a pin that projects from the outboard section. When the topside bolts are loosened the swltch opens and cuts power to the drive motors. The interlock switch is in series 


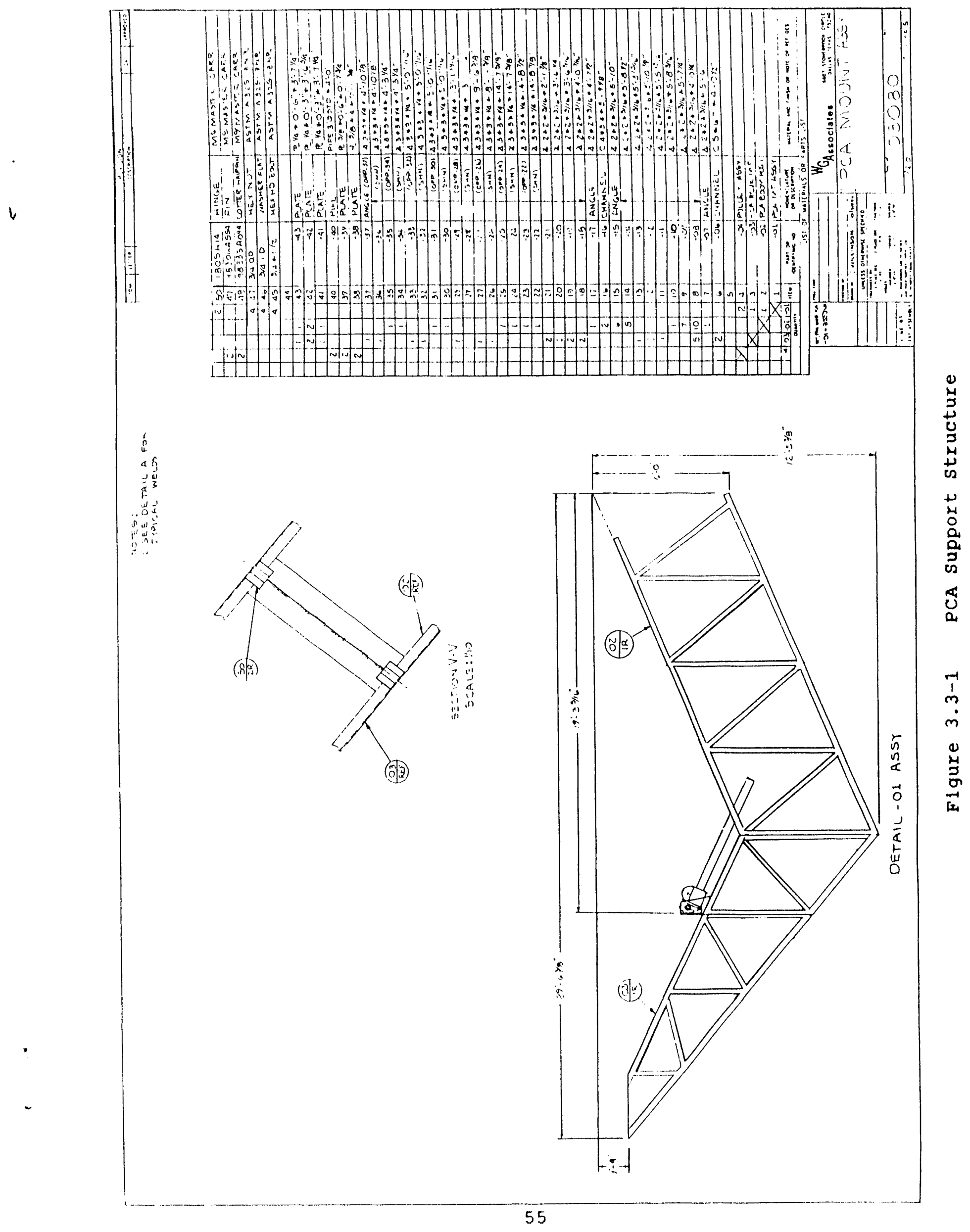




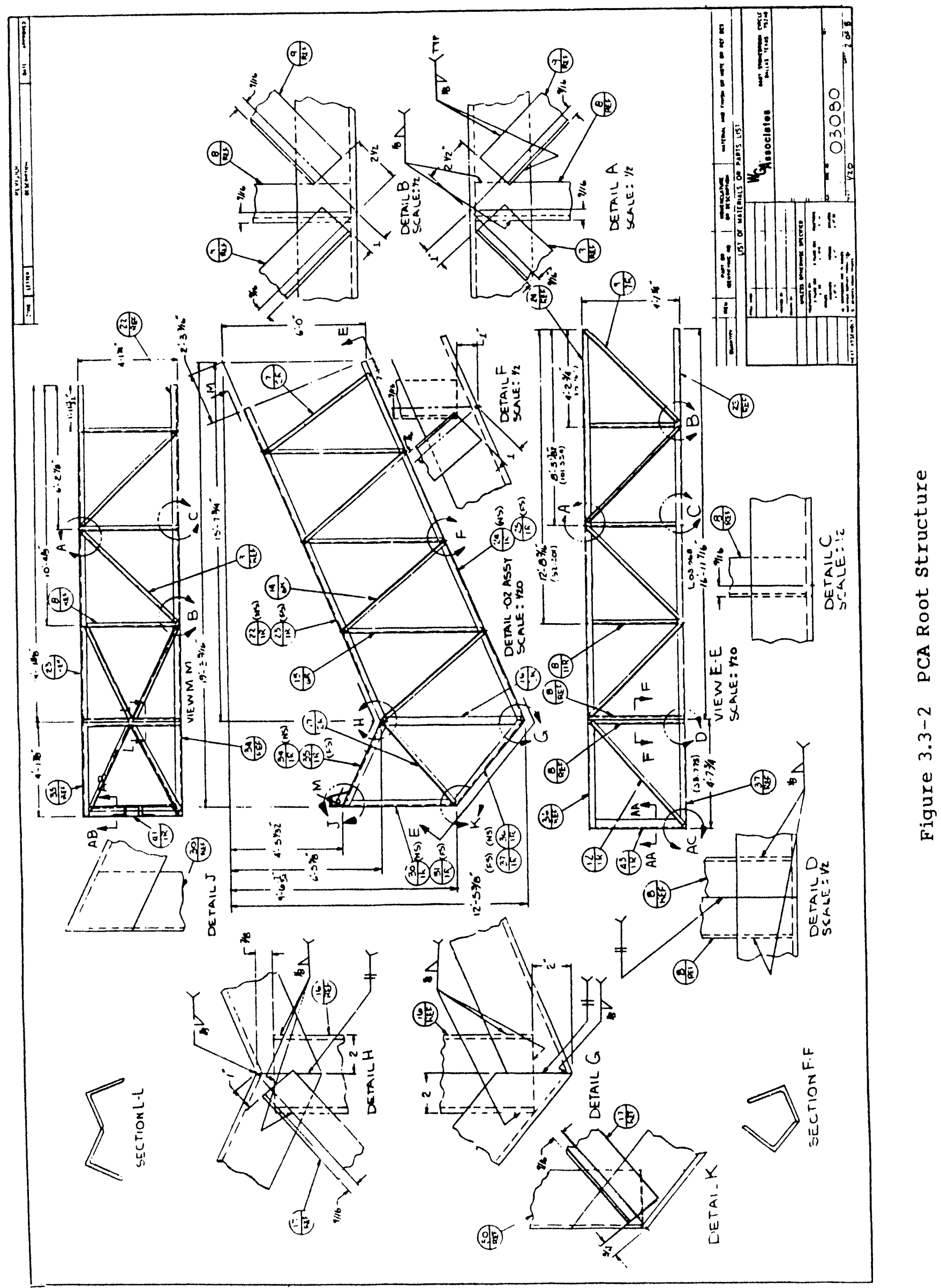


with the ernergency power cut-off palm switch located on the outside of the electronics housing. Both switches must be closed before the motors can be activated. An outlet for the drill motor is installed at the top of the root section. As an additional safety feature, the outlet is interlocked so that it has power available only after dish drive power is cut.

\subsection{Drive System Design}

The faceted dish concentrator requires a drive system that provides full hemisphere coverage for operation in near-equatorial locales. The drive system must be capable of at least 370 deg. travel in azimuth and 90 deg. in elevation. It must be compatible with operational pointing accuracy and with survival wind criterla. It must have travel rates consistent with sun acquisition, off-target tracking, and drive-to-stow requirements; it must be self-locking for stow purposes; and it must allow "bang-bang" drive control.

The drive load requirements were derlved from the LTV wind tunnel test curves and from gravity load calculations. structurally, the drive design is predicated on worst case combined loads as follows:

- overturning moment, drive to stow - 77,000 ft-lb

- overturning moment, stow position - 75,000 ft-1b

- Azimuth torque, drive to stow - 33,000 ft--1b

- Shear - 9,830 lb.

- Axial - 43,000 lb.

As in the structure, maximum loads and stresses occur at the driveto-stow condition of $50 \mathrm{mph}$. However, under operating conditions (wind velocity up to $27 \mathrm{mph}$ ), the combined load and stress levels are relatively low. In this operating range the critical design parameters are stiffness and backlash. For initial design of the azimuth drive, it was estimated that these factors would contribute a combined 3 sigma error of $1 \mathrm{mr}$. Based on early inertia and wind calculations, this allowed for a spring rate of $1.3 \mathrm{E} 08$ in-lb/radian and a backlash of $.018 \mathrm{ln}$. on a 36-1n.-dlameter output gear. 
The drive motors are sized using RMS wind loads since motor ratings are RMS values. The peak combined load consisting of gravity load plus the drive-to-stow RMS wind load, defines the required torque rating of the motor. The combined elevation and azimuth torque load curves for the faceted dish at the mean drive-to-stow wind of 31.25 mph are shown in Figures 3.4-1 and 3.4-2 respectively. The RMS torque loads are calculated by adding the gravity load (dead weight) to 1.06 times the mean wind moment.

\subsubsection{Azimuth Drive Design}

Several types of azimuth drives were considered, including those employing harmonic, planetary, spur gear, worm gear, and cycloidal reducers. On the basis of cost and other practicalities the number of candidate systems was quickly reduced to two, the winsmith azimuth drive, and a conventional drive train consisting of a bull spur gear/ bearing and pinion final stage with multistage speed reduction.

The winsmith drlve, shown in Figure 3.4-3, is a commerclally avallable single-bearing, self-contained unit consisting of two stages. The primary (input) stage is a planetary reducer with a $460: 1$ reduction. The secondary (output) stage is a planocentric reducer with a $72: 1$ reduction ratio. The overall ratio of this drive package is 33,120:1. In operation, free, synchronous rotation of two eccentrics in a slowspeed planet gear imparts an orbital action to the planet gear. This action, in turn, advances the output ring gear three teeth (the difference in the number of teeth of the ring gear and the planet gear) for every rotation of the synchronized eccentrics [Ref. 5].

The Winsmith azimuth drive is similar in function to a harmonic drive in that many teeth in the output ring gear are always engaged with the slow-speed driver planet gear. The mechanism is self-locking, 1.e., non-backdriving, because the primary stage reduction ratio is in excess of 400:1. Planetary reducers with ratios greater than 400:1 are generally consldered to be self-locking. The sallent characteristics of the winsmith azimuth drive are shown in Table 3.4-I. 


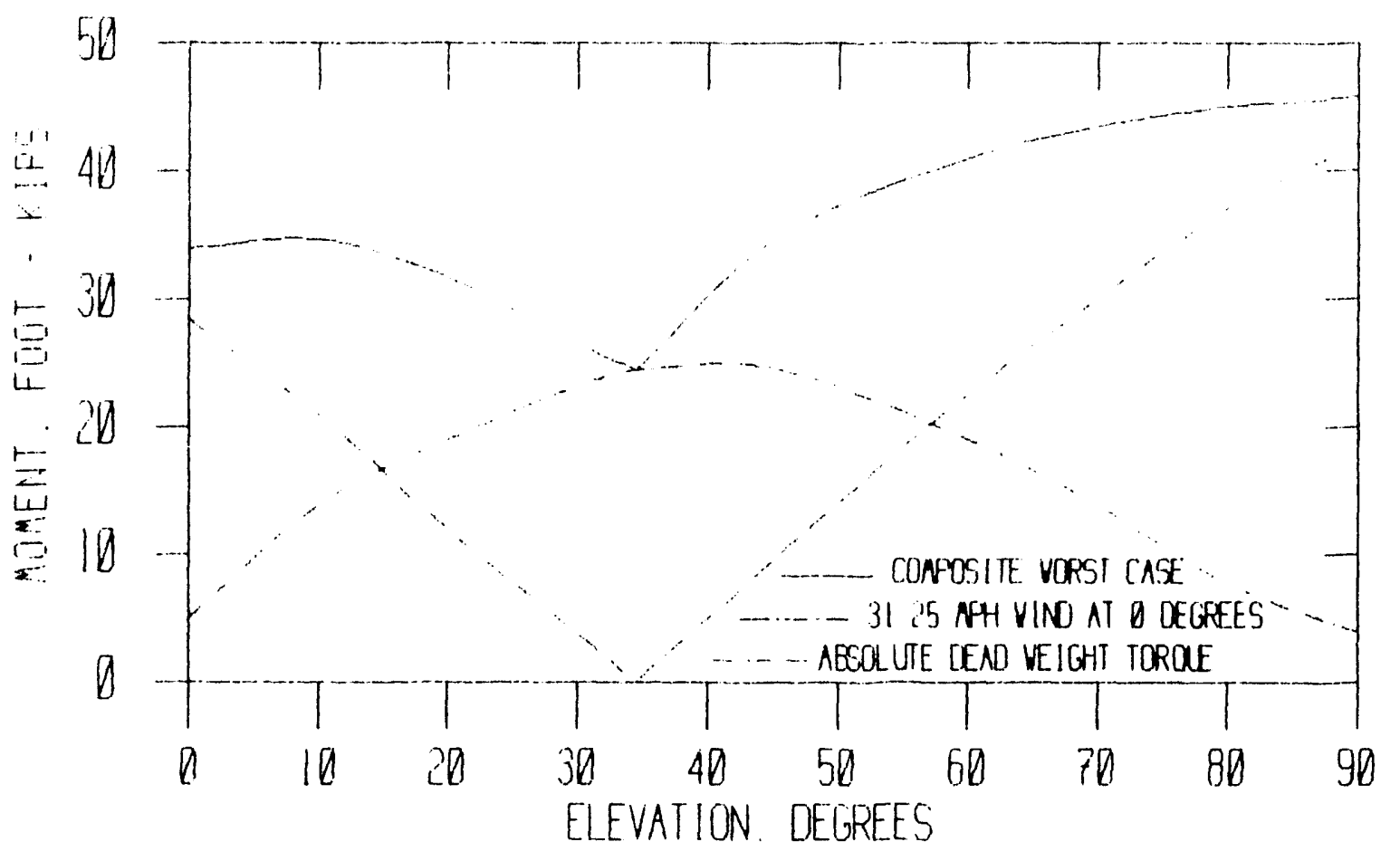

Figure 3.4-1 Elev. Torque Load w/31.25 MPH wind

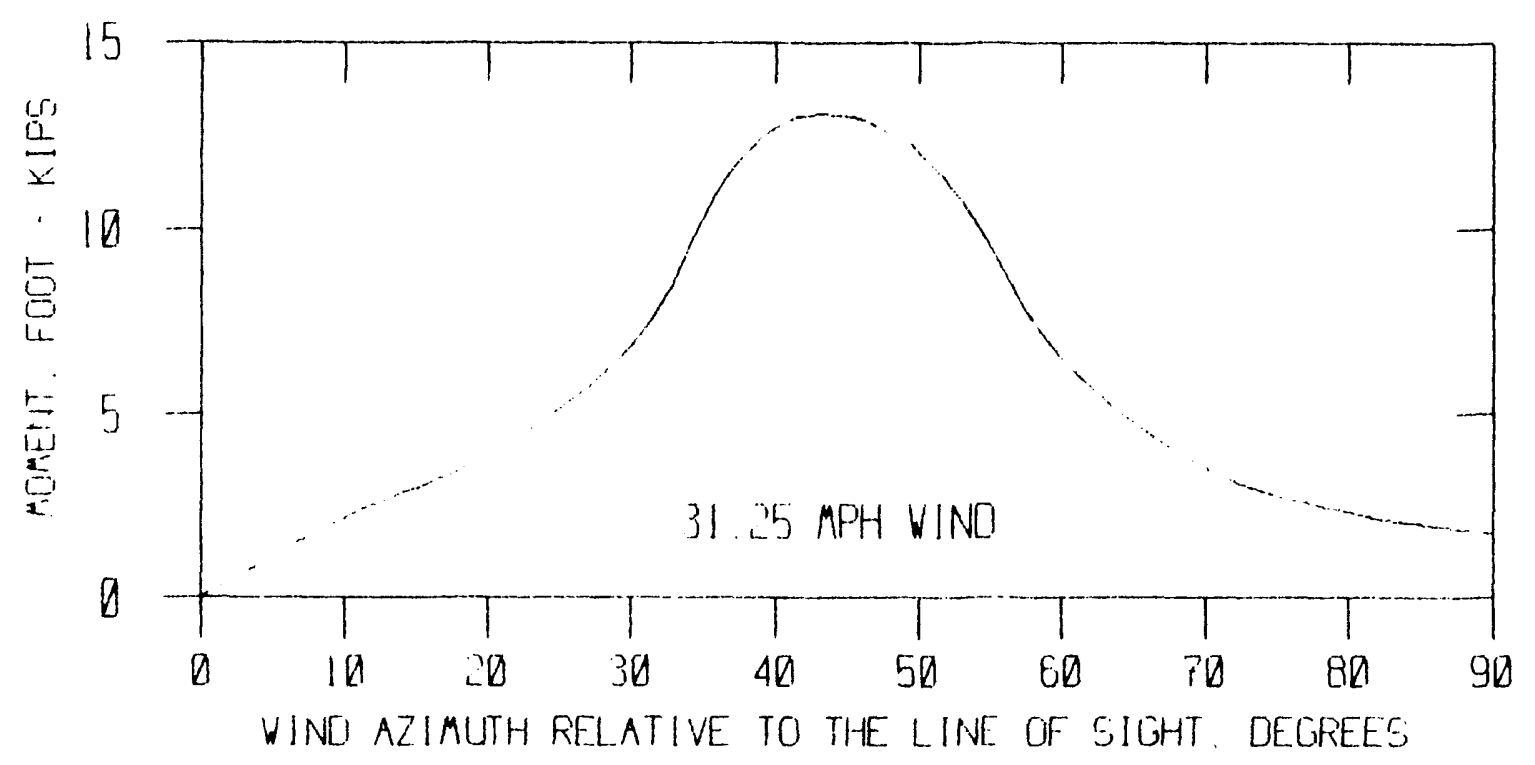

Figure 3.4-2 Azimuth Torgue Load, $31.25 \mathrm{MPH}$ Wind 


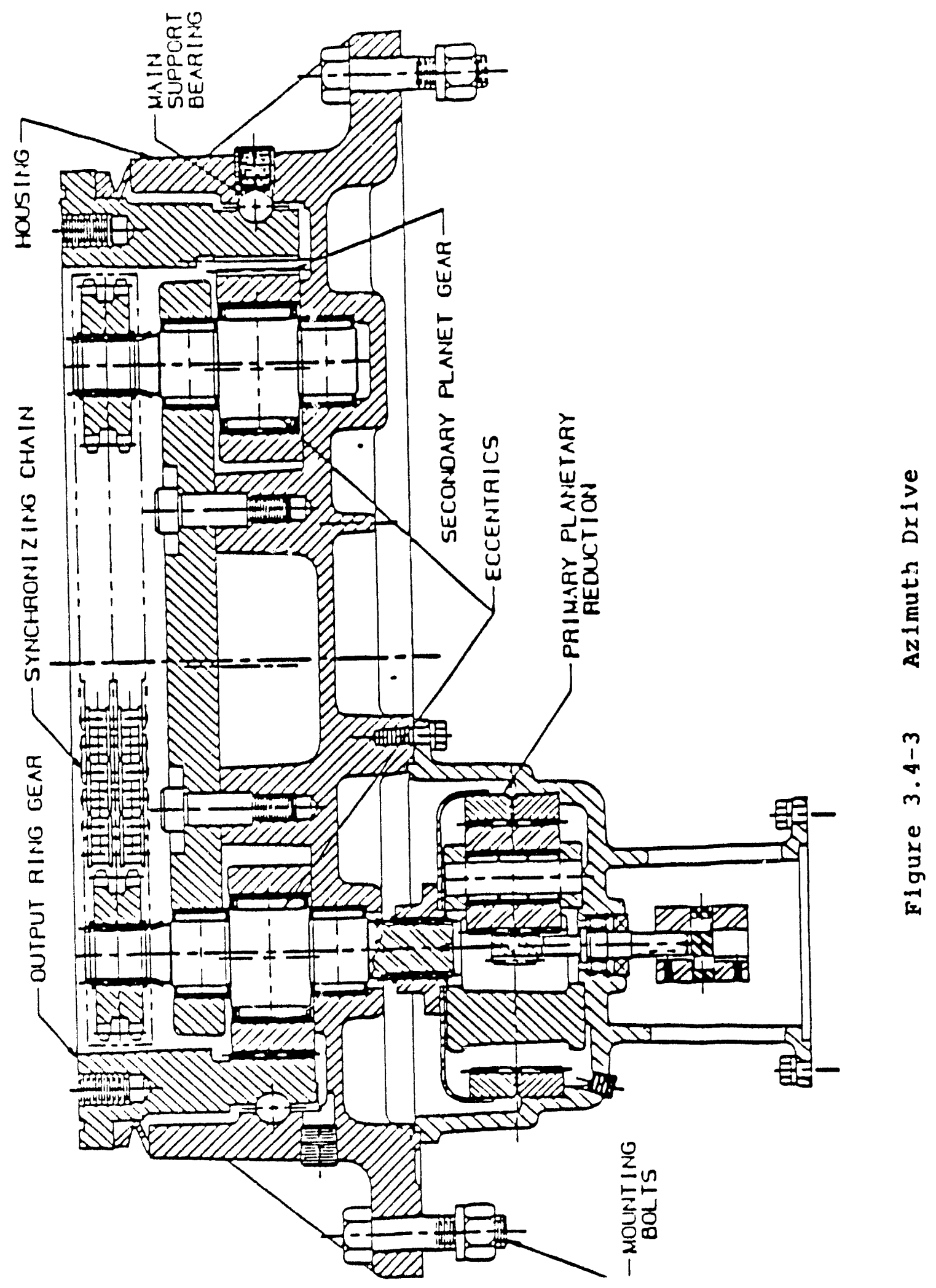


Table 3.4-I Winsmith Azimuth Drive Characteristics

- overturning Moment Capacity - 215,000 ft-lb

- Radial Shear Capacity - 250,000 ft-lb

- Drive Torque (Limit Load) - 65,000 ft-lb

- Axial Load Capacity - 250,000 ft-lb

- Backlash - $1.38 \mathrm{mr}$

- Spring Rate - $1.48 \mathrm{E} 08 \mathrm{in-1b/rad}$

- static Friction at Motor shaft - Less than 5 in-lb

The Winsmith azimuth drive was designed under contract to sandia National Laboratories for use on hellostats. It was fabricated anc, when tested under controlled conditions, performed essentially as advertised.

The conventional spur gear train employs an output spur gear either mounted on, or integral with, a crane bearing and driven through a pinion gear by a motor and speed reducer. Two major factors drive the design of this type mechanism - tooth loading and backlash. In spur gears tooth-bending stresses are often based on the premise that only a single iooth is engaged at any time. Therefore, each tooth must be capab'e of carrying the total load. With a given gear pitch diameter and with a given pitch, the only remaining variable available for increased tooth capacity is face width.

It a clear that increasing the face width of the bull gear to obtain the desired load capacity has cost implications. Preliminary calculations indicated that a face width of 4 in. was required on a 36 -in. pitch diameter gear. The gear would be heavy and expensive; thus this is an undesirable approach. Further, the inherent backlash zauses control problems.

Manufacturing tolerances applled to factors such as runout (eccentricityl, tooth-to-tooth spacing and tooth profile introduce potential for interference between mating geaxs. The interference can be exacerbated by a temperature differential. This condition is accommonated by increasing the center distance between the two 
gears so that under the RMS of worst case conditions, no interference can exist. But this also results in considerable backlash.

Both problems are addressed by driving the bull gear with two identical motor/reducer/pinion assemblies. The two pinions distribute the torque load so that tooth loading is minimized. This allows the use of a smaller face width, hence less costly, bull gear. Backlash is eliminated by biasing the torque loop of one of the drive motors so that, in operational winds where current draw is small, they work counter to each other. At higher winds, such as drive to stow, the motors work in a torque-aiding mode. Costs are higher than with a single motor/reducer, but the difference is minimized since the dual components are each only half the rating of the single pinion drive.

Several gear reducer manufacturers were contacted, including sumitomo and Graham, for their recommendations and costs. Different combinations of gear motors and reducers were considered in an attempt to minimize costs. However, it was concluded that the components were too e.pensive at this time, particularly since significant assembly and alignment time would be required.

The Winsmith drive was determined to be the prime candidate because

- it meets all load requirements,

- it has acceptable deflection characteristics,

- it is non-backdriving,

- it is compact,

- it has been built and tested, and

- it is affordable.

After close study, the only negative issue related to the winsmith drive is that the backlash on one unit was measured at a peak of 1.38 $\mathrm{mr}$. Since the manufacturer believes this is probably an anomalous measurement, a lower 3-sigma value is expected on subsequent units. In any case, it is likely that the total concentrator error budget will tulerate the $1.38 \mathrm{mr}$ with the control system as designed. 
In consideration of the above, the winsmith mechanism was selected for the azimuth drive for the faceted dish concentrator.

\subsubsection{Elevation Drive Design}

The elevation drive assembly is shown in Figure 3.2-2. The elevation axle is part of the stiffarm assembly. The stiffarm is hard-mounted on the output gear of the azimuth drive so that it rotates with the azimuth gear. The housing of the screw jack is flange-mounted to a pivoting trunnion on the transition assembly near the PCA support structure interface. The end of the screw jack is pinned to the stiffarm assembly. The three pinned points of attachment are the apexes of a structural triangle formed by the stiffarm assembly, the transition assembly and the adjustable-length screw jack. Thus, as the screw extends, the tracking structure rotates about the elevation axis toward the zenith position, completely independent of azimuth positioning.

The stiffarm assembly is a rigid, triangulated weldment that forms the primary load path from the screw jack to the azimuth bearing. It is designed to minimize the axial loads in the screw jack by maximizing the moment arm between the elevation axis and the screw jack. The stiffarm assembly bolts directly to the top (rotating) side of the azimuth drive and transmits all moment loads directly into the azimuth bearing.

In the design of the elevation drive, consideration was given to both machine screw jacks and ball screw jacks. The machine screw is less costly and is non-backdriving. However, its low efficiency (less than 1.8\%) must be accounted for in drive power requirements. Further, machine screws are subject to wear problems caused by sliding friction and the intrusion of foreign abrasive material on the mating surfaces. Ball screws, on the other hand, have a longer life expectancy, since they work on the principle of rolling friction. Being more efficient (on the order of $62 \%$ ), ball screws require less power. But the high efficiency allows the screw to backdrive under load. Thus, if a ball screw is used, either a brake must be provided or the 
efficiency of screw jack must be less than $50 \%$ if the drive is to be self-locking.

A ball screw jack has been selected for use on the faceted dish because of its longer life cycle and because its power requirements are more compatible with commercialization of the dish than is a machine screw jack. However, the backdriving problem requires special treatment. The magnetic clutch "power-off" brake approach was quickly discarded since it is considered undesirable when used in conjunction with a "bang-bang" type of control system. The frequency of on-off cycling is sufficiently high to shorten unacceptably the life of a brake.

The better solution lies in reducing the efficiency of the screw jack. This is done by providing a $70: 1$ primary (input) worm gear stage to drive a $1 / 2$ inch pitch ball screw jack. The calculated efficiency of the mechanism is reduced to about $35 \%$, causing it to be nonbackdriving. This approach was used by winsmith in the development of its drive tracking mechanism for heliostats and was successfully performance-tested on a 10-ton screw jack.

The geometry of the faceted dish places the CG of the moving structure about $18 \mathrm{in}$. above and $18 \mathrm{in}$. in front of the elevation axis when the collector is pointed toward the horizon. As the dish travels from horizon to zenith, its CG shifts from the focal point side of the elevation axis to the support structure side. The gravity load in the screw correspondingly goes from compression through a neutral point, at about 40 deg., to tension. Compression load is the limiting factor in any column, and the slenderness $(L / r)$ ratio is the critical parameter. The elevation drive is designed so that maximum compression loads occur at 0 deg. when the screw jack is in its shortest position and the slenderness ratio is at its minimum. Therefore, the Jack can easily perform to it.s rated capacity.

A 20-ton capaclty ball screw Jack was selected for the faceted dish with the screw length calculated to provide $73 \mathrm{in}$. of travel. The 
input shaft is driven by a $1 \mathrm{HP}, 1140$ RPM, direct-coupled, 3-phase induction motor. The screw average travel rate of $611 \mathrm{deg} / \mathrm{hr}$. (10.18 deg./min.) enables the concentrator to go from horizon to zenith in less than 9 minutes at rated motor speed.

To summarize, the proof-tested winsmith planocentric drive is used to provide the azimuth motion for the faceted dish. This drive is non-backdriving and is fully compliant with the dish-loading criteria. The elevation drive is a stock 20 ton ball screw linear actuator with a customized input gear ratio of $70: 1$ to cause the actuator to be non-backdriving. The actuator is interfaced with the azimuth drive by a stiffarm assembly that reacts the actuator loads. At rated motor speeds the dish will slew at average rates of about 19 dec./ min. in azimuth and $10 \mathrm{deg} . / \mathrm{min}$. in elevation.

\subsection{Pedestal}

The solar collector pedestal is shown in Figure 3.5-1. It is a tubular structure made in two sections. The upper section provides a mounting surface on its top surface for the azimuth drive. The opposite end of the upper section bolts to the larger lower section of the pedestal that mounts to the foundation. The pedestal is symmetrical in cross-section due to the random nature of the loads. It is stepped so that it can accommodate the 90 deg. elevation movement of the tracking structure while meeting structural stiffness requirements.

Ideally, the pedestal would be lighter and stiffer, under given load conditions, if it were a constant 36-in. diameter. However, as described earlier, when the tracking structure moves up in elevation, the spine center section overlaps the pedestal. To avoid structural interference the FSS is "notched" so that it nests with the pedestal. structural considerations require that the size of the notch be minimized; thus, the maximum pipe diameter with which the notch is compatible is $24 \mathrm{in}$. Therefore, a $24-i n$. constant section pedestal was evaluated. It was found that for stiffness characteristics equivalent to a 36-in. diameter, the wall thickness and weight required in a 24-in. pipe are impractical. The stepped pedestal 


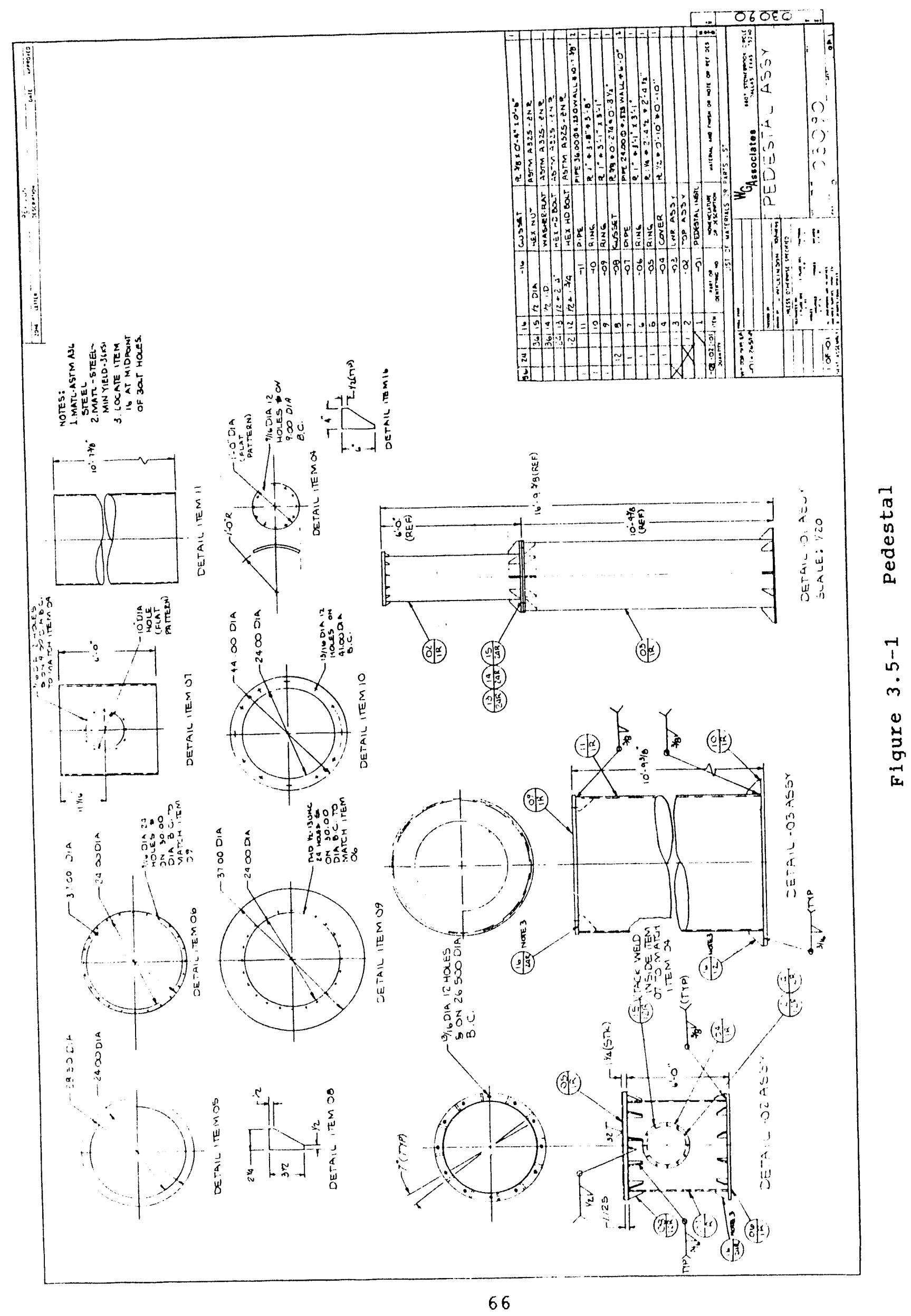


arrangement is a reasonable compromise. In this arrangement the tracking structure nests with the upper section, while the lower section provides the stiffness necessary to meet deflection requirements.

The lower section of the pedestal is a 36 -in. outside diameter by .25in. wall A36 steel pipe. It has an external flange with bolting holes at the bottom for installation on foundation studs. At its upper end the lower section is flanged internally. The underside of the flange is gusseted to the pipe to distribute the loads and reduce stresses on the relatively thin wall pipe. The internal flange has a tapped hole bolt pattern for attachment to the upper section.

The upper section of the pedestal is a 24-in. diameter standard (.375-in. wall) welded, A36 or equivalent, steel pipe. At each end it is welded to an identical flange with a bolting pattern for interfacing with the azimuth drive and the lower section of the pedestal, respectively. Both flanges are gusseted to minimize deflections. A port, with cover plate, is provided in the pipe for access to the azimuth drive motor for installation and maintenance purposes. The perimeter of the port is reinforced to restore the structural integrity of the pipe.

\subsection{Structural Analysis}

In the absence of ar: $:$ cest data for faceted dish configurations, the wind loads used in the analysis of the FSS were based on LTV aerodynamic data. These data resulted from wind tunnel tests of a solid parabolic reflector structure; these tests were originally conducted in support of LTV's work in the large earth station antenna field [Ref. 6]. The LTV modeling more closely approximated the faceted dish configuration than did models tested by MIT, JPL, Andrews Corp., and others. Whereas the other tests were run on smooth parabolic shells, the LTV model included a backup structure similar to that used in the faceted dish design. 
It should be noted that this the analysis does not account for the drag reduction due to spaces between facets; therefore, the analysis overpredicts loads and moments. Accordingly, it is reasonable to conclude that the analysis is conservative in this regard, i.e., design loads are greater than the dish would experience under similar wind load conditions.

The analysis was performed to insure that the structure complies not only with the functional criteria specified in the sow but also with the requirements of the AISC code. The AISC code establishes design standards to insure the integrity of the structure. Compliance with this code is mandatory for any structure in the public domain and is invariably contractually required throughout industry. The code was meticulously followed in the design of the faceted stretchedmembrane dish.

\subsubsection{Discussion}

Computerized finite-element techniques and classical structural analysis were used to design and evaluate the structure. The wind coefficients were taken from LTV wind tunnel data. The final specifications require the system to operate with required accuracy in a $16.7 \mathrm{mph}$ wind gusting to $27 \mathrm{mph}$, and with degraded performance in winds gusting to $35 \mathrm{mph}$. The system must be able to drive to stow in winds gusting to $50 \mathrm{mph}$ and survive winds gusting to $90 \mathrm{mph}$ in the stowed position.

A finite-element model was constructed to represent the faceted dish structure. The model consists of a series of line members with full properties, and membrane and shell elements to simulate plate and panel sections. Ordinary rules of finite element-modeling were followed. The node intersections were chosen to best represent the elastic (centroidal) axis of intersecting members. Panels were broken into finite numbers of sub-elements to obtain low aspect ratios, thus assuring accurate computational results. 
In the model, the intersections of all connecting members are assumed to be at a given node. Consideration of the member cross-section properties and the overall length ratios of structural members readily reveals that secondary bending due to elastic axis mismatch, where it might exist, produces essentially no effect on the overall strain energy of the system. since the shear panels are capped, the finite element assumption of a series of membrane elements is legitimate for structural simulation purposes.

For dead weight deflection calculations, the structural model is assumed to be fixed in space; gravity is rotated as shown in Figure 3.6-1 to simulate varying collector elevation angles. At a particular elevation angle, the gravity vector for each structural element is resolved into orthogonal vectors with one operating parallel to the $Y$ axis and one operating parallel to the $Z$ axis.

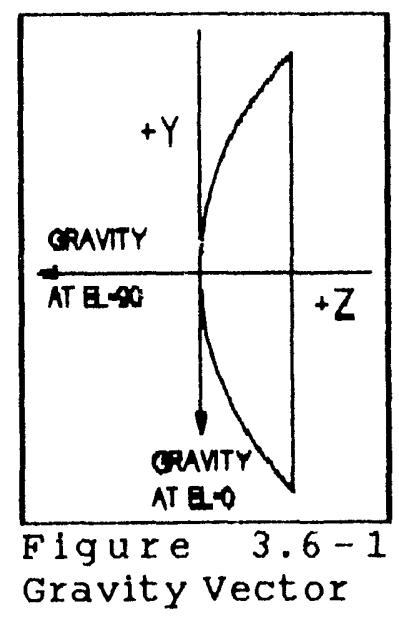

A finite-element program named SPACE $V$ [Ref. 7] was used for the analysis of the stretched-membrane dish. SPACEV is a proven code that has been used in the antenna industry for 25 years. The program is applicable to the analysis and reporting of members with respect to AISC code requirements. It has excellent plotting capabilities that aid in both pre-and post-analysis, and it allows the user the freedom of interactive programming.

The faceted dish design was altered several times, using the interactive feature of SPACE $v$, to optimize various sections of the structure and, in the final analysis, to optimize the entire structure. The effects of even slight member or geometry changes were readily evaluated.

In the finite-element model used in this analysis, a node numbering system was selected for grouping varlous elements of the structure together with the same 100's serles of numbers. All finite-element loading was introduced at nodal points, and member density factors 
were input using data from the drawings to accurately represent the dead weight loading of the structure.

Nodal deflections were used to evaluate the dish pointing accuracy, and calculated stresses were used to size members. In order to achieve an optimal design, the process was iterative. Dish fabrication considerations were invoked at every step of the analysis to place practical limitations on the design. Maximum effort was made to establish cummonallty of members while remaining weight-conscious, since sizing each member as an individual component based on critical design would lead to a costly structure made from many dissimilar parts.

The elevation wind torque loads were developed using coefflcients extracted from LTV wind tunnel test data. The worst-direction 50 mph wind result is shown in Figure 3.6-2.

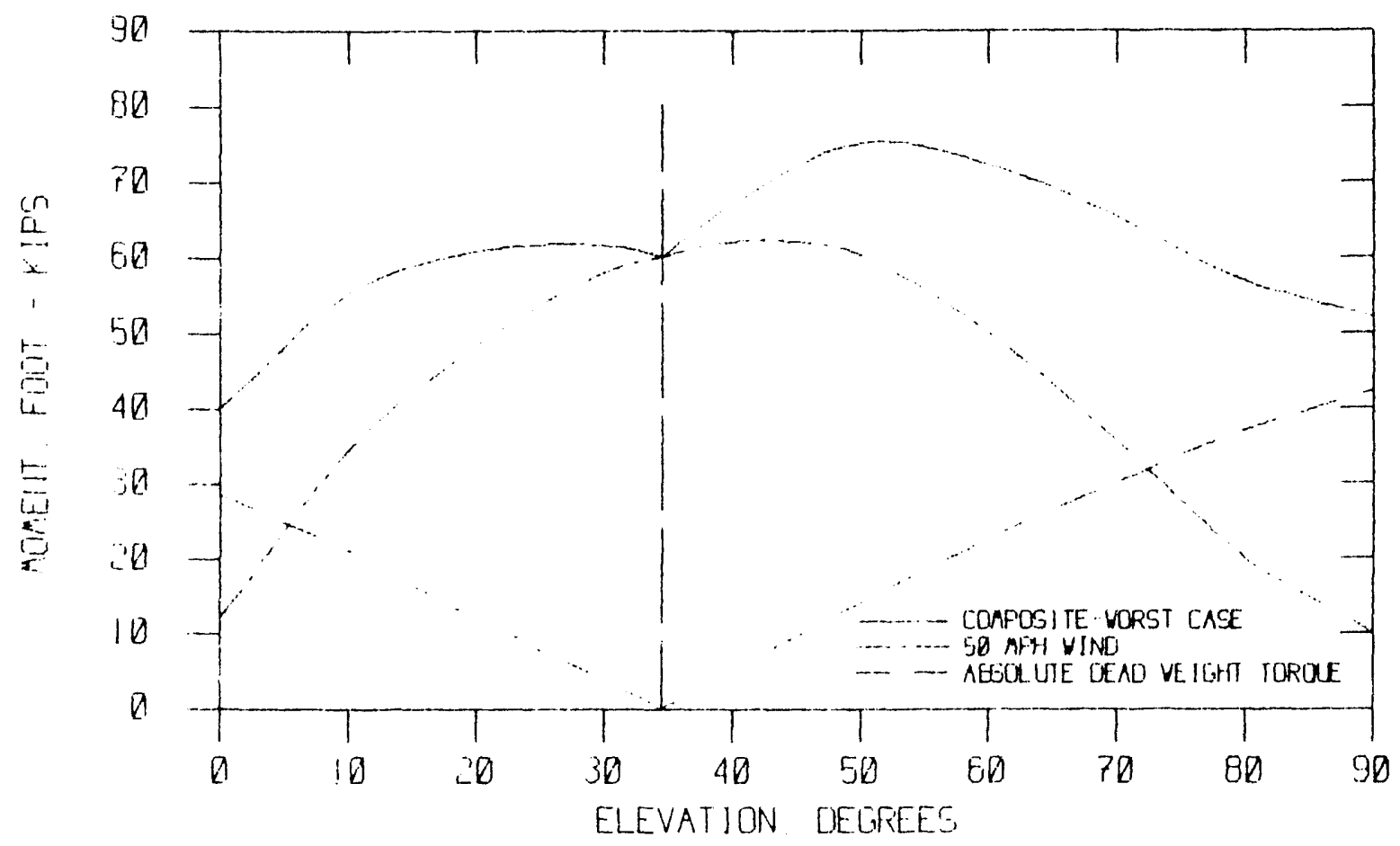

Figure 3.6-2 Elevation Torque Load, 50 MPH Wind 
The absolute value of the elevation dead weight (gravity) torque loads in Figure 3.6-2 are the resultant moments from calculation of the actual element weights and moment arms acting about the elevation axis. These loads are larger than anticipated because the CG of the moving structure is not on the elevation axis. When the collector is pointed toward the horizon, the CG is above the elevation axis and on the receiver side. As a result, the gravity torque load passes through zero as the dish elevation angle increases, and the structure experiences a gravity torque load reversal. The composite elevation torque load in Figure $3.6-2$ is the sum of the worstdirection wind torque and the absolute value of the gravity moment.

The azimuth torque load is the unbalanced wind torque since there is no unbalanced dead weight torque load in azimuth. The azimuth torque for a $50 \mathrm{mph}$ wind as a function of wind direction relative to the azimuth pointing angle, is shown in Figure 3.6-3.

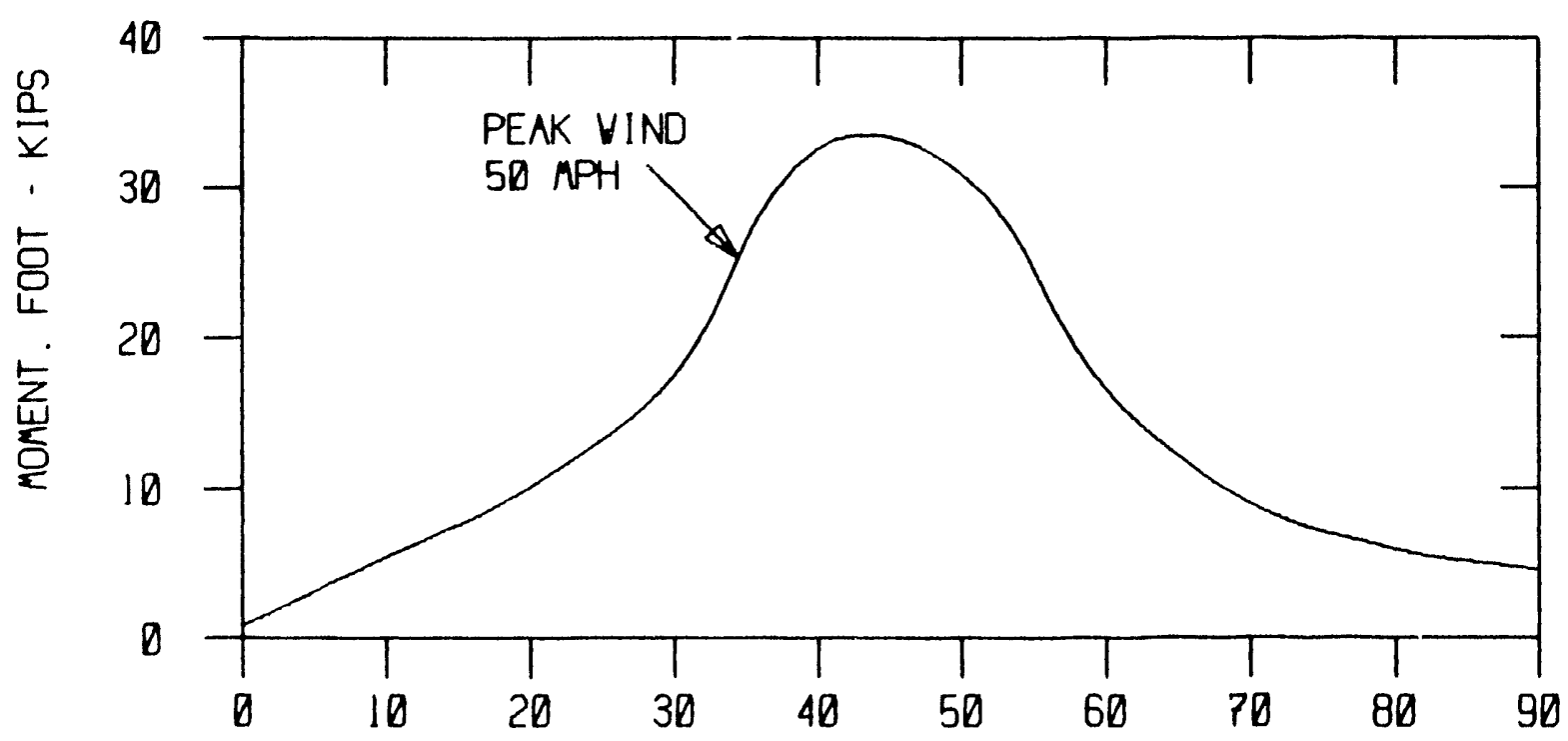

Figure 3.6-3 Azimuth Torque Load, 50 MPH wind 
The load curves in both Figures 3.6-2 and 3.6-3 represent peak loads for the worst case drive-to-stow condition, since the wind plots use the peak wind values.

The combined loads were used to calculate deflections and stresses for the pedestal, drives, and the moving structure. These data were used to determine the required compliance of the system. (Compllance is the inverse function of spring rate, usually expressed in radians/ ft-1b.) These compliances were then used to calculate the resonant frequency of the system.

The pedestal and drive elevation deflections due to the operating wind are shown in Figure 3.6-4.

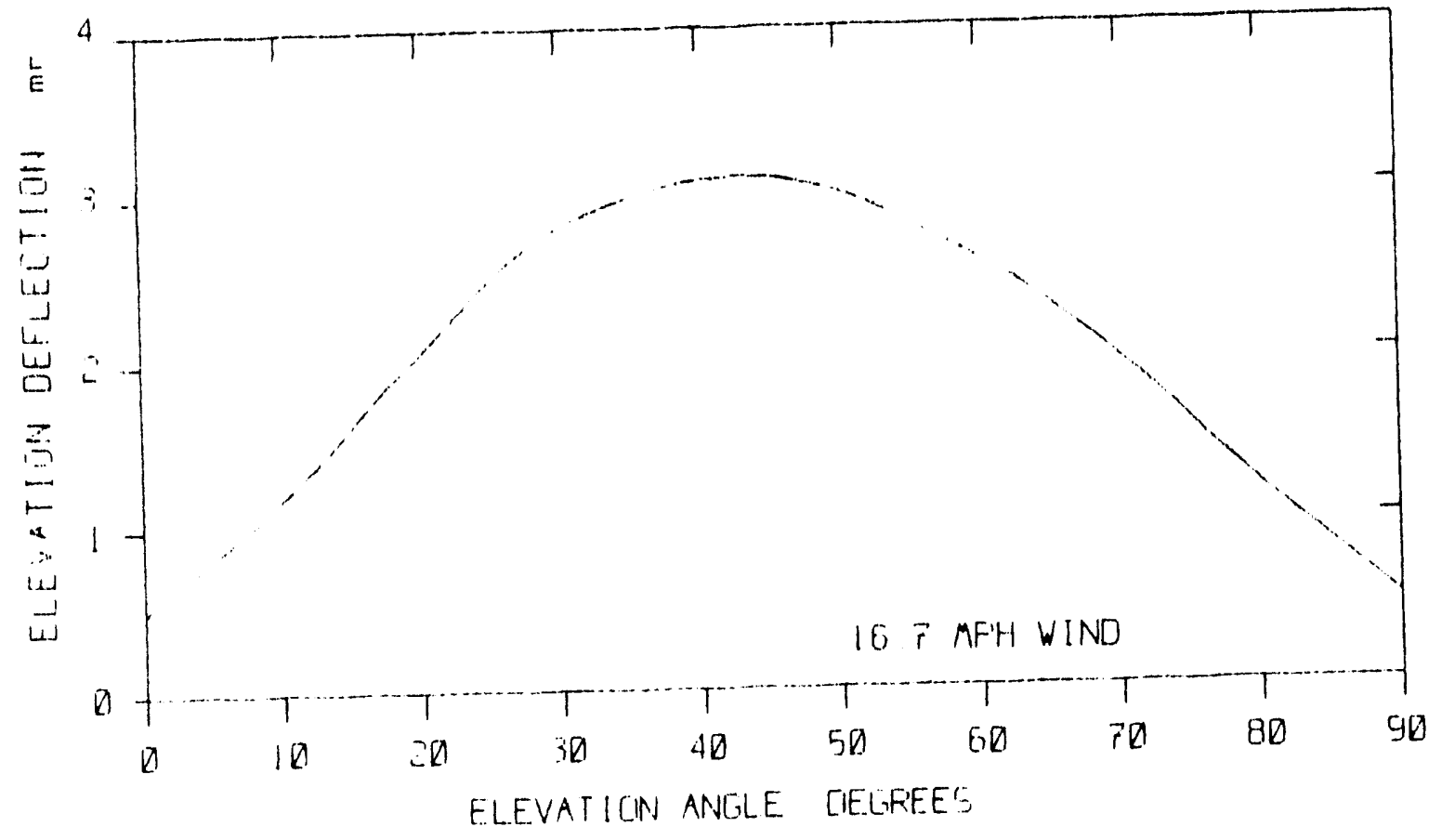

Flgure 3.6-4 Pedestal and Drive Elevation Wind Deflection 
The pedestal and drive azimuth deflections due to the operating wind are shown in Figure 3.6-5.

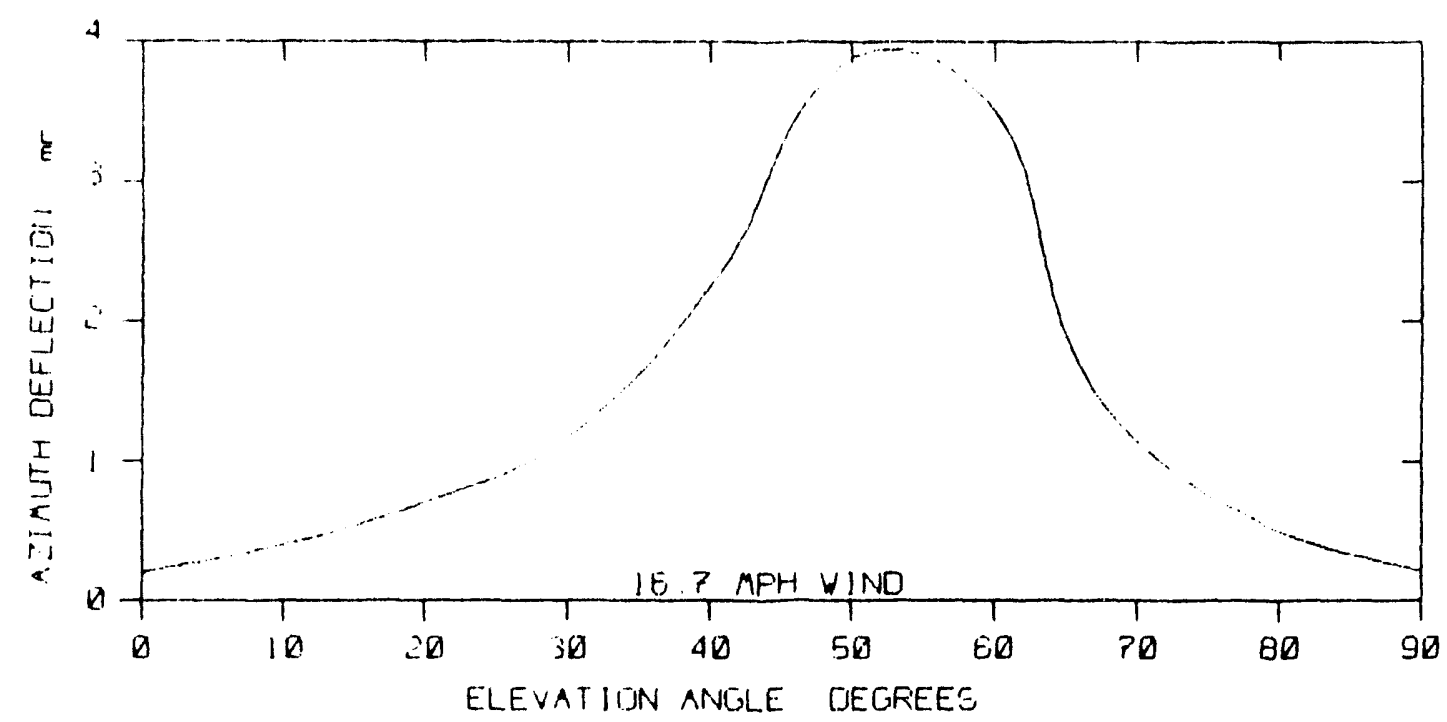

Flgure 3.6-5 Pedestal and Drive AzImuth wind Deflection

The pedestal and drive elevation deflections due to the dead weight are shown in Figure $3.6-6$.

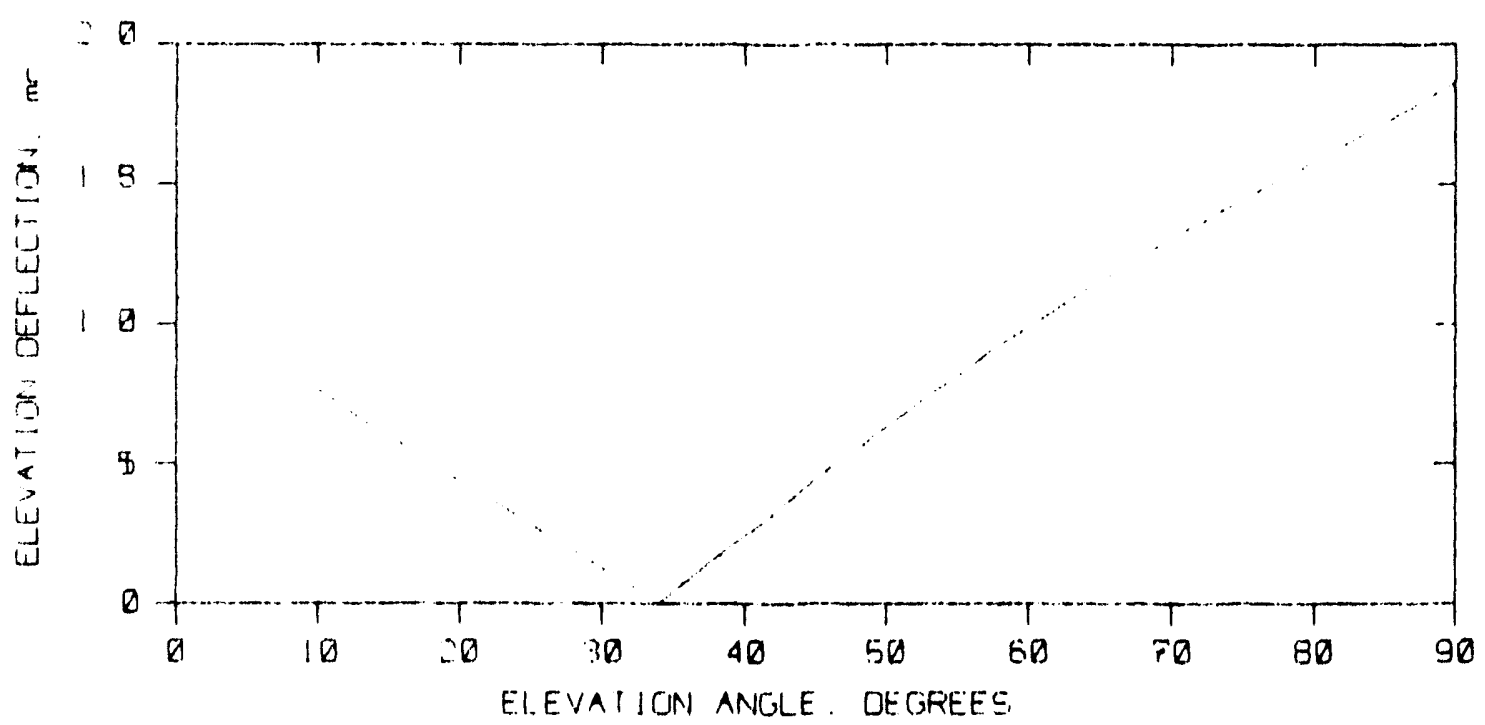

Figure 3.6-6 Pedestal and Drive Elevation Dead Welght Deflection 
Finally, the deflections of the PCA support structure due to dead weight are plotted in Figure 3.6-7. These curves show the effects on error accountability when the dish is aligned at elevation angles of 45 deg. and 90 deg., respectively. The curves reveal that the deflection margins between the travel limits - 0 deg. and 90 deg. are approximately the same for each alignment condition. However, aligning the dish at $45 \mathrm{deg}$. has the effect of dividing the deflection error around a mean of 0 deg. Thus the RMS error over the full 90 deg. of travel is significantly less than when the dish is allgned at zenith.

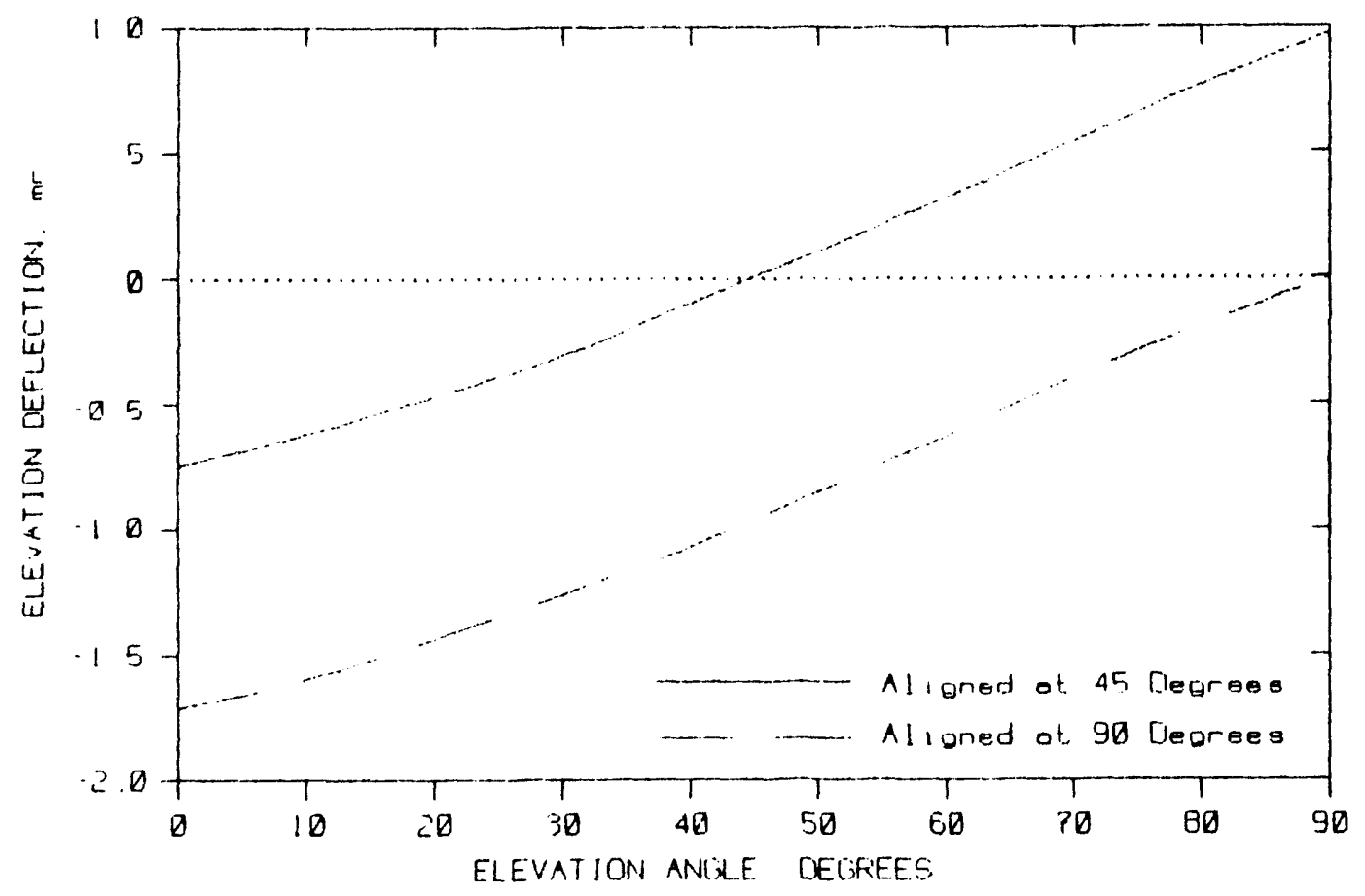

Figure 3.6-7 PCA Support Dead welght Deflection

\subsubsection{Summary}

A summary of the facet pointing errors is presented in Tables 3.6-I, 3.6-II and 3.6-III. In Table 3.6-I are listed the worst-case deflections due to dead weight. These occur when the collector is pointed horizontally after it has been correctly aligned at zenith. (The facet numbering is shown in Figure 2.1-1.). The $Y$ deflection and $X$ deflection values are the angular deflection of the line-of-sight of the facet in 
the $Y$ and $X$ planes, respectively. A negative value in $Y$ indicates that the facet line-of-sight is below 0 deg. elevation. A negative value in $x$ indicates that the line-of-sight has moved to the left when looking into the collector.

Table 3.6-I Worst Case Dead Weight Deflection zenith Alignment

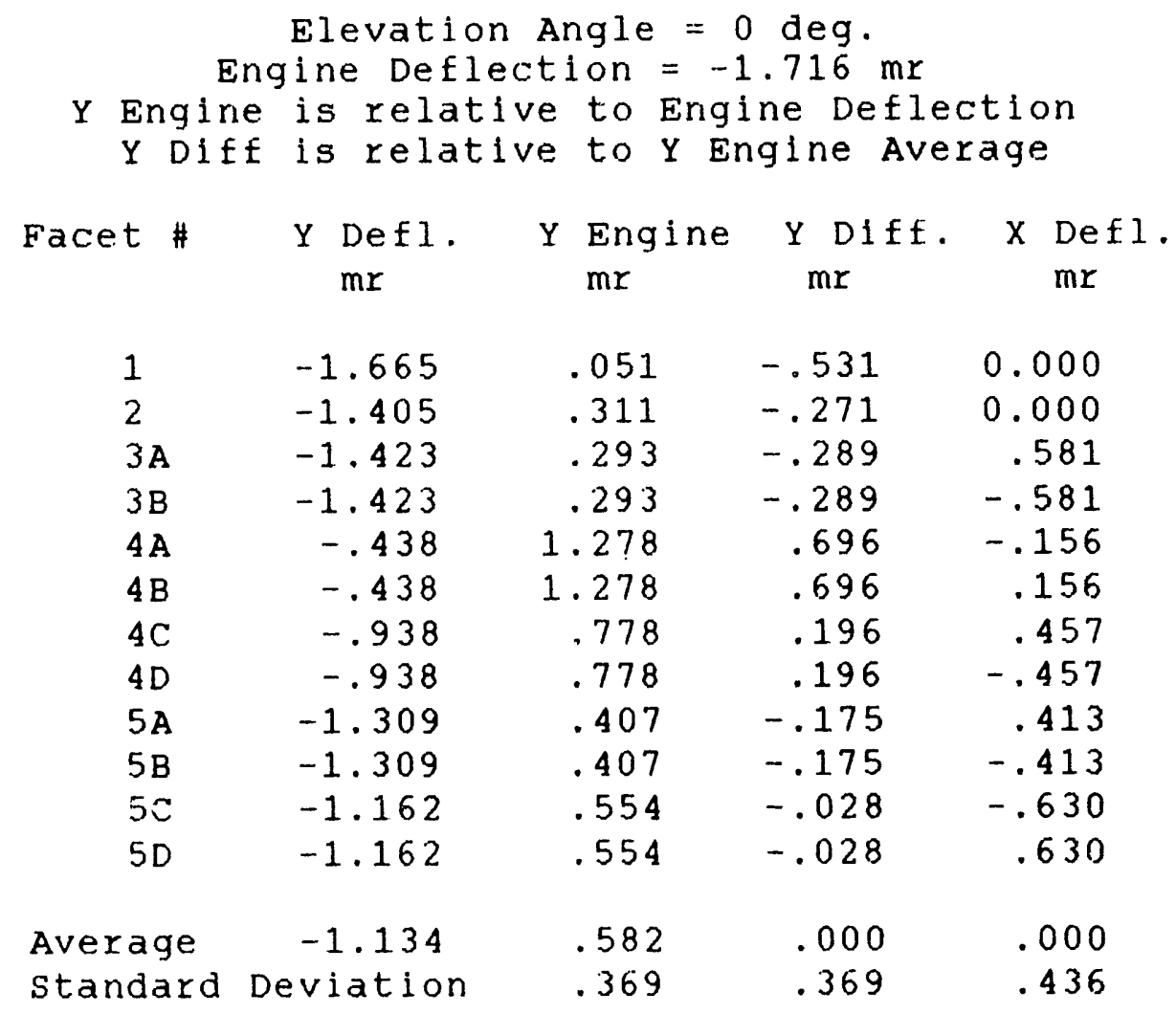

These errors, although systematic, cannot be completely biased out of the system due to the complex gravity-caused movement of the structure. The control system can make a correction for the collector as a unit but not for individual facets. If the control system corrected for the average error in $Y$ relative to the engine position ("Y Engine" column in the table), the residual errors would be the values in the "Y Diff." column in the table.

In Table 3.6-II, the deflections due to dead weight are listed for a collector pointed at the horizon after it has been correctly aligned at 45 deg. elevation. 
Table 3.6-II Dead Welght Deflection 45 deg. Allgn

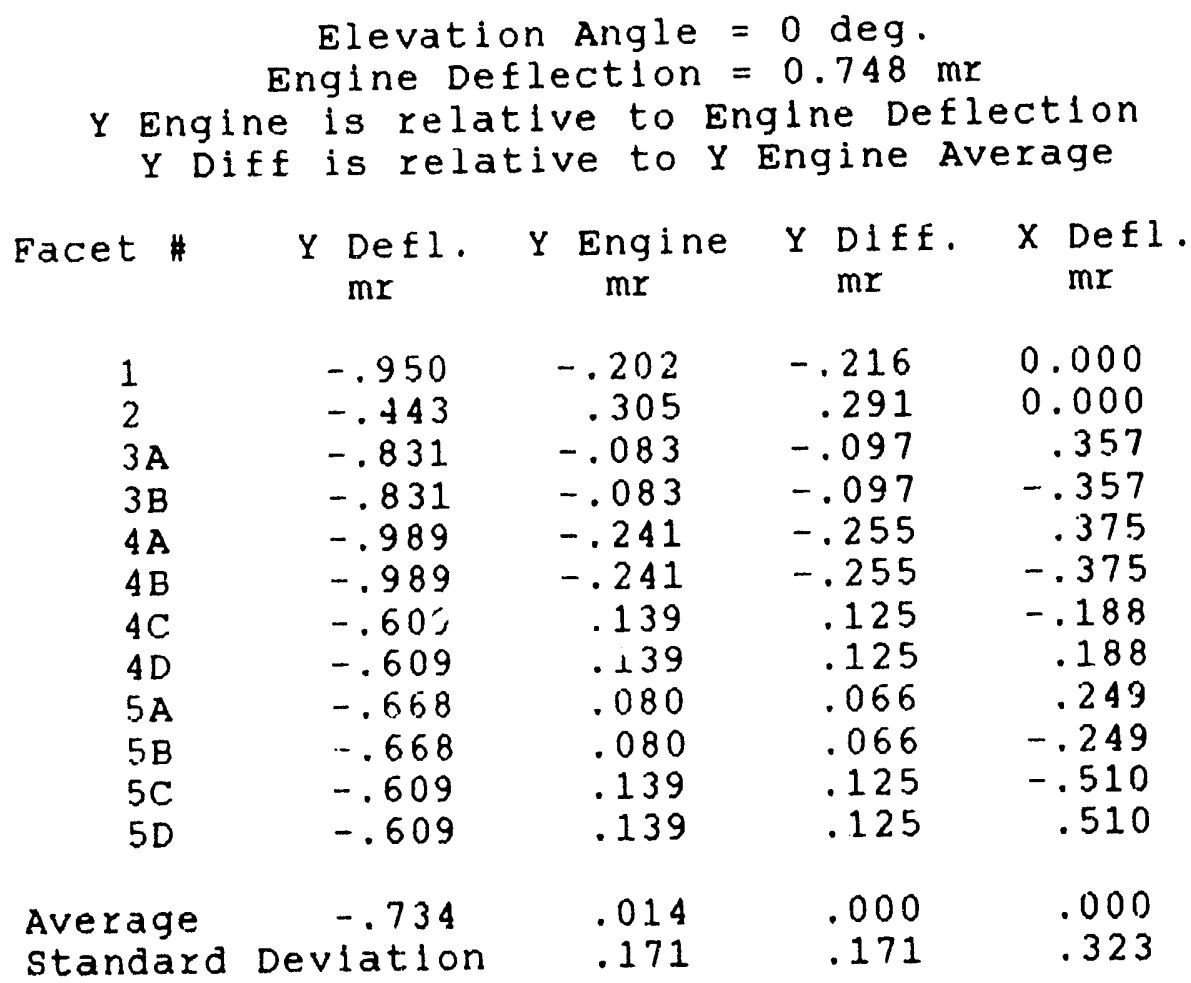

Comparison of Tables 3.6-I and 3.6-II shows that when the dish is allgned at $45 \mathrm{deg}$. and $90 \mathrm{deg}$. (zenith), the $Y$ standard deviations are $0.171 \mathrm{mr}$ and $0.369 \mathrm{mr}$, respectively. Thus, by aligning the collector at, or near, the middle of the operating elevation range, facet mounting point $Y$ deflection errors are reduced by a factor of about 2. The improvement in the $x$ deflections is approximately $35 \%$.

In Table 3.6-III, the error encountered by each facet due to wind loads is presented. The value at degraded operational conditions is proportional to the specified wind velocities squared. 
Table 3.6-III 20 MPH Wind Deflection

$$
\begin{aligned}
& \text { Wind Into the Face of Collector } \\
& \text { Elevation Angle }=0 \text { deg. } \\
& \text { Facet \# Y Defl. Y Diff. X Defl. } \\
& \text { mr }
\end{aligned}
$$

$\begin{array}{ccrr}1 & -.156 & -.054 & 0.000 \\ 2 & -.118 & -.016 & 0.000 \\ 3 \mathrm{~A} & -.115 & -.013 & .081 \\ 3 \mathrm{~B} & -. .115 & -.013 & -.081 \\ 4 \mathrm{~A} & -.112 & -.010 & .042 \\ 4 \mathrm{~B} & -.112 & -.010 & -.042 \\ 4 \mathrm{C} & -.065 & .037 & -.074 \\ 4 \mathrm{D} & -.065 & .037 & .074 \\ 5 \mathrm{~A} & -.0104 & -.002 & .054 \\ 5 \mathrm{~B} & -.104 & -.002 & -.054 \\ 5 \mathrm{C} & -.077 & .025 & -.082 \\ 5 \mathrm{D} & -.077 & .025 & .082 \\ \text { erage } & -.102 & .000 & .000 \\ \text { andard Deviation } & .025 & .063\end{array}$

The total collector deflection error consists of facet mount deflection errors and pedestal/drive errors resulting from wind loads and structural dead weight. The net overall, gravity-induced deflection of the line-of-sight relative to the receiver is repeatable. 'To the extent that gravity-induced errors can be accurately measured, they may be blased out with the control system. Th1s $1 \mathrm{~s}$ also true of errors due to structural and axis allgnment. However, the windInduced errors cannot be blased out of the system.

The structure was evaluated for compliance with the AISC code as well as stated deflection criterla. As in most large-aperture satellite earth stations, the driving criterla was stiffness of the structure rather than stress levels. When stiffness requirements were satisfled, the stress ratios were well below acceptable limits in the structure. Stresses of 5,000 to $8,000 \mathrm{ps} 1$ at worst case conditions are typical throughout the structure. The slenderness ratio (L/R) requirement of 120:1 used for column buckling design dominates in the selection of most truss cap members rather than the allowable stresa. Shear stresses within plate elements are well within the acceptable range for the thickness-to-widh ratlos of the 
pariel elements. plate thicknesses in the transition assembly were increased beyond those indicated by calculations to provide a greater buckling safety factor in this critical element.

The maximum stress encountered in the structure is 18,000 psi; it occurs only locally in a few members at maximum loading conz:ilons. Thus, based on minimum yield of $\mathrm{A} 36$ steel $(36,000$ psi), safety ractors throughout the structure are 2:1 or greater. Individual stresses in speclal components such as gear teeth, support pins and bolt connections are all within the limits of the special materials used in their design and the recommendations of the manufacturers. The resonant frequency of the total structure above grade, including the mass of the facets and the PCA, is about $2 \mathrm{~Hz}$ in both azimuth and elevation.

\subsection{Welght summary}

The weight of the faceted dish is summarized in this section. The weights were developed from the geometry inputs to the finite element analysis program. Where structure was not included in the analysis, such as brackets and fasteners, the welghts of the omitted elements were manually calculated and added to the computer output. In addition, some sub-assemblies were selected for independent weight analysis to verify the accuracy of the computer data. The variance was less than $3 \%$.

The breakdown of the faceted dish welghts by major assembly and the total weight are shown in Table 3.7-I. The total unit weight of the 14.86 pounds per square foot of facet area is further analyzed below.

1. The dish structure, which includes the Fss, the transition assembly, the PCA support structure, and the hardware and brackets, welghs 15,000 pounds, or $10.24 \mathrm{lb} / \mathrm{sq}$.ft. of facet.

2. The tracking structure, which includes the weight of the facets in addition to that of the dish structure, weighs 18,150 pounds, or $12.39 \mathrm{lb} / \mathrm{sq} . \mathrm{ft}$. of facet. 
3. The drives and pedestal, including the stiffarm assembly, are considered the base structure. These total 3,620 pounds, or 2.45 lb/sq.ft. of facet.

Table 3.7-I Faceted Dish weight summary

WEIGHT WEIGHT PER SQ.FT .
LBS.

\section{- structure}

Facet support structure

9,700

3,250

1,750

300

400

2,320

stiffarm

Pedestal

sub-total, structure weight

- Eacets

sub-total, Facet welght

- Drives

Elevation

Azimuth

Sub-Total, Drives

Total collector welght
300

600

$\frac{200}{21,770} \quad \frac{0.61}{14.86}$


. 


\subsection{TRACKING CONTROL SYSTEM DESIGN}

The tracking control system design objectives were to:

1. design a system that would provide sufficient tracking accuracy,

2. assemble the system from existing major units to the extent possible, and

3. minimize the costs consistent with the first two objectives.

As indicated in section 2.6, several alternatives were investigated before deciding on the conflguration. Based on the present perception of the accuracy required, the selected configuration satisfies all three objectives. This conflguration is deacribed below.

\section{1 system Design}

The tracking control system block diagram is shown in Figure 4.1-1.

The control system employs a central computer and a tracking control processor, called the front end processor (FEP), to provide passive tracking. In passive tracking, the position of the sun is calculated and this position, after transformation into the collector coordinate system, is compared to the collector position. Motor control signals then are generated to reduce the difference to zero. As wlll be seen later, this task is divided between the central computer and the FEP. The FEP is an exlsting solar collector tracking control processor, manufactured by Electronic Innovations Corp. and Advanced Thermal systems of Englewood, Co, that is altered to meet the requirements of this project.

The FEP generates commands for the motor controllers that control the power for the motors.

The drive-motor controllers are flux-vector inverters to accommodate a "bang-bang" control that is compatible with the existing processor and yet provides sufficient accuracy. The controllers drive three-phase induction motors. 


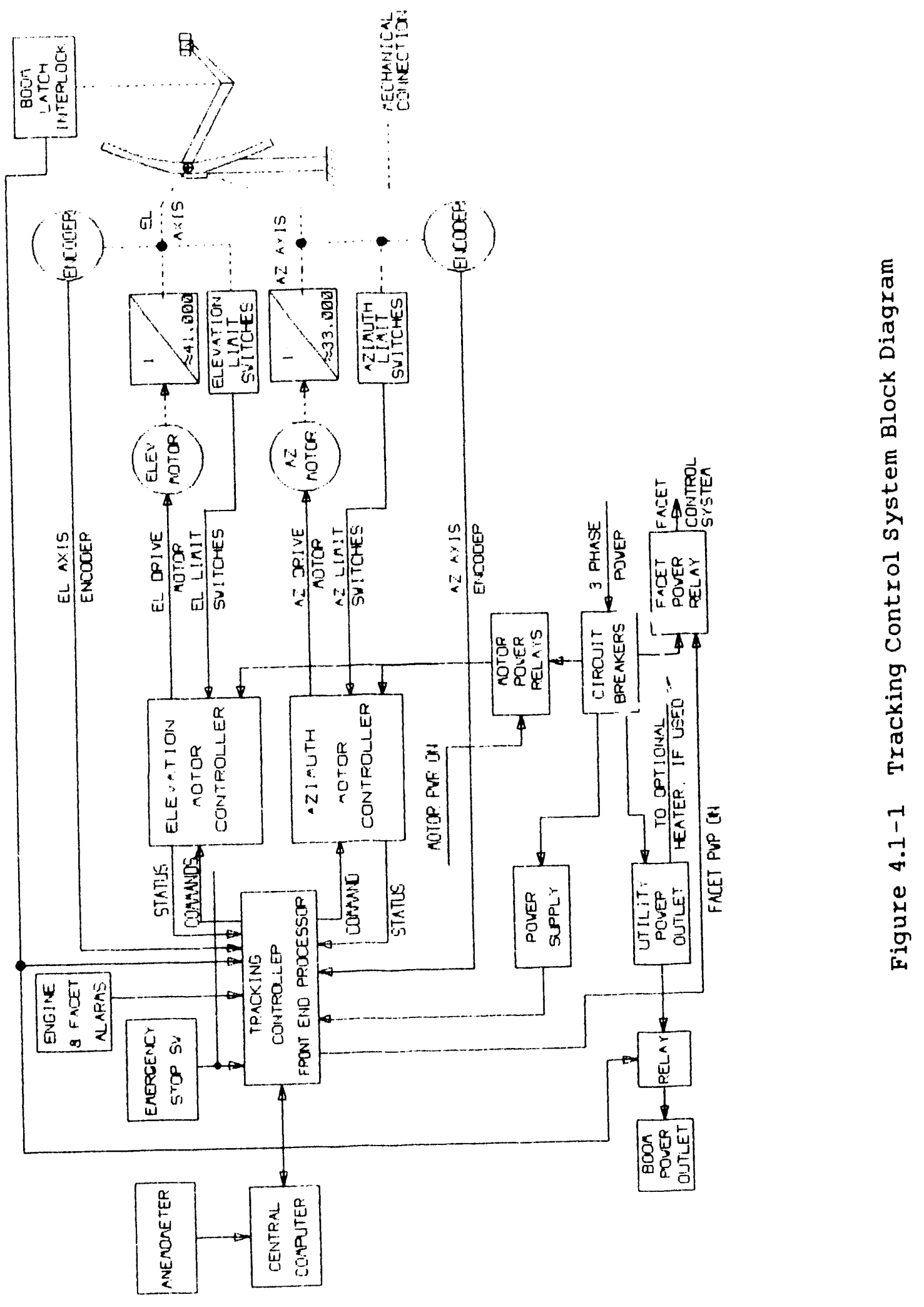


The collector is equipped with azimuth and elevation limit switches that not only interrupt the Run Direction command to the motor controllers but also provide a fault signal to the FEP. The limit-switch circuitry is arranged to inhibit the command to drive the collector further into the limit. The control system will allow the collector to be driven out of the limit position under power.

The collector position is monitored with incremental encoders coupled directly to the collector axes to provide the required accuracy. Each encoder is equipped to provide an index pulse to initialize a position counter in the FEP. If needed, limit-switch actuation can serve as a backup for the index pulses.

The PCA support structure has provisions for lowering the engine near ground level. An interlock switch prevents driving the collector except when the engine support is properly secured. When the support is not secured, this switch energizes a relay to provide power to a convenience outlet installed on the support structure. A temporary drive, such as a drill motor, may be plugged into the convenlence outlet to ralse and lower the engine.

Finally, provision is made to supply power under central computer control to the facet control system.

\subsection{Central Computer}

The central computer is compatible with an IBM Personal computer. The division of tasks between the central computer and the FEP is a strong function of the FEP design. In the selected design, the central computer has the following functions. (For details, please see WG Associates specification Control Drawing (SCD) number 03060.) 1. Provides the operator interface for control, status display, and capability for user-generated routines to control the collector.

2. Calculates the direction of the sun.

3. Stores both the site and collector-specific data base items, e.g., site location, encoder initialization, etc. 
4. Corrects the position commands to each collector to compensate for collector alignment and deflection errors.

5. Corrects the collector positions reported from each collector to compensate for collector allgnment and deflection errors before display.

6. Provides acquisition and escape paths suitable to minimize danger of structural damage.

It is noted that items (4) and (5) above are in conflict with the requirements of the $S C D$, paragraph 3.1.3, which states that the corrections unique to a particular collector shall be made in the FEP. This requirement is intended to prevent overload of the communications link when a relatively large number of collectors are serviced by a single computer. This requirement was waived for the prototype system since there will only be one system for the central computer to service. Also, the central computer can easily handle more than a hundred collectors at a time. The system can be readily modified to comply with the SCD requirement.

\subsection{Eront End Processor (FEP)}

In the selected design, the FEP has the following functions. (For detalls, please see WG Associates SCD number 03060.)

1. Provides for acceptance and execution of central computer control signals.

2. Transmits status data for the central computer status aisplay. These dita include internally generated status, external status (such as motor controller status and engine and facet alarms), and collector position.

3. Performs decoding of the encoder signals and updates the position counters accordingly. This includes use of the index pulses to check the position counters and update them, if necessary.

4. Generates separate commands for application of power to the motor controllers and to the facet controlier.

5. Generates approprlate commands for the motor controllers. The commands for each controiler include: 
- a Forward command to run the motor in one direction

- a Reverse command to run the motor in the other direction and

- a command to select one of four preset output frequencies from the controller for four different motor speeds.

\subsection{Motor Controllers}

The motor controllers are Polyspede Electronics Corporation Model $X L T$ solid-state, adjustable-frequency motor controllers. These controllers convert the applled $200 / 230$ volt, three-phase, $50 / 60 \mathrm{~Hz}$ power to a flxed potential. DC. Th1s DC voltage is converted by a three-phase, sine-coded, pulse width modulated inverter to an adjustable frequency (from 1 to $120+\mathrm{Hz}$ ), $200 / 230$ volt, three-phase power.

The controllers have a two binary blt input that selects one of four frequencles that are programmable through a manual entry keyboard. A low motor speed (commanded by a low controller output frequency) is used for normal elevation tracking and for azlmuth tracking at low elevation angles. An intermediate speed is used for azimuth tracking at moderate elevation angles. Rated speed is used for normal slewing and azimuth tracking at high elevation angles. Acquisition of, and escape from, the sun uses about twice the rated speed.

Each controller has a command input for forward anci another for reverse. These inputs are used by the FEP to pulse whe motors to produce "bang-bang" tracking. In this case the controller output frequency (analagous to velocity command) will be set to a low value to prevent excesslve motor velocity while stlll producing the required torque. This is the "soft bang-bang" tracking drive mode described in this report. As explained in section 2.6, this mode results in less drive error than the "bang-bang" mode where full frequency and power is used during the "on" perlod.

\subsection{Axis Encoders.}

The encoders used to determine the axis $p$;itions are BEI Motion systems Company model number H25D-SS-9000-M5-ABZ-5406-LED- 
sM16-s incremental encoders. They are heavy-duty industrial units with a NEMA Type 13 enclosure rating. They produce 9000 cycles per revolution so that: with quadrature decoding in the FEP, there will be 36,000 counts per revolution (resolution is 0.01 deg. or 0.175 mir). The encoder also produces one index pulse per revolution for initializing the position counter in the FEP. The encoders will be adjusted at installation to locate this index position near the wakeup position. 


\subsection{COLLECTOR SYSTEM POINTING ERROR BUDGET}

The FSS design is deflection driven, i.e., the structure is designed for maximum stiffness at operating conditions. Characteristic of an elevation-over-azimuth axis configuration, the gravity vector changes with the elevation pointing angle. This causes proportional varlations in the dead weight deflections. By limiting these deflections, system performance of the faceted dish is enhanced since changes in optical efficiency with elevation angle variations are minimized. Moreover, a stiff structure minimizes movement of the facets and unintentional superpositioning of their images, thereby reducing the possibility of receiver damage.

The error budget for the support structure and the control system is shown in Table 5.0-I. The budget incorporates the wind and dead weight deflection results of the structural analysis (Section 3.6) along with other values from the trade-off studies.

The results shown in Table 5.0-1 are slightly better $(1.19 \mathrm{mr}$ compared to $1.28 \mathrm{mr}$ in $16.8 \mathrm{mph}$ winds) than the results in Table 2.6 -IV. This is due to reductions in wind deflection values from the initial estimates that more than offset increases in dead weight deflections.

Table 5.0-I includes facet-pointing errors resulting from wind and gravity-induced deflections of the facet mounting planes. Facet alignment errors, slope errors and specularity errors are not: addressed in Table 5.0-1 or in this report. The individual facet.pointing errors due to dead weight deflections are shown for the worst case (errors at horizon with alignment at zenith) in Table 3.6-I, where the peak deviation from the average is approximately $0.7 \mathrm{mr}$ in elevation and $0.6 \mathrm{mr}$ in azimuth. The standard deviations are approximately $0.37 \mathrm{mr}$ and $0.44 \mathrm{mr}$, respectively. The case where alignment is performed at 45 deg. is shown in Table 3.6-II. Here the peak deviations in elevation and azimuth are $0.3 \mathrm{mr}$ and $0.5 \mathrm{mr}$, respectively. The standard deviations are $0.17 \mathrm{mr}$ and $0.32 \mathrm{mr}$, 
respectively. Corresponding deflection values for a $20 \mathrm{mph}$ wind are shown in Table 3.6-III. In this case, the peak deviations in elevation and azimuth are $0.05 \mathrm{mr}$ and $0.08 \mathrm{mr}$, respectively. The standard deviations are $0.025 \mathrm{mr}$ and $0.063 \mathrm{mr}$.

The budgeted error values demonstrate that the faceted dish exhibits stiffness characteristics consistent with the sow performance specifications.

Table 5.0-I collector system Pointing Error Budget (Exclusive of individual facet errors)

FINAL DESIGN SYSTEM

WITH POLYSPEDE CONTROLLERS \& AXIS ENCODERS

\section{ERROR SOURCE \\ 3 SIGMA OR PEAK VALUES}

Drlve \&ed. Wind Def

Facet vs Engine Wind Def

Facet vs Engine Dead wt.

Drlve \& Ped Dead wt.

Ped Lev \& El Axis Align

Bang-Bang w/Polyspede

Prediction Error

Time Error (5 Seconds)

Resolver Error

RSS AXIS RESULT

RSS TOTAL

\begin{tabular}{|c|c|}
\hline $\begin{array}{r}16.8 \mathrm{M} \\
\text { AZIMUTH }\end{array}$ & $\begin{array}{l}\text { MPH WIND } \\
\text { ELEVATION }\end{array}$ \\
\hline $1111 \mathrm{rad}$ & Millirad \\
\hline $\begin{array}{l}.40 \\
.05 \\
.00 \\
.00 \\
.20 \\
.50 \\
.20 \\
.40 \\
.30\end{array}$ & $\begin{array}{r}.31 \\
.10 \\
.12 \\
.38 \\
.20 \\
.50 \\
.20 \\
.00 \\
.30\end{array}$ \\
\hline .86 & \\
\hline
\end{tabular}

1.19
27 MPH WIND AZIMUTH ELEVATION Mllirad
Millirad

1.03

.13

.00

.00

.20

.50

.20

.40

.30

-....

1.29

$$
\begin{array}{r}
.80 \\
.26 \\
.12 \\
.38 \\
.20 \\
.50 \\
.20 \\
.00 \\
.30 \\
\hline 1.13
\end{array}
$$

1.72

NOTES: All of the error source values are estlmated peak values for the conditions stated except the dead welght values and Pedestal and Axis Alignment. These sources are assumed to be corrected in the control system with a resldual of 208 of the peak value. The errors in each axls are comblned by an RSS calculation for each axis. The values for the axls total are also the result of an RSS calculation.

Thus, it can be expected that, for a $16.8 \mathrm{mph}$ wind gustling to $27 \mathrm{mph}$, the result of the $16.8 \mathrm{mph}$ case represents a reasonable estlmate of the probable error (one slgma). The result of the $27 \mathrm{mph}$ case represents a reasonable estimate of the three slgma error for a $16.8 \mathrm{mph}$ wind gusting to $27 \mathrm{mph}$. 


\subsection{COLLECTOR PRODUCTION AND INSTALLATION COST}

The cost of production and installation of faceted stretchedmembrane dish collectors is described in this section. (The costs presented do not include facet and facet control system costs; for these, please refer to references 2 and 3.) Costs are projected for collector production quantities of 50,100 and 1,000 units per year. The processes identified and costed include: fabrication of the collector support structure, procurement of the tracking drives, procurement of the control system, procurement of miscellaneous specialty items, the shipping costs for both facets and support structures, and the installation and alignment of facets and support structures. The analysis incorporates subcontractor and vendor quotes, catalog pricing, and time and material estimates.

The three annual production quantities considered and their unit costs are summarized in Table 6.0-I.

$$
\text { Table } 6.0-I
$$

\section{COLLECTOR PRODUCTION COST SUMMARY}

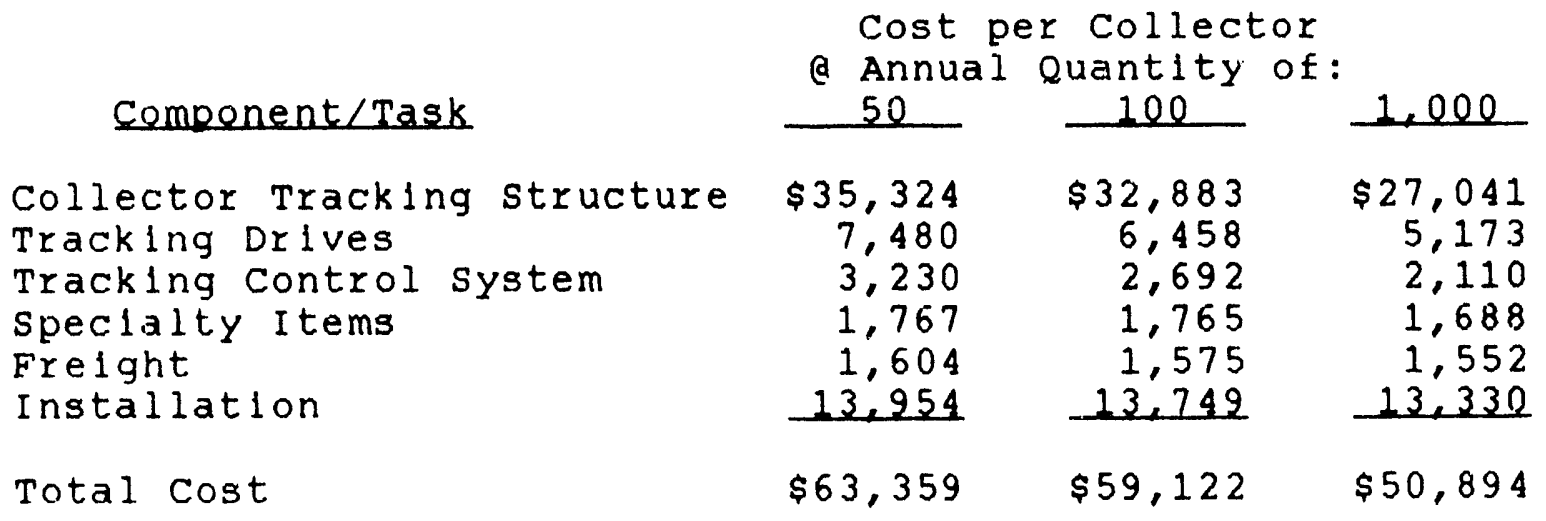

Specific ground rules and methodology used in developing these cost estimates are listed below. 
1. Collector support structure fabrication - indirect cost rates factored into labor rates for each level of annual collector production, are as follows:

$\begin{array}{lrrrr}\text { Overhead - of direct labor } & 85.00 \% & 80.75 \% & 76.50 \% \\ \text { G\&A - } 8 \text { of cost before G\&A } & 9.00 \% & 8.55 \% & 8.10 \% \\ \text { Fee - \& of cost through G\&A } & 7.00 \% & 7.00 \% & 5.00 \%\end{array}$

2. Depreciation of capital equipment (e.g., facet shipping racks) is calculated on a seven year - straight-line basis, with no salvage value.

3. support structure fabrication - subcontractor budgetary time and material estimates are used for quantity of 50 units annually, with wright Learning curve of $93 \%$ applied for larger quantities.

4. Tracking drive costs are estimates based on vendor quotes for guantities of $1,2,10$, and 100 per year. The cost for a quantity of 1,000 was obtained by extending the curve.

5. Shipping costs - facet loading manhours and frelght rates are per facet suppller's estimates; WGA's labor-rate estimates were applied to the supplier's time estimates. support structure loading is included in the subcontractor's estimates; freight, at $\$ 1,250$ per unit, and unloading time are WGA's estimates. No time or direct cost improvements with larger quantities are factored into the estimates.

6. Installation - facet, control system, and structure installation times are per supplier estimates, with WGA labor-rate estimates. per-unit crane rental times of: (a) truck crane, 4 hours @ $\$ 60 / \mathrm{hr}$.; (b) manlift, 13 hours a $\$ 20 / \mathrm{hr}$; (c) 25 -ton crane, 48 hours a $\$ 75 /$ hr.; are per suppliers' estimates. Due to the one-collectorper-site scenario, no direct cost improvement with quantity 
increases is factored into these estimates. A four-man installation crew is assumed, with $\$ 250 /$ man travel cost per site, and $\$ 100.00$ per man/day per diem and ground transportation. support structure installation is estimated to require 6 days. Control system installation is based on a $95 \%$ wright Learning Curve. Installation labor rates are factory labor rates plus $20 \%$.

7. No costs are included for foundation and site wiring (as differentiated from collector wiring), since they are site speciflc. Also, no costs are included for a central computer, estimated at $\$ 1,200.00$, with a capacity of up to 200 collectors at each installation site.

8. All costs are 1991 dollars, with no provision for inflation.

9. Tax (both income and sales/use) implications are ignored.

To summarize, it was assumed for all cases that only one collector would be installed on each site, with subcontractor activities and materials procurement supervised and coordinated by a general contractor/system owner. All costs included are those external to the general contractor/system owner; i.e., no general contractor's indirect cost recovery or management fee are factored into the totals. For the most part, the costs included are per vendor quotes or budgetary estimates for the various quantities required. Learning curve estimates (Wright curve) were utilized in calculating labor hours for the support structure fabrication (93\%) and control system installation (95\%). The support structure estimate began with a subcontractor estimate for an order quantity of 50 units as the baseline, while the control system installation used the vendor's estimate for one unit.

The results of the cost analysis are considered to be conservative, due to several factors: 
1. The use of an order quantity of 50 units as the baseline for the learning curve cstimate for support structure fabrication yields a relatively small improvement factor, even at an annual production of 1,000 units.

2. The "one-collector-per-site" scenario precludes the possibility of cost savings in items such as installer's travel/per diem costs, improvement in installation time, and crane/manlift rentals. (Note: In the 1,000-collector-per-year estimate, crane and manlift rentals for one year will total over $\$ 4$ million.)

3. Most significant, the analysis presumes no change of the collector design beyond that of the prototype, even for the 1,000-collectorper-year scenario.

In a market demanding hundreds of these collectors annually, the product would be redesigned to take advantage of labor-saving techniques normally associated with large-scale, automated manufacturing. As examples, extensive use could be made of castings for end fictings; truss sections could be press-formed, beaded sheet metal; and automatic welding and/or riveting, even robotics, could be employed. The result would be fewer piece parts and joints, less material handling and fixturing, and reduced linear inches of welding. It is estimated that with these methods the cost of fabricating the collector support structure in large quantities could be reduced from $\$ 27,000$ to the $\$ 16,000-18,000$ range.

The costs are detalled for the three annual production levels in Tables 6.0-II, 6.0-III, and 6.0-IV. specialty items and tracking drive costs are detalled in Table 6.0-V. 
Table 6.0-II Annual production Quantity - 50 Collectors

\begin{tabular}{|c|c|c|c|c|}
\hline Component/Task & $\begin{array}{l}\text { Labor } \\
\text { Hrs }\end{array}$ & $\underset{\$}{\text { Labor }}$ & $\begin{array}{l}\text { Matl' } \\
\text { ODC }\end{array}$ & Total \\
\hline $\begin{array}{l}\text { Collector support structure- } \\
\text { Truss Fabrication } \\
\text { spine Assembly } \\
\text { PCA Mount } \\
\text { Transition structure } \\
\text { Hardware } \\
\text { Paint \& Palnt supplies } \\
\text { Fab Facet Mounts \& Tee Lugs } \\
\text { Trlal Assy, Pkg, Loading } \\
\text { Coll. Supp. Struct. Totals } 1\end{array}$ & $\begin{array}{r}709.00 \\
77.00 \\
77.00 \\
335.00 \\
\text { N/A } \\
\text { N/A } \\
178.00 \\
0.00 \\
1,376.00\end{array}$ & $\begin{array}{r}13,003 \\
1,412 \\
1,412 \\
6,144 \\
\mathrm{~N} / \mathrm{A} \\
\mathrm{N} / \mathrm{A} \\
3,265 \\
0 \\
25,236\end{array}$ & $\begin{array}{r}2,333 \\
583 \\
641 \\
4,082 \\
816 \\
1,633 \\
0 \\
0 \\
10,088\end{array}$ & $\begin{array}{r}15,336 \\
1,995 \\
2,053 \\
10,226 \\
816 \\
1,633 \\
3,265 \\
0 \\
35,324\end{array}$ \\
\hline $\begin{array}{l}\text { Tracking Drives-- } \\
\text { Azlmuth Tracking Drlve } \\
\text { Elevation Tracking Drlve } \\
\text { Tracklng Drlves Totals }\end{array}$ & & & $\begin{array}{l}4,385 \\
3,095 \\
7,480\end{array}$ & $\begin{array}{l}4,385 \\
3,095 \\
7,480\end{array}$ \\
\hline Control system & & & 3,230 & 3,230 \\
\hline speclalty Items & & & 1,767 & 1,767 \\
\hline $\begin{array}{l}\text { Shlpping Costs-Facets-- } \\
\text { Racks (Amort of Capltal) } \\
\text { Loading/Unloading } \\
\text { Frelght Cost } \\
\text { Total Shlpping-Facets }\end{array}$ & $\begin{array}{l}1.80 \\
1.80\end{array}$ & $\begin{array}{l}33 \\
33\end{array}$ & $\begin{array}{r}57 \\
0 \\
264 \\
321\end{array}$ & $\begin{array}{r}57 \\
33 \\
264 \\
354\end{array}$ \\
\hline $\begin{array}{l}\text { Shlpping Costs-structure-- } \\
\text { Frelght Cost } \\
\text { Total shlpplng-structure }\end{array}$ & 0.00 & 0 & $\begin{array}{l}1,250 \\
1,250\end{array}$ & $\begin{array}{l}1,250 \\
1,250\end{array}$ \\
\hline $\begin{array}{l}\text { Facets Installation-- } \\
\text { Install Control System } \\
\text { Install Facet } \\
\text { Align Facet } \\
\text { Focus Adjustment } \\
\text { Manlift (13 Hrs) } \\
\text { Crane Rental (4 Hrs) } \\
\text { Total Facets Installation }\end{array}$ & $\begin{array}{l}2.04 \\
8.04 \\
8.04 \\
8.04\end{array}$ & $\begin{array}{r}45 \\
177 \\
177 \\
177\end{array}$ & $\begin{array}{r}0 \\
0 \\
0 \\
0 \\
260 \\
240 \\
500\end{array}$ & $\begin{array}{r}45 \\
177 \\
177 \\
177 \\
260 \\
240 \\
1,076\end{array}$ \\
\hline $\begin{array}{l}\text { Structure Installation-- } \\
\text { Labor } \\
\text { Wlring } \\
\text { Crane Rental ( } 48 \text { Hrs) } \\
\text { Total Structure Inst. }\end{array}$ & $\begin{array}{r}192.00 \\
16.00 \\
208.00\end{array}$ & $\begin{array}{r}4,226 \\
352 \\
4,578\end{array}$ & $\begin{array}{r}0 \\
3,600 \\
3,600\end{array}$ & $\begin{array}{l}4,226 \\
352 \\
3,600 \\
8,178\end{array}$ \\
\hline Control system Inst. & & & 1,300 & 1,300 \\
\hline $\begin{array}{l}\text { Installers Travel/Per Dlem- } \\
\text { Alrfare (4 r/t tlckets) } \\
\text { Per Dlem/Trsp(24 Mandays) } \\
\text { Total Travel/Per Dlem }\end{array}$ & & & $\begin{array}{l}1,000 \\
2,400 \\
3,400\end{array}$ & $\begin{array}{l}1,000 \\
2,400 \\
3,400\end{array}$ \\
\hline Total costs & $1,611.96$ & 30,423 & 32,936 & 63,359 \\
\hline
\end{tabular}


Table 6.0-III Annual Production Quantity - 100 Collectors

\begin{tabular}{|c|c|c|c|c|}
\hline Component/Task & $\begin{array}{l}\text { Labor } \\
\text { Hrs }\end{array}$ & $\begin{array}{c}\text { Labor } \\
\$\end{array}$ & $\begin{array}{c}\text { Matl/ } \\
\text { ODC }\end{array}$ & Total \\
\hline $\begin{array}{l}\text { Collector support structure-- } \\
\text { Truss Fabrication } \\
\text { Spine Assembly } \\
\text { PCA Mount } \\
\text { Transition structure } \\
\text { Hardware } \\
\text { Paint \& Paint Supplies } \\
\text { Fab Facet Mounts \& Tee Lugs } \\
\text { Trial Assy, Pkg, Loading } \\
\text { Coll. Supp. Struct. Totals } 1,\end{array}$ & $\begin{array}{r}659.37 \\
71.61 \\
71.61 \\
311.55 \\
\mathrm{~N} / \mathrm{A} \\
\mathrm{N} / \mathrm{A} \\
165.54 \\
0.00 \\
279.68\end{array}$ & $\begin{array}{r}11,766 \\
1,278 \\
1,278 \\
5,560 \\
\text { N/A } \\
\text { N/A } \\
2,954 \\
0 \\
22,836\end{array}$ & $\begin{array}{r}2,323 \\
581 \\
639 \\
4,065 \\
813 \\
1,626 \\
0 \\
0 \\
10,047\end{array}$ & $\begin{array}{r}14,089 \\
1,859 \\
1,917 \\
9,625 \\
813 \\
1,626 \\
2,954 \\
0 \\
32,883\end{array}$ \\
\hline $\begin{array}{l}\text { Tracking Drives-- } \\
\text { Azimuth Tracking Drive } \\
\text { Elevation Tracking Drive } \\
\text { Tracking Drives Totals }\end{array}$ & & & $\begin{array}{l}3,720 \\
2,738 \\
6,458\end{array}$ & $\begin{array}{l}3,720 \\
2,738 \\
6,458\end{array}$ \\
\hline Control system & & & 2,692 & 2,692 \\
\hline speclalty Items & & & 1,765 & 1,765 \\
\hline $\begin{array}{l}\text { Shlpping Costs-Facets-- } \\
\text { Racks (Amort of Capital) } \\
\text { Loading/Unloading } \\
\text { Frelght Cost } \\
\text { Total Shlpping-Facets }\end{array}$ & $\begin{array}{l}1.80 \\
1.80\end{array}$ & $\begin{array}{l}32 \\
32\end{array}$ & $\begin{array}{r}29 \\
0 \\
264 \\
293\end{array}$ & $\begin{array}{r}29 \\
32 \\
264 \\
325\end{array}$ \\
\hline $\begin{array}{l}\text { Shipping Costs-structure-- } \\
\text { Freight Cost } \\
\text { Total shipping-structure }\end{array}$ & 0.00 & 0 & $\begin{array}{l}1,250 \\
1,250\end{array}$ & $\begin{array}{l}1,250 \\
1,250\end{array}$ \\
\hline $\begin{array}{l}\text { Facets Installation-- } \\
\text { Install Control System } \\
\text { Install Facet } \\
\text { Align Facet } \\
\text { Focus Adjustment } \\
\text { Manlift (13 Hrs) } \\
\text { Crane Rental ( } 4 \text { Hrs) } \\
\text { Total Facets Installation }\end{array}$ & $\begin{array}{l}2.04 \\
8.04 \\
8.04 \\
8.04\end{array}$ & $\begin{array}{r}44 \\
172 \\
172 \\
172\end{array}$ & $\begin{array}{r}0 \\
0 \\
0 \\
0 \\
260 \\
240 \\
500\end{array}$ & $\begin{array}{r}44 \\
172 \\
172 \\
172 \\
260 \\
240 \\
1,060\end{array}$ \\
\hline $\begin{array}{l}\text { structure Installation-- } \\
\text { Labor } \\
\text { Wiring } \\
\text { Crane Rental ( } 48 \text { Hrs) } \\
\text { Total structure Inst. }\end{array}$ & $\begin{array}{r}192.00 \\
16.00 \\
208.00\end{array}$ & $\begin{array}{r}4,111 \\
343 \\
4,454\end{array}$ & $\begin{array}{r}0 \\
3,600 \\
3,600\end{array}$ & $\begin{array}{r}4,111 \\
343 \\
3,600 \\
3,054\end{array}$ \\
\hline Control system Inst. & & & 1,235 & 1,235 \\
\hline $\begin{array}{l}\text { Installers Travel/Per Dlem-- } \\
\text { Alrfare ( } 4 \text { r/t t lckets) } \\
\text { Per Dlem/Trsp(24 ManDays) } \\
\text { Total Travel/Per Dlem }\end{array}$ & & & $\begin{array}{l}1,000 \\
2,400 \\
3,400\end{array}$ & $\begin{array}{l}1,000 \\
2,400 \\
3,400\end{array}$ \\
\hline rotal costs & 15.61 & 27,882 & 31,240 & 59,122 \\
\hline
\end{tabular}


Table 6.0-IV Annual Production Quantity - 1000 Collectors

\begin{tabular}{|c|c|c|c|c|}
\hline Component/Task & $\begin{array}{l}\text { Labor } \\
\text { Hrs }\end{array}$ & $\begin{array}{l}\text { Labor } \\
\quad \$\end{array}$ & $\begin{array}{l}\text { Matl' } \\
\text { ODC }\end{array}$ & Total \\
\hline \multicolumn{5}{|c|}{ Collector support structure-- } \\
\hline $\begin{array}{l}\text { Truss Fabrication } \\
\text { spine Assembly }\end{array}$ & $\begin{array}{r}521.09 \\
56.59\end{array}$ & $\begin{array}{r}8,873 \\
964\end{array}$ & $\begin{array}{r}2,270 \\
568\end{array}$ & $\begin{array}{r}11,143 \\
1,532\end{array}$ \\
\hline PCA Mount & 56.59 & 964 & 624 & 1,588 \\
\hline $\begin{array}{l}\text { Transition structure } \\
\text { Hardware }\end{array}$ & $\begin{array}{r}246.21 \\
\text { N/A }\end{array}$ & $\begin{array}{r}4,193 \\
N / A\end{array}$ & $\begin{array}{r}3,973 \\
795\end{array}$ & $\begin{array}{r}8,166 \\
795\end{array}$ \\
\hline $\begin{array}{l}\text { Paint \& Paint Supplies } \\
\text { Fab Facet Mounts \& Tee Lugs }\end{array}$ & $\begin{array}{r}N / A \\
130.82\end{array}$ & $\begin{array}{r}N / A \\
2,228\end{array}$ & 1,589 & $\begin{array}{l}1,589 \\
2,228\end{array}$ \\
\hline Trial Assy, Pkg, Loading & 0.00 & 0 & 0 & \\
\hline Coll. supp. struct. Totals & $1,011.31$ & 17,222 & 9,819 & 27,041 \\
\hline \multicolumn{5}{|l|}{ Tracking Drives-- } \\
\hline $\begin{array}{l}\text { Azimuth Tracking Drive } \\
\text { Elevation Tracking Drive } \\
\text { Tracking Drives Totals }\end{array}$ & & & $\begin{array}{l}2,790 \\
2,383 \\
5,173\end{array}$ & $\begin{array}{l}2,790 \\
2,383 \\
5,173\end{array}$ \\
\hline Control system & & & 2.110 & 2110 \\
\hline & & & 2,210 & 6,110 \\
\hline specialty Items & & & 1,688 & 1,688 \\
\hline \multicolumn{5}{|l|}{ Shipping Costs-Facets-- } \\
\hline Loading/Unloading & 1.80 & 31 & 0 & 31 \\
\hline $\begin{array}{l}\text { Freight Cost } \\
\text { Total Shipping-Facets }\end{array}$ & 1.80 & 31 & $\begin{array}{l}264 \\
271\end{array}$ & $\begin{array}{l}264 \\
302\end{array}$ \\
\hline \\
\hline $\begin{array}{l}\text { Freight Cost } \\
\text { Total Shipping-structure }\end{array}$ & 0.00 & 0 & $\begin{array}{l}1,250 \\
1,250\end{array}$ & $\begin{array}{l}1,250 \\
1,250\end{array}$ \\
\hline \multicolumn{5}{|l|}{ Facets Installation-- } \\
\hline $\begin{array}{l}\text { Install Control system } \\
\text { Install Facet }\end{array}$ & $\begin{array}{l}2.04 \\
8.04\end{array}$ & $\begin{array}{r}42 \\
164\end{array}$ & $\begin{array}{l}0 \\
0\end{array}$ & $\begin{array}{r}42 \\
164\end{array}$ \\
\hline Al Ign Facet & 8.04 & 164 & 0 & 164 \\
\hline Focus adjustment & 8.04 & 164 & 0 & 164 \\
\hline $\begin{array}{l}\text { Manlift (13 Hrs) } \\
\text { Crane Rental (4 Hrs) }\end{array}$ & & & $\begin{array}{l}260 \\
240\end{array}$ & 260 \\
\hline Total Facets Instaliation & 26.16 & 534 & $\begin{array}{l}240 \\
500\end{array}$ & $\begin{array}{r}240 \\
1,034\end{array}$ \\
\hline \multicolumn{5}{|l|}{ structure Installation-- } \\
\hline $\begin{array}{l}\text { Labor } \\
\text { Wiring }\end{array}$ & $\begin{array}{r}192.00 \\
16.00\end{array}$ & $\begin{array}{r}3,923 \\
327\end{array}$ & 0 & $\begin{array}{r}3,923 \\
327\end{array}$ \\
\hline $\begin{array}{l}\text { Crane Rental ( } 48 \text { Hrs) } \\
\text { Total structure Inst. }\end{array}$ & 208.00 & 4,250 & $\begin{array}{l}3,600 \\
3,600\end{array}$ & $\begin{array}{l}3,600 \\
7,850\end{array}$ \\
\hline Control system Inst. & & & 1,046 & 1,046 \\
\hline $\begin{array}{l}\text { Installers Travel/Per Dlem- } \\
\text { Alrfare ( } \mathrm{r} / \mathrm{t} \text { t lckets) } \\
\text { Per Dlem/Trsp(24 Mandays) } \\
\text { Total Travel/Per Dlem }\end{array}$ & & & $\begin{array}{l}1,000 \\
2,400 \\
3,400\end{array}$ & $\begin{array}{l}1,000 \\
2,400 \\
3,400\end{array}$ \\
\hline Total Costs & $1,247.27$ & 22,037 & 28,857 & 50,894 \\
\hline
\end{tabular}


Table 6.0-IV specialty Items

Specialty Items--
Description

Azlmuth Drive Motor

Elevation Drive Motor PCA Screwfack

Bearing

Bearing

Coupling

Hinges

Limit switches

winch safety switch

Misc Hardware

Total spectalty Items

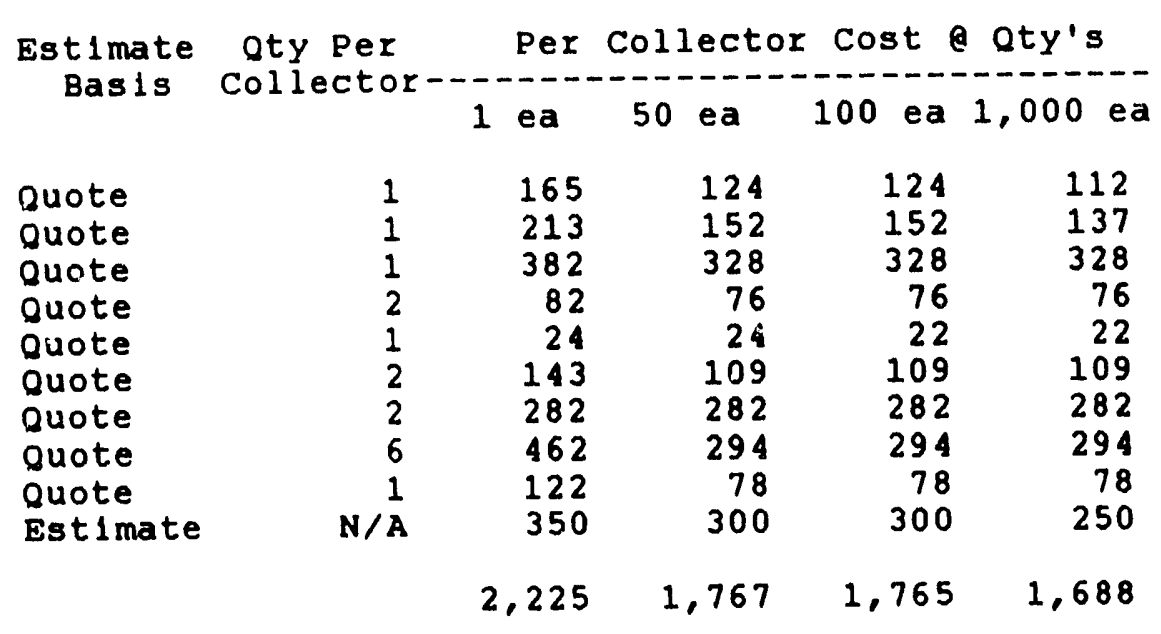

Tracking Drives--

Annual oty 50 collectors

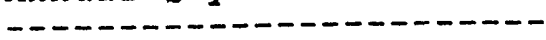

Azlmuth Tracking Drive Elevation Tracking Drive

Tracking Drives Totals

Annual Qty 100 Collectors

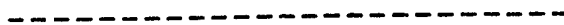

Azimuth Tracking Drive

Elevation Tracking Drive

Tracklng Drives Totals

Annual aty 1,000 Collectors

\section{screw-
Jack}

3,720
2,480

6,200

Englneng Patterns

2,790

2,356

Incl 11

5,146

Incl
210

Incl

210

210

Englnrng Patterns

Incl

105

1ncl

105

105

Azlmuth Tracking Drive Elevation Tracking Drive

Tracklng Drives Totals
11

11
Tools Total

$\begin{array}{rr}\text { Incl } & 4,385 \\ 95 & 3,095 \\ 95 & 7,480\end{array}$

Tools Total

$\begin{array}{rr}\text { Incl } & 3,720 \\ 48 & 2,738 \\ 48 & 6,458\end{array}$

Tools Total

$\begin{array}{rr}\text { Incl } & 2,790 \\ 5 & 2,383 \\ 5 & 5,173\end{array}$




\subsection{SUMMARY}

In this section of the report the results of the faceted dish concentrator design are summarized, and recommendations are made for future work. Each of the five major technical sections - Trade-off studies, structure Design, Control system Design, Tracking Error Budget, and Production cost Estimates - are summarized. Recommendations are made that address both detall elements of the design and overall structure considerations.

\subsection{Trade-off studies}

The configuration of the faceted dish concentrator largely reflects the results of the trade-off studies that preceded design. Each of the studies is summarized below.

\subsubsection{Facet Arrangement}

selection of the 2TOP facet arrangement was based on a comparative analysis with the 4INLINE arrangement. The analysis included comparison of structural welght, wind load effects, facet-to-structure interface, PCA-to-structure interface, and ease of fabrication. other considerations included shear loads, axial loads, facet mountIng facilities, and fleld installation and allgnment. The determination was made to use the 2 TOP arrangement because it exhibits greater stiffness, leading to a higher system resonant frequency and better tracking accuracy.

\subsubsection{Parabollc vs. Spherical Facet support structure}

Prior optical studies showed that the contour of the facet support structure had little effect on dish performance. The objective of this study was to identify a structure configuration that would accommodate elastically-formed and plastically-formed facets in the same facet $f / D$ range. A comparison between parabolic and spherical dish structures showed that both had problems. A compromise contour was selected which $1 \mathrm{~s}$ within the adjustment range of plasticallyformed and elastlcally-formed facets while having little effect on optical performance. The compromise contour allows placement of the 
facets in close proximity to the backup structure, thereby minimizing mounting pad off-sets and resulting structural deflections.

\subsubsection{Focal Length}

Prior studies showed that at dish $f / D$ of about 0.6 , optical efficiency is almost independent of dish contour. structural design considerations assumed potentially greater significance. The drive system, in particular, is sensitive to load changes which could occur with focal length changes. In this study the effects on the drive system of spherical and parabollc support structure conflguration, each with dish $\mathrm{f} / \mathrm{D}$ ratios varying from $25 \mathrm{ft}$. to $34.5 \mathrm{ft}$., were examined. In the studies the impact of changing weight, center of gravity, drive inertia and drive spring welght within the limited focal length range was analyzed. It was concluded that varying the dish focal length between $25 \mathrm{ft}$. and $34.5 \mathrm{ft}$. has little impact on the drive system.

\subsubsection{Windmill option}

wind loads on dish structures can be reduced by allowing the structure to windmill, or feather, when at the stow position. In this study the availability of the windmill option was investigated for use with the faceted dish. The windmilling option is available only on drives that can backdrive. The elevation drive, for safety reasons, must be non-backdriving. The winsmith azimuth drive is non-backdriving due to its high reduction ratio primary stage. Therefore, the windmilling option is not available in the faceted dish design. To minimize potential problems arising from power failure in high winds, the decision was made to provide the faceted dish with an uninterruptable power source.

\subsubsection{Solar walk-off Protection}

In this study methods were investigated to protect the structure from being damaged by the concentrated solar image in times of sun acquisiton, off-axis tracking or power loss. The most critical condition occurs when emergency off-sun tracking is necessary. This requires a high-speed capability in the elevation drive since, at high elevation angles, the azimuth drive contribution is slight. Consider- 
ation was given to using the articulated PCA support structure in a dual role for walk-off protection. However, in this application the drive motor is too large to be practical. It was concluded that the elevation drive can readily provide walk-off protection since it can be run at twice its rated speed for a limited time period.

\subsubsection{Tracking Error Considerations}

The sow defines the tracking error requirements for the structure (less facets) in terms of deflections and control system error. These were combined into an equivalent system pointing error. several tracking control system alternatives were evaluated, under the ground rules that they would use existing, proven equipment; have compliant accuracy; and would be reasonable in cost. The studies resulted in the decision to use passive tracking control centered around an existing heliostat controller. A modified "bang-bang" motor drive configuration with axis-position sensor feedback was selected. This configuration yielded tracking errors somewhat greater than orlginally specifled, but well within the modifled requirements developed during the project.

\section{2 structure Design}

The faceted dish concentrator is a kingpost type, elevation-overazimuth tracking structure in which the facet support structure and the recelver-engine-generator assembly are balanced about the elevation axis. It is configured in compliance with the results of the trade-off studies made early in the project. The tracking structure employs triangulated space-frame technology to develop high stiffness-to-welght characteristics and acceptable pointing accuracies. After meeting deflection requirements, the design was checked for compliance with AISC codes for buckling and stress. since the design is deflection-driven, stress levels throughout the structure are low.

The faceted dish structure is designed to comply with the requirement for a low-risk, near-term solar concentrator. It is made from standard structural steel shapes and is designed for ease of fabri- 
cation and installation. within shipping and fleld handling practicalities, parts are factory-assembled to reduce installation time. Field assembly of the structure requires only conventional material-handling equipment. A small truck crane (5-10 ton capacity) is adequate for placement of all parts with the possible exception of the transition section. If the transition can be shipped assembled, considerable field time will be saved. However, the present design requires a wide load permit for shipping and possibly a 15-20 ton crane for installing it. Facet mounts are readily accessed for ease of facet installation and alignment of the facets.

The drive system uses a proven azimuth drive bullt by winsmith. It is a planocentric reducer with non-backdriving characteristics. It has adequate margin in overturning moment and torque limit. loads for the faceted dish application. The elevation drive is a conventional linear ball screw actuator that has been customized to make it nonbackdriving. Both the azimuth and elevation drives use one HP (rated) motors for input power. The drive pedestal is a stepped tubular kingpost designed to minimize deflections. The pedestal and azimuth drive can be conveniently factory-assembled and shipped to save field installation time.

The tracking structure, the drives and the pedestal (less facets and PCA) weigh about 12 pounds per square foot of facet area. The total collector, including facets and power conversion unit, weighs less than 16 pounds per square foot.

\subsection{Tracking Control system}

The tracking control system is designed to provide the specifled system pointing accuracy at minimum cost using existing equipment wherever possible. The system consists of a central computer, a front end processor, drive motors and controllers for each axis, axis position encoders, and ancillary components including switches, alarm circuitry, etc. In a multiple collector fleld, the system components 
are replicated on each collector with the exception of the central computer.

The control system employs passive tracking with modifled "bangbang" motor control and direct axis feedback. The drive control uses controllable frequency inverters to permit more accurate tracking than can be achieved with conventional methods.

\subsection{Tracking Error Budget}

wind and aeac-welght deflections as well as other values from the trade-off studies were used to develop the pointing error budget for the faceted dish structure. The estimated error, based on the final control system design using polyspede controllers with axis encoders for position feedback, is about $1.19 \mathrm{mr}$, one sigma, in operating winds of $16.8 \mathrm{mph}$ winds gusting to $27 \mathrm{mph}$. This is compatible with the accuracy requirements established during the project.

\subsection{Cost Estimates}

The estimated cost of the installed faceted dish (less facets and facet controls) in small quantity production (100 per year) is in the order of $\$ 2,300$ per $\mathrm{kW}$ (electric). This estimate is conservative since it is based on installing only a single dish at each site. Installation costs would be significantly reduced as a result of installing multiple dishes on a glven site. Also, the estimates are made cn a prototype design and do not take into account any redesign for guantity manufacturing. It is reasonable to conclude that, with generational improvements and design for true production, the costs wil. be substantially reduced.

\subsection{Recommendations}

The design of the faceted dish solar concentrator meets the requirements and specifications of the sow. However, some further effort on specific elements of the structure design could improve both the performance and the cost of the prototype as well as subsequent models. The general level of effort on each of the affected elements with recommended action is described below. 


\subsubsection{Transition}

In the present design the center of gravity of the tracking structure is about $18 \mathrm{in.}$ in front of, and $18 \mathrm{in.} \mathrm{above,} \mathrm{the} \mathrm{elevation} \mathrm{axis.} \mathrm{This}$ static imbalance causes a continuous change in gravity momer.; as a function of elevation angle with a gravity load reversal occurring at about 40 deg. elevation. The result is higher drive loads than originally anticipated. Although the drives are designed to comfortably handle these loads, it is possible that less costly drives could be used if the imbalance were eliminated. The present design of the transition will not accommodate any further improvement in the location of the center of gravity.

- It is recommended that the transition design be reviewed and the design modifled with the objective of reducing the static imbalance.

- Once this has been done, it is recommended that the drive requirements be re-evaluated.

\subsubsection{Tubes vs. structural shapes}

The facet support structure is configured to be stiff and relatively lightweight using standard structural steel shapes. Nevertheless, the material content and the attendant cost of the structure may be greater than it has to be. Tubes are more efficient in cross section than equivalent structural shapes; thus, lighter weight tubes can supplant structural shapes, resulting in slgnificant welght savings. The design decision was made to use shapes because the labor content in tube fabrication was belleved too great to justify the weight savings.

- with the better knowledge of the speciflc structure resulting from a completed design effort, it is recommended that the issue of tubes vs. structural shapes be re-examined for potential long-range cost savings in large quantity production. 


\subsubsection{Pedestal}

The Initial pedestal design used a one-plece, 24-in. diameter standard pipe, flanged at each end for interfacing with the azimuth drive and the foundation, respectively. This approach was relatively inexpensive because it had a relatively small labor content; its stiffness-to-weight ratio was less than desired. In the present design, the pedestal is incrementally stepped from a 36 -in. diameter base section to a 24-in. upper section. This configuration exhibits a significant increase in stiffness and reduction in weight, but its cost is high due to a substantial escalation in the labor content. Although the present design is satisfactory for the prototype dish, the mass production design must be simplifled to reduce cost. one of the most promising configurations, considering function, cost and manufacturabllity, would employ a tapered tube similar to those used in light standazds. This approach offers the labor cost saving advantages of the one-plece pedestal and the stiffness-to-weight ratio advantage of the stepped configuration.

- It is recommended that the pedestal design be reviewed, and revised as applicable, with the objective of achieving production quantity cost savings.

\subsubsection{Elevation Drive}

In the present design the elevation drive is a non-backdriving ball screw jack linear actuator. For compatibility with the "bang-bang" control system, a commercial screw jack has been customized to include a high-reduction input worm gear stage to develop the nonbackdriving characteristics. The one-time costs for engineering, patterns and tools for the customized screw jack are high and have a significant impact on production quantity costs of the screw Jack. The cost of the elevation drive could possibly be reduced by changing the elevation drive control to linear instead of "bang-bang". This would allow use of a power $\cdots$ off brake in conjunction with an off-theshelf ball screw fack for the non-backdrlving capability and thereby eliminate the customizing costs. This approach potentially has the additional advantages of reducing tracking control system error, 
increasing elevation drive efficlency and reducing the size of the drive motor.

- It is recommended that the elevation drive design be reviewed and redesigned, in conjunction with its control system, with the objective of reducing costs and Improving system performance.

\subsection{5 wind Test Data}

The faceted dish was designed using wind tunnel data developed on solid-surface parabolic reflector models. No test data exists for faceted dishes nor for any solld-surface reflector with large volds in 1ts surface. Any wind load reductions used in the design of the faceted dish attributable to the spaces between facets would be nothing more than a quess. Therefore, no credit was taken in the design for the voids. As a result, the design is conservative. If the faceted dish is to become a commercial reality, every effort must be made to reduce the loads since that is the best way to reduce the weight and cost of the structure.

- It is recommended that the faceted dish be modeled in a wind tunnel to determine drag coefficients specifically applicable to this configuration.

- It is further recommended that the prototype dish, after construction, be instrumented to verify the wind tunnel data.

\subsection{Conclusions}

The faceted dish concentrator structure is conservatively designed to ensure meeting or exceeding the performance specifications of the sow. The design is in conformance with construction industry codes and with good commexcial practice. It makes maximum use of off-the-shelf components and is readily fabricated with conventional tools and flxturing. The result is a low-risk, first-generation dish 
structure that will first provide proof of performance of the concept and then serve as the building block for generational progress. 


\section{-}

.

106 


\subsection{GLOSSARY}

$2 \mathrm{TOP}$

A facet arrangement (see Figure 2.1-1)

AINLINE

A facet arrangement (see Figure 2.1-1)

$10 \mathrm{E} 08$

Ten to the eighth power

AISC

American Institute of steel construction

bang-bang

A control system drive mode where full power is applied for short pulses to provide tracking motion

C

Celsius

CG

center of gravity

DC

Direct Current

$f / D$

Focal length divided by diameter

FEP

Front End processor, control system processor unit at the individual collect or

FSS

Facet support structure

Ft - Lb

Foot Pounds

$\mathrm{Hz}$

Hertz, cycles per second

In $-\mathrm{L}, \mathrm{b}$

Inch pounds

JPL

Jet Propulsion Laboratory

ksi

Kips (1000 pounds) per square inch

$\mathrm{kW}$

Kilowatts

$\mathrm{L} / \mathrm{Y}$

Length divided by radius of gyration

Lb/sq. ft. Pounds per square foot 


\begin{tabular}{|c|c|}
\hline L,TV & Ling Temco Vought \\
\hline $\mathrm{m}$ & Meters \\
\hline MIT & Massachusetts Institute of Technology \\
\hline$m r$ & Mllliradians \\
\hline os & over shoot \\
\hline $\mathrm{PCA}$ & Power Conversion Assembly \\
\hline psf & Pounds per square foot \\
\hline RH & Relative Humidity \\
\hline RMS & Root Mean Square \\
\hline RPM & Revolutions per minute \\
\hline RSS & Root Sum Square \\
\hline SAIC & Sclence Applications International Corporation \\
\hline SCD & Specification Control Drawing \\
\hline SKI & Solar Kinetics, Inc. \\
\hline sow & statement of work \\
\hline SPACE V & $\begin{array}{l}\text { structural preprogrammed Analysis Capabllity for } \\
\text { Engineers, a linear finite element analysis program }\end{array}$ \\
\hline Winsmith & Peerless-Winsmith, Inc. \\
\hline WGA & WG Associa \\
\hline
\end{tabular}




\subsection{BIBLIOGRAPHY}

1. T. R. Mancini, optical and Thermal Performance of a Faceted, Stretched-Membrane Dish Concentrator, Dec. 1989.

2. Stretched Membrane Facet Development by SAIC, Scientific Applications International Corporation, San Diego, CA, SAND917008, Contract 42-9814A, June 1991.

3. P. T. Schertz, D. C. Brown, A. Connerth, Stretched Membrane Facet Development by SKI, Solar Kinetics, Inc., Dallas, TX, SAND91-7009, Contract 42-9814B, June 1991.

4. T. R. Mancini, "Faceted Dish Pointing Error Budget", Memorandum, April 13, 1990.

5. Werner H. Heller and Joseph S. Peters, Development of a Low-Cost Drive Tracking Mechanism for Solar Heliostats, Peerless-Winsmith, Inc., Feb. 1989.

6. Wind Loading of Parabolic Antennas, LTV Electrosystems, R\&D Report G-3705.18.04A, Sept. 1970.

7. SPACE V Users Manual, Digital Analysis Consultants, Inc., 1983. 


\section{UNLIMITED DISTRIBUTION INITIAL DISTRIBUTION}

U.S. Department of Energy (5)

Forrestal Building

Code CE-314

1000 Independence Avenue, SW

Washington, DC 20585

Attn: M. Scheve

S. Gronich

U.S. Department of Energy (2)

Forrestal Building

Code CE-33

1000 Independence Avenue, SW

Washington, DC 20585

Attn: B. Annan

U.S. Department of Energy (3)

Albuquerque Operations Office

P.O. Box 5400

Albuquerque, NM 87115

Attn: C. Garcia

G. Tennyson

N. Lackey

U.S. Department of Energy

San Francisco Operations Office

1333 Broadway

Oakland, CA 94612

Attn: R. Hughey

AAI Corporation

P. O. Box 6787

Baltimore, MD 21204

Acurex Corporation (2)

555 Clyde Avenue

Mountain View, CA 94039

Attn: J. Schaefer

H. Dehne

Advanced Thermal Systems

7600 East Arapahoc

Suite 319

Englewood, CO 80112

Altn: D. Gorman
Arizona Public Service Company

P.O. Box 21666

Phoenix, AZ 85036

Attn: J. McGuirk

Arizona Solar Energy Office

Dept. of Commerce

$1700 \mathrm{~W}$. Washington, 5th Floor

Phoenix, AZ 85007

Attn: F. Mancini

Australian National University

Department of Enginecring Physics

P. O. Box 4

Canberra ACT 2600 AUSTRALIA

Attn: S. Kaneff

Barber-Nichols Engineering 6325 West 55th Avenue

Arvada, CO 80002

Attn: R. Barber

Battelle Pacific Northwest

Laboratory (2)

P.O. Box 999

Richland, WA 99352

Attn: T. A. Williams

D. Brown

BDM Coporation

1801 Randolph Street

Albuquerque, NM 87106

Attn: W. Schwinkendorf

Bechtel National, Inc.

50 Beale Street

50/15 D8

P. O. Box 3965

San Francisco, CA 94106

Attn: P. DeLaquil

Black \& Veatch Consulting

Engineers

P.O. Box 8405

Kansas City, MO 64114

Attn: J. C. Grosskreutz. 
Tom Brumleve

1512 Northgate Road

Walnut Creek, CA 94598

Califomia Energy Commission

1516 Ninth Street, M-S 43

Sacramento, CA 95814

Attn: A. Jenkins

Califomia Polytechnic University

Dept. of Mechanical Engineering Pomona, CA 91768

Attn: W. Stine

Califomia Public Utilities Com.

Resource Branch, Room 5198

455 Golden Gate Avenue

San Francisco, CA 94102

Attn: T. Thompson

Cummins Engine Co.

MC 60125

P. O. Box 3005

Columbus, IN 47202-3005

Attn: R. Kubo

Dan Ka

3905 South Mariposa

Englewood, CO 80110

Attn: D. Sallis

DL.R

Pfaffenwaldring 38-40

7000 Stuttgart 80 WEST GERMANY

Attn: R. Buck

\section{DSET}

P. O. Box 1850

Black Canyon Stage I

Phoenix, AZ 85029

Attn: G. Zerlaut

Electric Power Research

Institute

P.O. Box 10412

Palo Alto, C 94303

Attn: J. St: ffer
Enginecring Perspectives

2019 th Avenue

San Francisco, CA 94121

Attn: John Doyle

Energy Technology Engr. Center

Rockwell International Corp.

P. O. Box 1449

Canoga Park, CA 91304

Attn: W. Bigelow

ENTECH, Inc.

P. O. Box 612246

DFW Airport, TX 75261

Attn: R. Walters

Florida Solar Energy Center

300 State Road 401

Cape Canaveral, FL 32920

Attn: Library

Ford Aerospace

Ford Road

Newport Beach, CA 92663

Attn: R. Babbe

Foster Wheeler Solar Development

Corporation (2)

12 Peach Tree Hill Road

Livingston, NJ 07039

Attn: M. Garber

R. Zoschak

Garrett Turbine Engine Co.

111 South 34th Street

P. O. Box 5217

Phoenix, AZ 85010

Attn: E. Strain

Georgia Power (2)

7 Solar Circle

Shenandoah, GA 30265

Attn: W. King

Harris Corporation (2)

Govermment and Aerospace

Systems Division

P. O. Box 9400

Melboume, FL 32902

Attn: K. Schumacher 
Industrial Solar Technologies 5775 West 52nd Avenue Denver, CO 80212

Attn: R. Gee

Institute of Gas Technology

34245 State Street

Chicago, IL 60616

Attn: Library

ISEIR

951 Pershing Drive

Silver Spring, MD 20910

Attn: A. Frank

Jet Propulsion Laboratory

4800 Oak Grove Drive

Pasadena, CA 91109

Attn: M. Alper

LaJet Energy Company

P. O. Box 3599

Abilene, TX 79604

Attn: M. McGlaun

L'Garde, Inc. (2)

1555 Placentia Avenue

Newport Beach, CA 92663

Attn: M. Thomas

J. Williams

Lawrence Berkeley Laboratory

MS 90-2024

One Cyclotron Road

Berkeley, CA 94720

Attn: A. Hunt

Luz International (2)

924 Westwood Blvd.

Los Angeles, CA 90024

Attn: D. Kearney

3M-Energy Control Products (2)

207-1 W 3M Center

St. Paul, MN 55144

Attn: R. Dahlen
Mechanical Technology, Inc. (2)

968 Albany Shaker Road

Latham, NY 12110

Attn: G. Dochat

J. Wagner

Meridian Corporation

4300 King Street

Alexandria, VA 22302

Attn: D. Kumar

NASA Lewis Research Center (4)

21000 Brook Park Road

Cleveland, $\mathrm{OH} 44135$

Attn: R. Beremand 500-215

R. Evans 500-210

J. Savino 301-5

R. Corrigan 500-316

Nevada Power Co.

P. O. Box 230

Las Vegas, NV 89151

Attn: Mark Shank

Pacific Gas and Electric Company (2) 3400 Crow Canyon Road

San Ramon, CA 94526

Attn: G. Braun

J. Iannucci

Polydyne, Inc.

1900 S. Norfolk Street, Suite 209

San Mateo, CA 94403

Attn: P. Bos

Power Kinetics, Inc.

415 River Street

Troy, NY 12180-2822

Attn: W. Rogers

Renewable Energy Institute 1001 Connecticut Ave. NW

Suite 719

Washington, DC 20036

Attn: K. Porter 
Rocketdyne Division 6633 Canoga Park Ave. Carioga Park, CA 91304

Altn: W. Marlatt

San Diego Gas and Electric Company P.O. Box 1831

San Diego, CA 92112

Attn: R. Figueroa

SCE

P. O. Box 800

Rosemead, CA 91770

Attn: P. Skvarna

Schlaich, Bergermann \& Partner

Hohenzollernstr. 1

D - 7000 Stuttgart 1

West Germany

Attn: W. Schiel

Sci-Tech Intemational

Advanced Alternative Energy

5673 W. Las Positas Blvd.,Suite 205

P.O. Box 5246

Pleasanton, CA 84566

Attn: U. Ortabasi

Science Applications International

Corporation (2)

10343 Roselle Street, Suite G

San Diego, CA 92121

Attn: K. Beninga

Solar Energy Research Institute (5)

1617 Cole Boulevard

Golden, CO 80401

Attn: B. Gupta

L. M. Murphy

G. Iorgensen

$\mathrm{T}$. Wendelin

A. Lewandowski
Solar Kinetics, Inc. (2)

P.O. Box 540636

Dallas, TX 75354-0636

Attn: J. A. Hutchison

P. Schertz

D. Konnerth

Solar Power Enginecring Company

P.O. Box 91

Morrison, CO 80465

Altn: H. Wroton

Solar Steam

P. O. Box 32

Fox Island, WA 98333

Attn: D. Wood

SPECO

P. O. Box 91

Morrison, CO 80465

Attn: W. Hart

SRS Technologies

990 Explorer Blvd., NW

Huntsville, AL 35806

Attn: R. Bradford

Stcarns Catalytic Corporation

P.O. Box 5888

Denver, CO 80217

Attn: T. E. Olson

Stirling Thermal Motors

2841 Boardwalk

Ann Arbor, MI 48104

Attn: B. Ziph

Sun Power, Inc.

6 Byard Street

Athens, OH 45701

Attn: W. Beale

Tom Tracey

6922 South Adams Way

Littleton, CO 80122 
United Solar Tech, Inc.

3434 Martin Way

Olympia, WA 98506

Attn: R. Kelley

University of Chicago

Enrico Fermi Institute

5640 Ellis Avenue

Chicago, IL 60637

Attn: J. O'Gallagher

University of Houston

Solar Energy Laboratory

4800 Calhoun

Houston, TX 77704

Attn: L. Vant-Hull

University of Utah

Mechanical and Industrial

Enginecring

Salt Lake City, UT 84112

Attn: B. Boehm

Eric Weber

302 Caribbean Lane

Phoenix, AZ 85022

WG Associates

6607 Stonebrook Circle

Dallas, TX 75240

Attn: V. Goldberg
1840 R. E. Lochman

1846 D. H. Doughty

1846 C. S. Ashley

3141 S. A. Landenberger (5)

3145 Document Processing (8)

For DOE/OSTI

3151 G. C. Claycomb

6000 V. L. Dugan, Actg.

6200 B. W. Marshall, Actg.

6210 J. T. Holmes, Actg.

6215 C. P. Cameron

6215 R. M. Houser

6216 C. E. Tyner

6216 L. Yellowhorse

6216 D. J. Alpert

6216 J. W. Grossman

6216 T. R. Mancini (30)

6216 J. E. Pacheco

6217 P. C. Klimas

6217 K. L. Linker

6217 R. B. Diver

6220 D. G. Schueler

6221 E. C. Boes

6223 G. J. Jones

6224 A. R. Mahoney

7470 J. L. Ledman

7476 F. P. Gerstle

7476 S. T. Reed

8523 R. C. Christman 

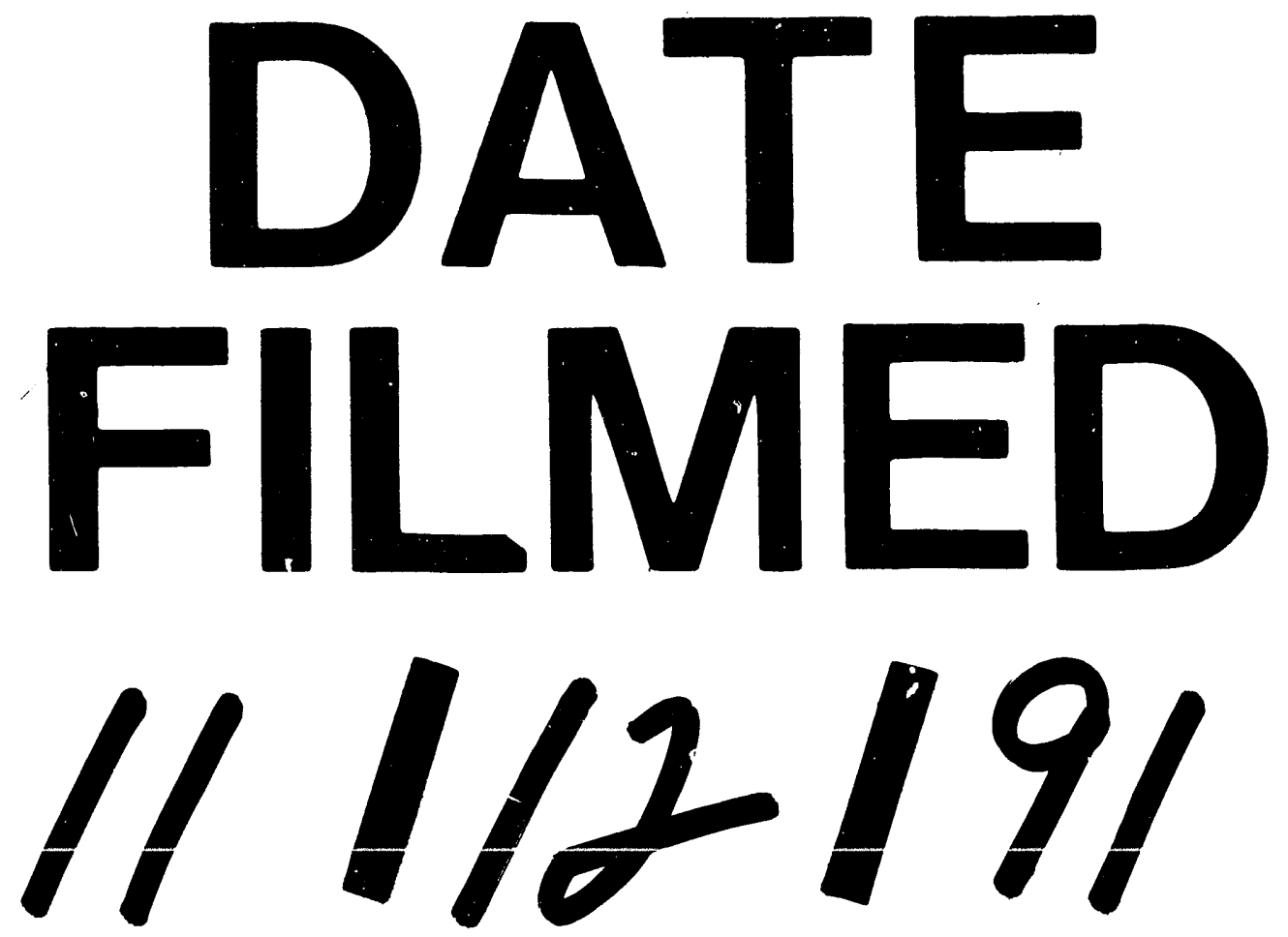
V 